Universidade de São Paulo

Instituto de Astronomia, Geofísica e Ciências Atmosféricas

Departamento de Ciências Atmosféricas

Bruna Segalin

Características dos Sistemas Convectivos de
Mesoescala nas simulaçôes climáticas do
RegCM4

São Paulo 

Bruna Segalin

\section{Características dos Sistemas Convectivos de Mesoescala nas simulações climáticas do $\mathrm{RegCM} 4$}

Dissertação apresentada ao Departamento de Ciências Atmosféricas do Instituto de Astronomia, Geofísica e Ciências Atmosféricas da Universidade de São Paulo como requisito parcial para obtenção do título de Mestre em Ciências.

Área de Concentração: Meteorologia Orientadora: Prof ${ }^{\mathrm{a}}$. Dr ${ }^{\mathrm{a}}$. Rosmeri Porfírio da Rocha

Versão corrigida. A versão original se encontra arquivada no Serviço de Pós-Graduação do IAG.

São Paulo 


Aos meus pais, Maria Helena e Hermenegildo, por todo incentivo, dedicação e amor ao longo da minha vida. 



\section{AGRADECIMENTOS}

Inicialmente agradeço aos meu pais, Maria Helena e Hermenegildo, que sempre incentivaram a minha educação, por todo apoio e carinho ao longo desta jornada. Foi por vocês que cheguei até aqui. Obrigada por tudo!

Ao meu namorado e melhor amigo, Kaonan, pela enorme ajuda com o ForTraCC, ensinamentos de programação, auxílio e dicas ao longo de todo esse mestrado, por sempre me apoiar e incentivar, pela paciência e, principalmente, pelo carinho e amor constantes. Obrigada por estar sempre ao meu lado!

À minha orientadora Profa ${ }^{a}$ Dr ${ }^{a}$. Rosmeri Porfírio da Rocha pelo apoio intelectual e oportunidade de fazer parte do "European Community's Seventh Framework Programme (FP7/2007-2013) under Grant Agreement No. 212492 (CLARIS LPB-A Europe-South America network for climate change assessment and impact studies in La Plata Basin)".

Aos amigos Luiz F. Kruger, Luiz F. Gozzo, Juliano, e Glauber, pelos ensinamentos e auxílios com programas e texto desta dissertação, mas principalmente pelas risadas e ótima amizade.

Às grandes amigas Camila, por me defender, ajudar, incentivar e ser meu "foco no positivo", e Angélica pelas dicas, apoio e amizade desde a graduação. Obrigada pelo carinho e momentos de alegria!

Aos irmãos de coração Vanessa, Annanda e Douglas pelo apoio e incentivo desde a graduação até agora, mesmo com a distância. Obrigada pelo carinho!

À amiga e colega de sala Laura pelos conselhos e incentivo, às amigas Fabiani e Flávia pelas ótimas conversas e ao amigo Dilon por confiar no meu potencial.

Aos demais colegas e amigos, que estão perto ou longe, pelos momentos de alegrias e incentivo durante esta jornada.

Ao Prof. Dr. Carlos Augusto Morales Rodriguez por disponibilizar o aplicativo ForTraCC, aos amigos Cristiano, Helber e Diego pelas dicas com este aplicativo e à Marta pelas simulações do RegCM4.

À Coordenação de Aperfeiçoamento de Pessoal de Nivel Superior (CAPES/PROCAD) e ao Centro Nacional de Desenvolvimento Científico e Tecnológico (CNPq), pelo apoio financeiro durante o desenvolvimento deste projeto de pesquisa. 

"Não há vento favorável, para quem não sabe aonde vai." 



\section{RESUMO}

SEGALIN, B. Características dos Sistemas Convectivos de Mesoescala nas simulações climáticas do RegCM4. 2012. 119 f. Dissertação (Mestrado em Meteorologia) - Instituto de Astronomia, Geofísica e Ciências Atmosféricas, Universidade de São Paulo, São Paulo, 2012.

Técnicas de rastreamento como o Forecasting and Tracking the evolution of Cloud Clusters (ForTraCC) e simulações numéricas têm sido utilizadas para entender o desenvolvimento de sistemas convectivos de mesoecala (SCMs), que estão associados à precipitação intensa, rajadas de vento, granizo e até mesmo tornados. Este trabalho adaptou o ForTraCC para rastrear SCMs na radiação de onda longa emergente (ROLE) nas simulações climáticas do RegCM4. As simulações utilizaram a reanálise ERA-Interim como condições inicial e de fronteira em um domínio cobrindo a América do Sul (AS) para os períodos outubro-maio (8 meses) de 1997-2003. A climatologia simulada pelo RegCM4 reproduziu os principais padrões atmosféricos observados na AS, com melhor desempenho no setor sul da AS. Foram investigadas características (morfológicas e cinemáticas) dos SCMs no setor tropical (AMZ) e subtropical (BP). O ForTraCC rastreou número semelhante de SCMs nestas regiões, mas com características diferentes. Na AMZ (BP) a simulação mostra máxima frequência de SCMs em novembro (janeiro) e com padrão de ciclo de vida apresentando início às 03 UTC (09 UTC), máxima extensão às 06 UTC (14 UTC) e dissipação às 12 UTC (23-00 UTC). Isto indica discrepância entre o ciclo de vida dos SCMs simulados e observados de acordo com a literatura, que mostra que os SCMs acompanham predominantemente o ciclo de radiação solar. A forte influência do jato de baixos níveis (JBN) explicaria o horário preferencial de início dos SCMs na BP. Nas simulações, os SCMs subtropicais são em geral maiores, duram mais tempo, possuem temperatura mínima menor e são mais lineares que os tropicais, características também reportadas na literatura. Na AMZ os SCMs não apresentam local preferencial de gênese e dissipação e nem trajetórias típicas, enquanto na BP embora se iniciem em qualquer posição movem-se principalmente para leste. Adicionalmente, para a área entre $10-45^{\circ} \mathrm{S}$ e $75-30^{\circ} \mathrm{W}$ foram rastreados os complexos convectivos de mesoescala (CCMs). Nas simulações, os CCMs formam-se preferencialmente às 04 UTC, atingem máxima extensão às 12 UTC (coincidindo com a máxima atividade do JBN) e dissipam-se às 15 UTC e 23 UTC. Os CCMs são predominantemente continentais, duram aproximadamente 16,5 horas (i.e., duração é maior que a reportada na literatura) e são maiores que os SCMs. O centro-norte da Argentina, sul-sudeste do Brasil, sul do Peru são as regiões preferenciais de gênese dos CCMs simulados e apresentam trajetórias típicas para leste. Embora existam algumas restrições e diferenças (p.ex.: resolução horizontal, intervalo de tempo entre "imagens") nos critérios utilizados na classificação dos SCMs e CCMs simulados e os da literatura, o RegCM4 simulou as principais características morfológicas e cinemáticas desses sistemas.

Palavras-chave: ForTraCC, RegCM4, Sistema Convectivo de Mesoescala, América do Sul 



\title{
ABSTRACT
}

\author{
SEGALIN, B. Characteristics of Mesoscale Convective Systems in the climate \\ simulations of RegCM4. São Paulo: Institute of Astronomy, Geophysics and At- \\ mospheric Sciences, University of São Paulo, 2012, 119 p. Masters Dissertation in Mete- \\ orology.
}

Forecasting and Tracking the evolution of Cloud Clusters (ForTraCC) technique and numerical simulations have been used to understand the development of Mesoscale Convective Systems (MCSs). In general, these systems are associated with intense rainfall, wind gusts, hail and sometimes with tornados. This work has adapted the ForTraCC to track MCSs in the outgoing longwave radiation (OLR) from RegCM4 climatic simulations. The RegCM4 was nested in ERA-Interim reanalysis in a domain covering the South America (SA) for the periods of October-May (8 months) of 1997-2003. The RegCM4 simulated climatology reproduced the main atmospheric patterns observed in SA, with best performance in its southern part. The MCSs' morphological and kinematic features were investigated in the tropical (AMZ) and subtropical (BP) sectors. ForTraCC tracked a similar number of MCSs in both regions, but the systems presented different features. In AMZ (BP) the simulations show the maximum frequency of MCSs in November (January). In terms of life cycle, in the AMZ (BP) the MCSs start at 03 UTC (09 UTC), attain the maximum extension at 06 UTC (14 UTC) and dissipate at 12 UTC (23-00 UTC). This indicates a discrepancy between simulated and observed MCSs' life cycle according to the literature, which shows MCSs in AMZ following mainly the solar radiation cycle. The strong influence of low level jet (LLJ) could explain the preferred time (09 UTC) of initiation of MCSs in the BP. In the simulations, the subtropical MCSs are generally larger, long-lived and colder and they are more linear than tropical ones, features also reported in the literature. In AMZ the MCSs do not show a preferential place for genesis and dissipation neither typical trajectories, while in BP they have no preferential place to start but move mainly eastward. Additionally, mesoscale convective complexes (MCCs) were tracked in the area between $10^{\circ}-45^{\circ} \mathrm{S}$ and $75^{\circ}-30^{\circ} \mathrm{W}$. On average, the simulated MCCs form at 04 UTC, attain the maximum extension at 12 UTC (coinciding with maximum activity of LLJ), and dissipate at 15 UTC and 23 UTC. The MCCs are mostly continental, last approximately 16.5 hours (long-lived than reported in observations) and are larger than MCSs. The central-northern Argentina, southern-southeastern Brazil and southern Peru are the preferred regions for genesis of simulated MCCs, which present a typical eastward trajectory. Although there are some restrictions and differences (e.g. horizontal resolution, interval between "images") in the used criteria to classify the simulated MCSs and MCCs and literature, the RegCM4 simulated the main observed morphological and kinematics features of these systems.

Keywords: ForTraCC, RegCM4, Mesoscale Convective System, South America 



\section{LISTA DE FIGURAS}

1 Representação esquemática das situações de rastreamento. As figuras brancas com contorno tracejado são os SCMs no instante $t$ e as figuras cinzas são os SCMs no tempo $t+\Delta t$. As setas representam a evolução do SCM para um caso de continuidade (a), divisão (b) e fusão (c) (VILA et al., 2008). 45

2 Porcentagem de área de sobreposição entre duas elipses com diferentes excentricidades como uma função do tamanho da elipse. Excentricidade igual a 1 significa um circulo perfeito (VILA et al., 2008) . . . . . . . . . . . . 46

3 Esquema da estrutura do algoritmo fortracc.f (MACEDO et al., 2004). . 49

4 Região de estudo dos SCMs (4a) na AS (entre as latitudes $45^{\circ} \mathrm{S}$ e $10^{\circ} \mathrm{N}$ e as longitudes 90 e $20^{\circ} \mathrm{W}$ ) e nas regiões tropical AMZ (entre as longitudes 67,5 e $48,5^{\circ} \mathrm{W}$ e as latitudes 15 e $5^{\circ} \mathrm{S}$ ) e subtropical BP (entre as longitudes 63 e $49^{\circ} \mathrm{W}$ e as latitudes 32,5 e $20^{\circ} \mathrm{S}$ ) e região de estudo dos CCMs (CCM - 4b - entre as longitudes 75 e $30^{\circ} \mathrm{W}$ e as latitudes 10 e $\left.45^{\circ} \mathrm{S}\right) . \quad \ldots . . .552$

5 Ciclo de vida do SCM1, entre 09-23 UTC de 13 de janeiro de 2001, rastreado pelo ForTraCC, na simulação do RegCM4. Os limiares de ROLE 145, 158 e $175 \mathrm{~W} . \mathrm{m}^{-2}$ se referem às temperaturas de $-48{ }^{\circ} \mathrm{C},-43{ }^{\circ} \mathrm{C}$ e $-38{ }^{\circ} \mathrm{C}$, respectivamente. O sinal "+" indica o centro geométrico do SCM1, e o número abaixo deste indica o tamanho do SCM1 em pixels. . . . . . . . . . 54

5 Continuação. . . . . . . . . . . . . . . . 55

$6 \quad$ Semelhante a figura 5, mas para o SCM2 simulado pelo RegCM4 entre 09 UTC do dia 19 e 01 UTC do dia 20 de janeiro de 2001, e apresentou fusão e divisão em seu ciclo de vida. . . . . . . . . . . . . . . . . . . . . 56

6 Continuação. . . . . . . . . . . . . . . 57

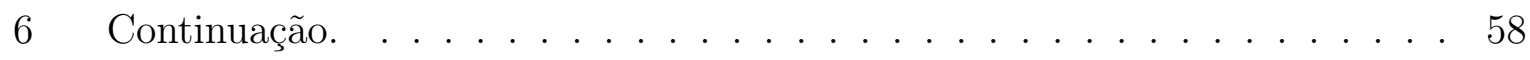

7 Trajetórias, em linha reta, do SCM1 e SCM2 a partir do momento de início, representado pelo sinal " +", até a dissipação marcada pelo ponto. . . . . 58 
8 Climatologia de precipitação média diária (mm/dia) do RegCM4 (8a) e do CMAP (8b) de outubro a maio de 1997 a 2003, e do TRMM (8c) de outubro a maio de 1998 a 2003 . . . . . . . . . . . . . . . . . . . . 6 60

9 Precipitação média diária ( $\mathrm{mm} /$ dia) e desvio padrão de outubro a maio do ano subsequente de 1997 a 2003, no CMAP (azul), RegCM4 (vermelho) e TRMM (verde) para as regiões AMZ (9a) e BP (9b). . . . . . . . . . . 62

10 Climatologia de radiação de onda longa emergente $\left(\mathrm{Wm}^{-2}\right)$ do RegCM4 (10a) e do NCEP (10b) de outubro a maio de 1997 a $2003 . \ldots . .63$

11 Radiação de onda longa emergente $\left(\mathrm{Wm}^{-2}\right)$ média e desvio padrão de outubro a maio do ano subsequente de 1997 a 2003, no CMAP (azul), RegCM4 (vermelho) e TRMM (verde) para as regiões da AMZ (11a) e da BP (11b). 64

12 Climatologia de umidade específica (g/kg) em 850 hPa do RegCM4 (12a) e reanálise do ERA-Interim (12b) de outubro a maio de 1997 a 2003. . . . 65

13 Climatologia de vento (linhas de corrente e intensidade em m/s) em 200 hPa do RegCM4 (13a) e reanálise do ERA-Interim (13b) de outubro a maio de 1997 a $2003 . \ldots \ldots \ldots$. . . . . . . . . . . . . . 66

14 Climatologia de vento (vetor e intensidade em m/s) em 850 hPa do RegCM4 (14a) e reanálise ERA-Interim (14b) de outubro a maio de 1997 a 2003. . . 67

15 Climatologia de temperatura $\left({ }^{\circ} \mathrm{C}\right)$ em $850 \mathrm{hPa}$ do RegCM4 (15a) e do ERA-Interim (15b) de outubro a maio de 1997 a $2003 . \quad \ldots . . . .68$

16 Número de SCMs rastreados por mês na AMZ (16a) e na BP (16b) de outubro a maio de 1997 a $2003 . \ldots \ldots$. . . . . . . . . . . . 70

17 Número de SCMs rastreados por mês na AMZ (17a) e na BP (17b) de outubro a maio de 1997 a $2003 . \ldots$. . . . . . . . . . . . . . 70

18 Distribuição de frequência (em porcentagem) de SCMs na AMZ (18a) e na BP (18b) com relação ao horário de início (azul), máxima extensão (vermelho) e dissipação (verde), de outubro a maio de 1997 a 2003. . . . . 71

19 Distribuição de frequência (em porcentagem) do tempo de vida dos SCMs simulados pelo RegCM4 na AMZ (19a) e na BP (19b) de outubro a maio de 1997 a $2003 . \ldots \ldots$. . . . . . . . . . . . . . . . . . . 74 
20 Distribuição de frequência (em porcentagem) de tamanho dos SCMs simulados pelo RegCM4 na AMZ (20a) e na BP (20b), e uma ampliação para o intervalo de 0 a 50 pixels de ambas as regiões (20c e 20d), de outubro a

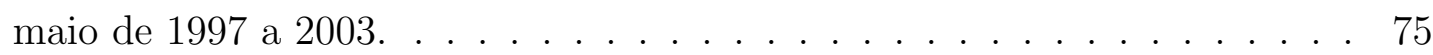

21 Distribuição de frequência (em porcentagem) de excentricidade dos SCMs simulados pelo RegCM4, no momento de máxima extensão, na AMZ (21a) e na BP (21b), de outubro a maio de 1997 a $2003 \ldots \ldots$. . . . . . . . 76

22 Distribuição de frequência (em porcentagem) de temperatura mínima dos SCMs na AMZ (21a) e na BP (22b), de outubro a maio de 1997 a 2003. . . 77

23 Relações entre tamanho máximo e tempo de vida dos SCMs simulados pelo

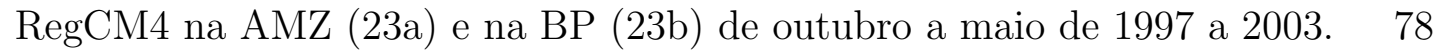

24 Relação entre tempo de vida e temperatura mínima dos SCMs na AMZ (24a) e na BP (24b) de outubro a maio de 1997 a 2003. . . . . . . . . . 78

25 Relação entre temperatura mínima e tamanho máximo dos SCMs simulados pelo RegCM4 na AMZ (25a) e na BP (25b) de outubro a maio de 1997 a 2003. . . . . . . . . . . . . . . . . . . . 79

26 Relação entre temperatura mínima e tamanho máximo (26a) e tempo de vida e excentricidade (26b) dos SCMs simulados pelo RegCM4, de outubro a maio de 1997 a $2003 \ldots$. . . . . . . . . . . . . . . . . . . . . . . . 80

27 Relação entre excentricidade e tamanho máximo dos SCMs na AMZ (27a) e na BP (27b) de outubro a maio de 1997 a $2003 . \ldots . . . .80$

28 Relação entre excentricidade e temperatura mínima dos SCMs na AMZ (28a) e na BP (28b) de outubro a maio de 1997 a 2003. . . . . . . . . . . . 80

29 Posição inicial (29a) e final dos SCMs (29b) simulados pelo RegCM4 na AMZ de outubro a maio de 1997 a 2003 . . . . . . . . . . . . . . . . . 82

30 Posição inicial (30a) e final dos SCMs (30b) simulados pelo RegCM4 na AMZ de outubro a maio de 1997 a 2003 . . . . . . . . . . . . . . . . . . . 83

31 Trajetória em linha reta dos SCMs rastreados na AMZ que ocorreram em outubro (31a), novembro (31b), dezembro (31c), janeiro (31d), fevereiro (31e), março (31f), abril (31g) e maio (31h) de 1997 a 2003. O sinal " +"representa a posição central do início do SCM e o ponto é a posição central final do sistema. . . . . . . . . . . . . . . . . . . . . . . . . . . . . . . . 84 


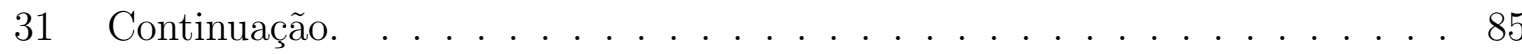

32 Trajetória em linha reta dos SCMs rastreados na BP que ocorreram em outubro (32a), novembro (32b), dezembro (32c), janeiro (32d), fevereiro (32e), março (32f), abril (32g) e maio (32h) de 1997 a 2003. O sinal " +"representa a posição centra do início do SCM e o ponto é a posição central final do sistema. . . . . . . . . . . . . . . . . . . . . . 86

32 Continuação. $\ldots \ldots \ldots \ldots \ldots \ldots \ldots \ldots \ldots \ldots \ldots \ldots$

33 Número de SCMs por mês (33a),dos horários de início (azul), máxima extensão (vermelho) e dissipação (verde) dos SCMs (33b) na AS de outubro a maio de 1997 a $2003 . \ldots \ldots$. . . . . . . . . . . . . . . . 87

34 Distribuição de frequência de tempo de vida dos SCMs simulados pelo RegCM4 na AS (34a) e uma ampliação para SCMs com até 20 horas (34b) de outubro a maio de 1997 a $2003 . \ldots \ldots$. . . . . . . . . . 88

35 Tamanho máximo dos SCMs simulados pelo RegCM4 na AS (35a) e uma ampliação até 200 pixels (35b) de outubro a maio de 1997 a $2003 . \ldots .88$

36 Excentricidade (36a) e temperatura mínima (36b) dos SCMs simulados pelo RegCM4 na AS, no momento de máxima extensão, de outubro a maio de 1997 a $2003 . \ldots \ldots$. . . . . . . . . . . . . . . . 89

37 Relações entre tempo de vida e temperatura mínima (37a) e tamanho máximo (37b), e temperatura mínima e tamanho máximo (37c) dos SCMs simulados pelo RegCM4 na AS de outubro a maio de 1997 a 2003. . . . . . 90

38 Relações entre a excentricidade e temperatura mínima (38a), tempo de vida (38b) e tamanho máximo (38c) dos SCMs simulados pelo RegCM4 na AS de outubro a maio de 1997 a $2003 . \ldots$. . . . . . . . . . . . . 91

39 Posição inicial (39a) e final dos SCMs simulados pelo RegCM4 na AS (39b) de outubro a maio de 1997 a $2003 . \ldots \ldots$. . . . . . . . . 92

40 Número de CCMs rastreados pelo FroTraCC por mês (40a), e por período anual (40b), de outubro a maio de 1997 a $2003 . \ldots \ldots$. . . . . . . 93

41 Distribuição de frequência dos horários de início (azul), máxima extensão (vermelho) e dissipação (verde) dos CCMs, de outubro a maio, de 1997 a $2003 \ldots \ldots \ldots \ldots \ldots \ldots \ldots \ldots$ 
42 Distribuição de frequência do tempo de vida dos CCMs (42a), e uma ampliação do intervalo entre 6 e 20 horas de duração (42b), simulados pelo RegCM4 entre outubro e maio de 1997 a 2003. . . . . . . . . . . . . . . 95

43 Distribuição de frequência do tamanho máximo dos CCMs (43a) e um agrupamento a cada 25 pixels (43b), simulados pelo RegCM4 de outubro a maio de 1997 a 2003. . . . . . . . . . . . . . . . . . . . . . . . . 97

44 Distribuição de frequência de excentricidade no momento de máxima extensão(44a) e de temperatura mínima (44b) dos CCMs simulados pelo RegCM4, de outubro a maio de 1997 a 2003. . . . . . . . . . . . . . . . 98

45 Relações do tempo de vida dos CCMs simulados pelo RegCM4 com seu tamanho máximo (45a) e sua temperatura mínima (45b), de outubro a maio, de 1997 a 2003. . . . . . . . . . . . . . . . . . . . . . . . 98

46 Relações do tamanho máximo dos CCMs com sua temperatura mínima (46a) e sua excentricidade (46b), simulados pelo RegCM4 de outubro a

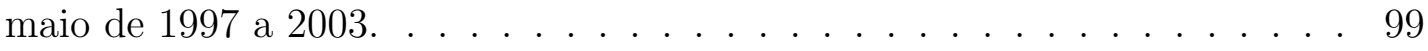

47 Relações entre a excentricidade no momento de máxima extensão dos CCMs e sua temperatura mínima (47a) e seu tempo de vida (47b), simulados pelo

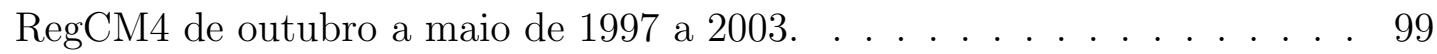

48 Posição do centro geométrico dos CCMs simulados pelo RegCM4 no momento de início (48a), máxima extensão (48b) e dissipação (48c) do sistema.101

49 Trajetória (em linha reta) dos CCMs simulados pelo RegCM4 em outubro (49a), novembro (49b), dezembro (49c) e janeiro (49d) de 1997 a 2003. O sinal " +"representa a posição inicial e o ponto a posição final do CCM. . 102

50 O mesmo que na figura 49, mas para os meses de fevereiro (50a), março (50b), abril (50c) e maio (50d). . . . . . . . . . . . . . . 103 



\section{LISTA DE ABREVIATURAS E SIGLAS}

$\mathrm{AB}$

AMZ

AS

ASAS

ASPS

BATS

BP

DSA

CPTEC

$\mathrm{CC}$

$\mathrm{CCM}$

CLARIS-LPB

CMAP

$\mathrm{CPC}$

ForTraCC

JAN

JBN

INPE

LI

NCAR

NCEP

NOAA

RegCM4

ROLE

$\mathrm{RS}$

$\mathrm{SC}$

SCM

SUBEX
- Alta da Bolívia

- Região tropical da América do Sul entre as longitudes 67,5 e $48,5^{\circ} \mathrm{W}$ e as latitudes 15 e $5^{\circ} \mathrm{S}$

- América do Sul

- Alta Subtropical do Atlântico Sul

- Alta Subtropical do Pacífico Sul

- Biosphere-Atmosphere Transfer Scheme

- Região subtropical da América do Sul entre as longitudes 63 e $49^{\circ} \mathrm{W}$ e as latitudes 32,5 e $20^{\circ} \mathrm{S}$

- Divisão de Satélites e Sistemas Ambientais

- Centro de Previsão do Tempo e Estudos Climáticos

- Célula Convectiva

- Complexo Convectivo de Mesoescala

- Climate Change Assessment and Impact Studies in La Plata Basin

- $\quad$ CPC Merge Analysis of Precipitation

- Climate Prediction Center

- Forecasting and Tracking the evolution of Cloud Clusters

- Jato de Altos Níveis

- Jato de Baixos Níveis

- Instituto Nacional de Pesquisas Espaciais

- Linha de Instabilidade

- National Center for Atmospheric Research

- National Centers for Environmental Prediction

- National Oceanic and Atmospheric Adminstration

- Regional Climate Model version 4

- Radiação de onda longa emergente

- Rio Grande do Sul

- Sistema Convectivo

- Sistema Convectivo de Mesoescala

- Subgrid Explicit Moisture Scheme 
TRMM - Tropical Rainfall Measuring Mission

ZCAS

- Zona de Convergência do Atlântico Sul

ZCIT

- Zona de Convergência Intertropical 


\section{LISTA DE SÍMBOLOS}

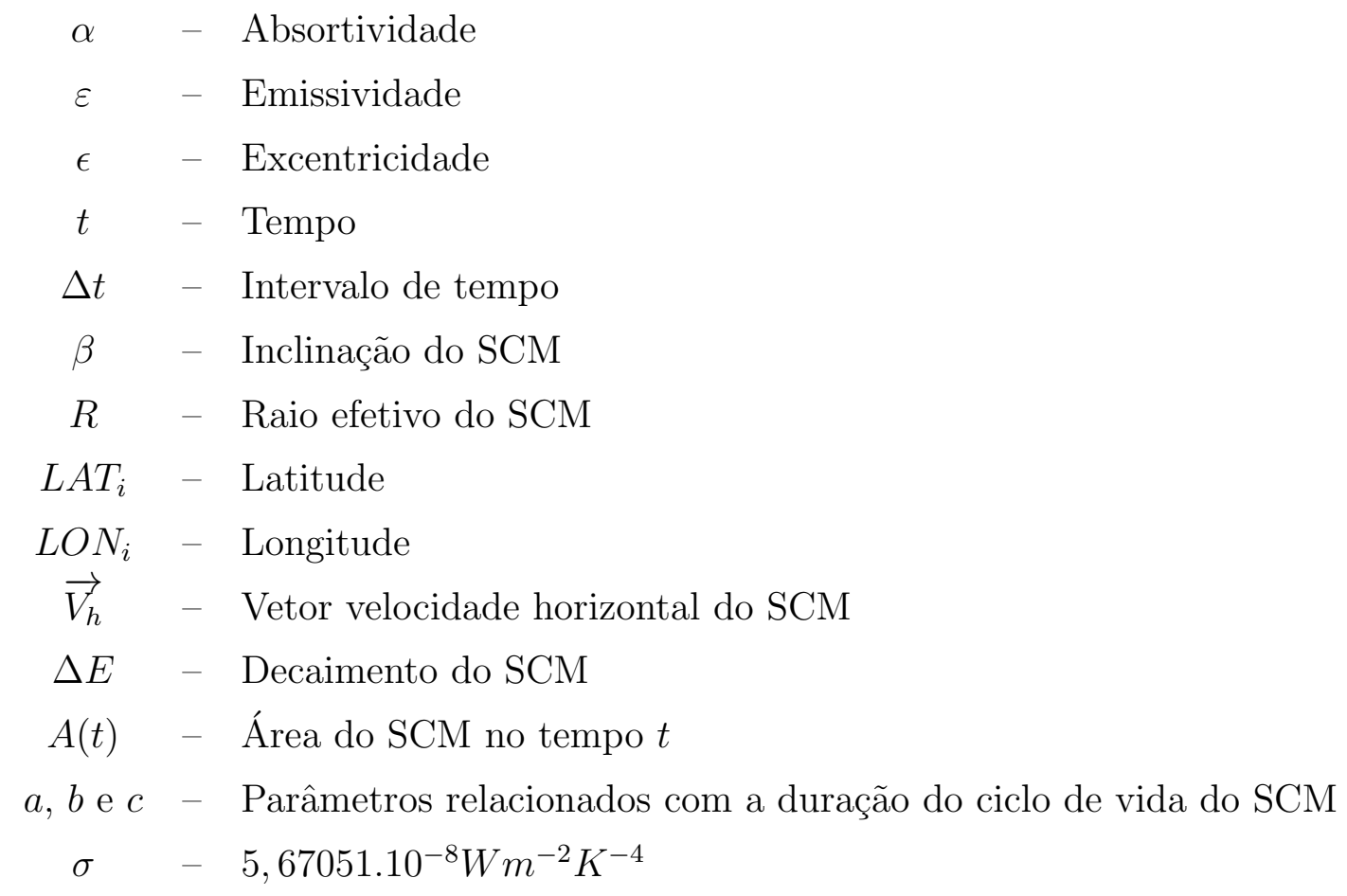





\section{SUMÁRIO}

\begin{tabular}{llr}
1 & Introdução & 27 \\
\hline
\end{tabular}

1.1 Motivação $\ldots \ldots \ldots \ldots$. . . . . . . . . . . . . . . . 27

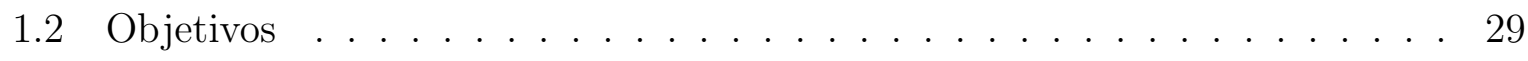

$\begin{array}{lll}2 & \text { Revisão bibliográfica } & 31\end{array}$

3 Dados e metodologia $\quad 37$

3.1 Modelo Climático Regional versão 4 - RegCM4 . . . . . . . . . . . . . . . 37

3.1 .1 Dinâmica do RegCM4 . . . . . . . . . . . . . . . . 37

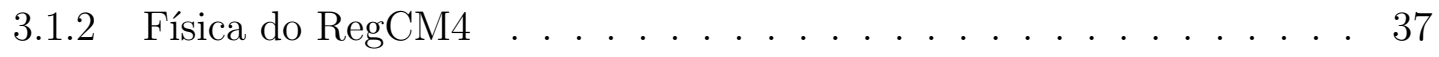

3.1.3 Simulações numéricas . . . . . . . . . . . . . . . . . . . . . . . 40

3.1.4 Validação da simulação do RegCM4 . . . . . . . . . . . . . . . . . . 41

3.2 Programa ForTraCC $\ldots \ldots \ldots \ldots \ldots \ldots$. . . . . . . . . . . . . 42

3.3 Código do ForTraCC $\ldots \ldots \ldots \ldots \ldots \ldots$. . . . . . . . . . . . . 47

3.3 .1 Adaptação do ForTraCC . . . . . . . . . . . . . . . . . . . . . 48

3.4 Rastreamento dos SCMs e CCMs $\ldots \ldots \ldots \ldots$. . . . . . . . . 50

3.4.1 Regiões de estudo . . . . . . . . . . . . . . . . 51

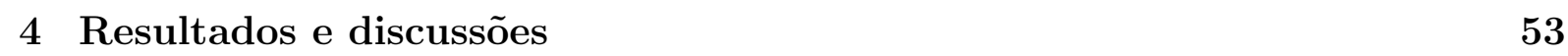

4.1 Validação do ForTraCC . . . . . . . . . . . . . . . . 53

4.2 Climatologia - RegCM4 . . . . . . . . . . . . . . . 59

4.3 Sistemas Convectivos de Mesoescala na AMZ e na BP . . . . . . . . . . 68

4.3.1 Características morfológicas dos SCMs na AMZ e BP . . . . . . 72

4.3.2 Relação entre as características morfológicas dos SCMs $\ldots . .77$ 
4.3.3 Características cinemáticas dos SCMs na AMZ e na BP . . . . . . . 79

4.4 Características gerais dos SCMs em toda a AS . . . . . . . . . . 85

4.5 Complexos Convectivos de Mesoescala . . . . . . . . . . . . . . . . . . . 90

4.5.1 Características morfológicas dos CCMs . . . . . . . . . . . . 94

4.5.2 Características cinemáticas dos CCMs . . . . . . . . . . . . . 99

5 Sumário e Conclusões

105

$\underline{\text { Referências Bibliográficas }}$

111 


\section{INTRODUÇÃO}

\subsection{Motivação}

A América do Sul (AS) abrange tanto baixas quanto médias latitudes e possui diferentes formas de relevo, como a Cordilheira dos Andes (região montanhosa que se estende de norte a sul na costa oeste da AS), vastas planícies contendo enormes superfícies aquáticas constituídas por rios como o Amazonas e o Orinoco, a grande floresta equatorial Amazônica, e uma das áreas mais áridas do planeta, o deserto do Atacama, localizado no norte do Chile. Estes fatores proporcionam a atuação e o desenvolvimento de diferentes sistemas atmosféricos, que contribuem para a não homogeneidade climática desta região (REBOITA et al., 2010).

Um dos sistemas atmosféricos que se desenvolvem na AS são os Sistemas Convectivos de Mesoescalas (SCMs). Esses sistemas são aglomerados de nuvens convectivas que se apresentam de várias formas, com área contínua de precipitação (HOUZE, 1994). Os SCMs que possuem forma de linha são denominados Linhas de Instabilidade (LI), os que apresentam formato circular são os Complexos Convectivos de Mesoescala (CCM) ou simplesmente, SCM, os de formas irregulares. Os SCMs estão associados a eventos de forte precipitação, rajadas de vento, inundações, intensas tempestades elétricas, granizo e até tornados (MADDOX, 1983), causando sérios danos na infra-estrutura das cidades e no campo e até mesmo perdas de vidas, afetando principalmente a população mais vulnerável.

A ocorrência de fenômenos severos associados aos SCMs é motivo de preocupação para a sociedade, não só por abalar a economia devido ao seu alto poder de destruição, mas também pela perda de vidas. Em virtude disso grande atenção tem sido dada ao estudo dos SCMs, mas não só pela severidade das condições de tempo associadas, mas também por gerarem, em determinado estágio de evolução, precipitação contínua sobre extensas áreas. Isso é importante do ponto de vista da agricultura e também na geração hidroelétrica quando a ocorrência dos SCMs é frequente em uma determinada época do 
ano e região (MADDOX, 1983) .

O sudeste da AS é conhecido como a região onde ocorrem as tempestade mais intensas do globo (ZIPSER et al., 2006), possivelmente devido à presença de SCMs. Na região tropical da AS, os SCMs são os principais responsáveis pelas transferências verticais de energia na troposfera tropical (LAURENT; MACHADO; 2002). Durante a estação quente a precipitação no sudeste da AS é modulada pela presença de processos de mesoescala associada com a atividade dos SCMs (DEMARIA et al., 2011). Nesta região está localizada a Bacia do Prata que é o segundo maior sistema fluvial da AS depois do Bacia do Rio Amazonas (DEMARIA et al., 2011). A ocorrência de SCMs possui importante influência no ciclo hidrológico dessas regiões.

A evolução e manutenção dos SCMs ainda não são bem conhecidas, principalmente os aspectos dinâmicos da atmosfera associados a estes sistemas. O conhecimento da evolução e ciclo de vida dos SCMs é de fundamental importância para entender o tempo e o clima, e é essencial para melhorar a previsão com consequente redução da vulnerabilidade a danos extremos. Climatologias de SCMs são muito úteis para melhorar nosso conhecimento desses sistemas (MOREL; SENESI, 2002). Estudos numéricos são realizados há anos buscando simular o desenvolvimento dos SCMs.

Na AS, experimentos numéricos conduzidos por DA ROCHA (1992) mostraram movimento ascendente intenso em mesoescala, convergência de massa entre baixos e médios níveis e divergência mais intensa em altos níveis no SCM e que o jato de baixos níveis (JBN) simulado transporta ar quente e úmido para a área do sistema em baixos níveis. Adicionalmente, as simulações indicaram que processos diabáticos associados à convecção cumulus tem papel dominante na evolução do SCM, enquanto processos turbulentos próximos à superfície atuam como modificadores da intensidade do sistema.

A baixa resolução horizontal dos modelos globais limita a representação de processos de mesoescala (MISRA et al., 2002), existindo assim, a necessidade da utilizar modelos regionais em estudos climáticos. A possibilidade de utilizar alta resolução aumentou o uso destes modelos para fins climáticos nas últimas décadas (GIORGI et al., 2012; DA ROCHA et al., 2012).

Muitos estudos usaram a técnica Forecasting and Tracking the evolution of Cloud Clusters (ForTraCC; VILA et al., 2008) para rastrear SCMs na AS, buscando entender melhor suas características (SALIO et al., 2007; VILA et al., 2008, VIANA et al., 2009; SAKAMOTO, 2009; SAKAMOTO et al., 2011; FERNANDES, 2010; EICHHOLZ, 2011). Enquanto que Gomes (2007) adaptou o ForTraCC para rastrear CCMs nas si- 
mulações do Modelo Regional Climático versão 3 (RegCM3). O autor analisou algumas características dos CCMs para os verões austrais de 1997-1999 e discutiu circulações características simuladas pelo RegCM3 para CCMs observados em imagens de satélite por Velasco e Fritsch (1987). Gomes (2007) mostrou que a variabilidade interanual dos CCMs na região sul-sudeste da AS foi simulada pelo RegCM3, indicando a habilidade do modelo em reproduzir este tipo de sistema. Contudo, o autor não analisou os demais tipos de SCMs, concentrou-se em um curto período de tempo, uma única área e nas características sinóticas dos CCMs sem focar na morfologia e cinemática desses sistemas. Portanto é necessário uma análise mais prolongada e abrangente dos SCMs e CCMs nas simulações dos modelos regionais para toda a AS.

\subsection{Objetivos}

Dentro desse contexto, o objetivo do presente trabalho é adaptar o ForTraCC para rastrear SCMs nas simulações do Modelo Climático Regional versão 4 (RegCM4) e avaliar a eficiência deste em reproduzir as características morfológicas e cinemáticas destes sistemas reportados na literatura. O período de estudo compreende os meses de outubro a maio de 1997 a 2003. Especificamente, pretende-se com este estudo:

- Adaptar o código do ForTraCC para as simulações do RegCM4;

- Validar a adaptação do ForTraCC;

- Avaliar as simulações climáticas do RegCM4;

- Rastrear os SCMs e também os CCMs nas simulações do RegCM4 para a AS;

- Comparar as características dos SCMs tropicais e subtropicais;

- Avaliar as características morfológicas e cinemáticas dos SCMs e CCMs rastreados;

- Obter uma climatologia (6 anos) dos SCMs e CCMs rastreados. 


\section{REVISÃO BIBLIOGRÁFICA}

Os SCMs, segundo Cotton (2010), são sistemas convectivos profundos que são consideravelmente maiores do que uma tempestade individual e que possuem muitas vezes uma extensa camada de nuvem de até centenas de quilômetros de dimensão horizontal, têm vida útil de seis a 12 horas e, em algumas ocasiões, a porção estratiforme da bigorna do sistema pode sobreviver durante vários dias. Com base na resolução horizontal e temporal os sistemas convectivos são classificados na categoria de mesoescala divididos nas subescalas, em ordem crescente de dimensões horizontais meso- $\gamma$ (cumulonimbus individuais), meso- $\beta$ (LIs) e meso- $\alpha$ (CCMs) (ORLANSKI, 1975 apud SILVA DIAS, 1987).

A nuvem cumulonimbus, ou tempestade, é uma nuvem convectiva, ou sistema de nuvens, que produz chuvas e relâmpagos, muitas vezes com granizo, rajadas de vento, e até mesmo tornados (COTTON, 2010). LIs consistem de um conjunto de cumulonimbus alinhados que se deslocam de maneira uniforme, mantendo uma certa identidade durante seu tempo de vida, que varia entre poucas horas até um dia (SILVA DIAS,1987). Os CCM são aglomerados de nuvens organizadas de maneira quase-circular, sua definição é descrita por Maddox (1980), que considerou única e exclusivamente a temperatura de brilho do topo das nuvens em imagens de satélites no canal infravermelho para classificá-los:

1. Tamanho:

- (A) cobertura de nuvem com temperatura no canal infravermelho $\leq-32^{\circ} \mathrm{C}$ deve ter área $\geq 10^{5} \mathrm{~km}^{2}$;

- (B) cobertura de nuvem com temperatura no canal infravermelho $\leq-52^{\circ} \mathrm{C}$ deve ter área $\geq 5 \times 10^{4} \mathrm{~km}^{2}$;

2. Início: critérios A e B são satisfeitos;

3. Duração: critérios A e B são satisfeitos por intervalo de tempo $\geq 6$ horas;

4. Máxima extensão: cobertura de nuvem com temperatura $\leq-32^{\circ} \mathrm{C}$ atinge tamanho máximo; 
5. Forma: excentricidade $\geq 0,7$ no momento de máxima extensão;

6. Dissipação: critérios A e B não são mais satisfeitos;

Segundo Maddox (1980) o formato circular dos CCMs indica a predominância de circulações de mesoescala geradas convectivamente. No entanto, para DA ROCHA (1992) seria o resultado da presença de uma região onde a vorticidade é ciclônica em baixos níveis, e anticiclônica em altos níveis. Esses sistemas se desenvolvem em ambientes condicionalmente instáveis, sob forte advecção quente em baixos níveis e em associação com um fraco cavado de onda curta em níveis médios e uma região frontal quase estacionária (MADDOX, 1983).

Na AS a presença da cordilheira dos Andes, a mais longa do mundo, é um fator importante para a canalização dos ventos em uma direção, originando fortes escoamentos em baixos níveis que apresentam máxima magnitude, o jato de baixos níveis (JBN), em torno de 850 hPa (SOUZA; CAVALCANTI, 2004). Segundo Salio et al. (2007) o JBN é uma característica recorrente do ambiente durante os estágios de formação e maturação de SCMs advectando calor e umidade da bacia Amazônica para o sudeste e sul da AS, gerando condições ideais para a convecção inicial e desenvolvimento de SCMs. O cisalhamento horizontal na região do JBN dá origem a vorticidades ciclônica e anticiclônica nos dois lados do jato, que podem contribuir para a interação da circulação local com a circulação de ventos vale-montanha. Essas características são mais fortes no desenvolvimento de CCMs (SOUZA; CAVALCANTI, 2004).

Para uma análise global, Laing e Fritsch (1997) também encontraram associação entre os CCMs e os JBNs, e que cerca de 400 CCMs ocorrem ao redor do globo a cada ano. Os CCMs são observados em todos os continentes, com exceção da Antártica, e ocorrem sobre a terra a sotavento de cadeias montanhosas. Segundo Sakamoto (2009) o JBN afeta a formação de SCMs continentais, porém sua atuação sobre os oceânicos é mínima. Segundo Guedes (1985) o acoplamento do JBN e do jato de altos nívies (JAN) favorece a formação dos SCMs. O JBN, o aquecimento diurno da camada limite convectiva, o cavado em 500 hPa e a circulação transversa atuam juntos como pré-condicionantes e gatilho dos SCMs (SAKAMOTO, 2009).

$\mathrm{Na}$ AS as temperaturas mais altas ocorrem ao norte dos SCMs (GUEDES, 1985). Segundo Duquia e SILVA DIAS (1994) a presença de advecção quente e temperaturas altas em baixos níveis reforçam a instabilidade na região do CCM. Valores mais altos de razão de mistura são encontrados no setor norte dos CCMs na AS (GUEDES, 1985; DUQUIA; 
SILVA DIAS, 1994). Na região dos CCMs e ao norte o vento é predominantemente meridional, com procedência de norte (GUEDES, 1985). Os oceanos Atlântico tropical e Pacífico subtropical, e a região Amazônica, são as principais fontes da umidade para a gênese dos SCMs, contudo, a atuação dessas fontes depende da região de formação do sistema e das condições sinóticas (SAKAMOTO, 2009).

Os sistemas convectivos são responsáveis pela maioria das chuvas nas regiões tropicais e latitudes temperadas durante a estação quente (MACHADO; LAURENT, 2004), sendo então os principais motores do ciclo hidrológico e, portanto, essenciais para a sobrevivência de milhões de pessoas que vivem nessas regiões. A AS abrange tanto regiões tropicais como subtropicais, onde existem grandes bacias hidrográficas. A maior delas é a bacia hidrográfica do rio Amazonas, incluindo a bacia do rio Tocantins/Araguaia, que cobre uma área de $7,1 \times 10^{6} \mathrm{~km}^{2}$ (JUNK; MELLO, 1990), e a segunda é a Bacia do Prata, que abrange cerca de $3,2 \times 10^{6} \mathrm{~km}^{2}$ e está localizada entre as latitudes $14^{\circ} \mathrm{S}$ e $38^{\circ} \mathrm{S}$ e entre as longitudes $67^{\circ} \mathrm{W}$ e $43^{\circ} \mathrm{W}$. Esta bacia é compartilhada pelo Brasil, Argentina, Paraguai, Bolívia e Uruguai que ocupam aproximadamente 46\%, 30\%, 13\%, 7\% e 4\% de sua superfície, respectivamente (BERBERY; BARROS, 2002). Segundo Anabor et al. (2009) eventos de SCMs ao longo do sudeste da AS são importantes contribuintes para o ciclo hidrológico local, podendo fornecer cerca de metade do total mensal da precipitação no verão.

Para a AS um estudo fundamental sobre CCMs é o de Velasco e Fritsch (1987) que utilizaram critérios semelhantes aos de Maddox (1980), porém com limiares de temperatura um pouco diferentes $\left(-40^{\circ} \mathrm{a}-42^{\circ} \mathrm{C}\right.$ ao invés de $-32^{\circ} \mathrm{C}$ e $-62^{\circ} \mathrm{a}-64^{\circ} \mathrm{C}$ ao invés de $\left.-52^{\circ} \mathrm{C}\right)$; quanto às áreas, os valores são os mesmos. Velasco e Fritsch (1987) mostraram que a Bacia do Prata é uma região favorável ao desenvolvimento de CCMs, que ocorrem com maior frequência nos meses quentes do ano, com pico em novembro. Suas trajetórias têm início geralmente a leste da Cordilheira dos Andes em latitudes subtropicais, por volta de $25^{\circ} \mathrm{S}$ sobre os vales dos rios Paraná e Paraguai. Há uma grande variabilidade nas trajetórias, mas existe clara tendência zonal, de oeste para leste, na primavera e início de outono, e algumas trajetórias para norte no verão. Figueiredo e Scolar (1996) estudaram 25 casos de CCMs, e encontraram que $70 \%$ tinham trajetória para leste e sudeste enquanto em $30 \%$ as trajetórias foram para norte e nordeste, com tempo de vida médio de 13 horas.

Conforme os resultados obtidos por Velasco e Fritsch (1987), a máxima extensão dos CCMs ocorre durante a madrugada na maioria dos casos estudados. A frequência de CCMs na madrugada é uma das características distintas desses sistemas em latitudes 
médias em ambos os hemisférios. As primeiras células convectivas que precedem os CCMs ocorrem geralmente no início da tarde ou durante a noite, o que implica na existência de diferentes mecanismos de formação das primeiras tempestades. As primeiras, por volta das $1400 \mathrm{HL}$, podem estar associadas com máximo aquecimento diurno e as segundas, por volta das $2200 \mathrm{HL}$, podem ser devidas à convergência noturna na zona do Rio Paraná reforçada pelo escoamento catabático a leste dos Andes. A dissipação da maioria dos CCMs ocorre em torno do meio dia. O tempo de vida desses sistemas situa-se entre 10 e 20 horas, com tempo de vida médio de 11,5 horas.

Recentemente Durkee e Mote (2010) fizeram uma climatologia de CCMs na região subtropical da AS de outubro a maio, entre os anos de 1998 a 2007. Os autores rastrearam de forma semi-automática 330 CCMs, com uma mediana (média) de 33 (37) eventos por estação, com máxima frequência durante dezembro-janeiro e tempo de vida médio de 14 horas, diferindo dos resultados de Velasco e Fritsch (1987). Isso ocorre devido às diferentes metodologias e períodos de estudo. A título de exemplo, Goyens et al. (2011) apresenta uma tabela com diferentes metodologias para rastrear SCMs, o que explica as diferenças nos resultados obtidos.

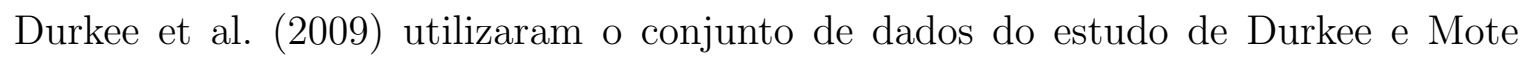
(2010) e encontraram que a precipitação média produzida por CCMs é de 15,7 mm sobre uma área de $381.000 \mathrm{~km}^{2}$, com um volume de 7,0 km³ . Os CCMs contribuem com $11 \%$ a $20 \%$ para o total de precipitação na AS subtropical em todos os meses analisados. Viana et al. (2009) encontraram entre outubro e dezembro de 2003, 22 eventos de CCMs através do ForTraCC (VILA et al., 2008) no estado do Rio Grande do Sul. Segundo estes autores, os sistemas contribuíram para os totais de precipitação no período, causando uma série de danos e riscos à população local. Quase dois terços da precipitação registrada (63\%) esteve associada aos eventos de CCMs.

Os SCMs e CCMs são estudados em várias partes do mundo (LAING; FRITSCH, 1997). Recentemente, na região do Sahel, Goyens et al. (2011) encontraram que os SCMs geralmente apresentam uma cobertura de nuvens máxima de cerca de 57.000 km², duração de 9 h e picos de precipitação em torno de 12,3 mm/h. Seus resultados também mostraram que a máxima cobertura de nuvens é precedida por um mínimo de temperatura de brilho no núcleo convectivo frio e é seguida por um pico em precipitação. Adicionalmente, os SCMs de longa duração e maiores, assim como os SCMs de longa duração e muito frios, exibem uma probabilidade maior de induzir precipitação mais intensa.

Li et al. (2012) recentemente apresentaram uma climatologia sobre o leste da Ásia 
e mostraram que os SCMs apresentam deslocamentos para sul e norte, acompanhando aumento e recuo da monção de verão. O verão foi o período de maior atividade dos SCMs, com um pico em julho. A mediana dos valores de área $\left(41.382 \mathrm{~km}^{2}\right)$, duração $(3,84 \mathrm{~h})$, e elipticidade $(0,55)$ mostra que um grande número de SCMs são pequenos, de curta duração, e têm formas alongadas. Formas mais alongadas (excentricidade menor que 0,31 ) provavelmente são devidos à proximidade com frentes frias. OS SCMs têm velocidade média (mediana) de $55,8 \mathrm{~km} / \mathrm{h}(48 \mathrm{~km} / \mathrm{h})$. Do total de SCMs, $54 \%$ moveramse lentamente com velocidades inferiores a $50 \mathrm{~km} / \mathrm{h}$, e geralmente causaram fortes chuvas e inundações. Muito pouco se sabe sobre a previsibilidade de CCMs (WANDISHIN et al., $\underline{2010)}$ e segundo Li et al. (2012) a velocidade com que os SCMs se movem é um importante parâmetro, já que está relacionada com a ocorrência de inundações, pois um SCM lento pode causar mais inundação do que um mais veloz.

Devido a dificuldade de analisar características morfológicas e cinemáticas em uma grande quantidade de SCMs observados em períodos longos, foram criados algoritmos que facilitam o rastreamento dos mesmos, como o ForTraCC (VILA et al., 2008) e o Maximum Spatial Correlation Tracking Technique (MASCOTTE; CARVALHO; JONES, 2001), além de métodos semi-automáticos como o usado por Durkee e Mote (2010). O ForTraCC tem sido muito utilizado na AS a fim de obter padrões dos SCMs (SALIO et al., 2007; GOMES, 2007; VIANA et al., 2009; SAKAMOTO, 2009; SAKAMOTO et al., 2011, FERNANDES, 2010; EICHHOLZ, 2011).

Por exemplo, Sakamoto (2009) também utilizou o ForTraCC para rastrear SCMs ao sul de $20^{\circ}$ da AS entre 15 de dezembro de 2002 e 15 de fevereiro de 2003. Seus resultados mostraram que a maior parte dos SCMs é continental, têm tempo de vida médio em torno de 12 horas, os com maior duração têm taxa de expansão maior, e o tamanho médio dos SCMs continentais e oceânicos é de $161.600 \mathrm{~km}^{2}$ e $97.600 \mathrm{~km}^{2}$, respectivamente. Esses resultados mostram que o tempo de vida e tamanho dos SCMs na AS é maior que em outras regiões do globo (GOYENS et al., 2011; LI et al., 2012). Eichholz (2011) também utilizou o ForTraCC para rastrear SCMs, mas para uma área menor (o estado do Rio Grande do Sul) e um período de tempo maior, de 2004 a 2008. O autor encontrou que a maioria dos SCMs têm entre 6 e 12 horas de duração, formato alongado, trajetória de oeste para leste e maior frequência nos períodos quentes do ano.

Modelos regionais têm se tornado uma importante ferramenta em estudos climáticos e devido a isso o interesse em modelagem climática regional vem aumentando nas últimas décadas. Uma das vantagens desses modelos com relação aos globais é que eles repre- 
sentam o clima atual de forma mais realista (OYAMA, 2006), pois podem utilizar maior resolução horizontal, representando melhor aspectos topográficos em alta resolução.

DA ROCHA et al. (2009) mostraram que, apesar de diferenças regionais, o RegCM3 simula os principais aspectos observados na climatologia do verão associados com a precipitação (Zona de Convergência Atlântico Sul - ZCAS) e a temperatura do ar (ar quente na parte central do continente e mais frio no leste do Brasil e Cordilheira dos Andes). Também constataram que o RegCM3 simula chuva noturna sobre Paraguai e norte da Argentina o que seria um indício da presença de CCMs nestas simulações.

Estudos com a nova versão do RegCM (quarta versão) têm sido feitos recentemente para a AS. Giorgi et al. (2012) utilizaram uma nova opção da versão do RegCM4 que combina duas parametrizações de convecção de cumulus, ou seja, esquema de Grell (GRELL, 1993) sobre a terra e Emanuel (EMANUEL, 1991) sobre o oceano. Os autores encontraram que, em termos de climatologia, a fase e intensidade do ciclo anual de precipitação simulado sobre Amazônica e a Bacia do Prata seguem a análise global de precipitação diária do CPC-NOAA (Climate Prediction Center - National Oceanic and Atmospheric Adminstration).

Llopart e DA ROCHA (2012) analisaram a sensibilidade dos fluxos de superfície e variáveis meteorológicas no RegCM4.1 com esquema de vegetação dinâmica, usando os esquemas convectivos de Grell (RegGrell) e Emanuel (RegEmanuel). Os autores encontraram que o RegEmanuel mostrou melhorias na representação dos fluxos de superfície, resultando em temperatura e precipitação semelhante ao observado (ERA-Interim) no período seco, enquanto que a concordância do RegGrell com a observação é grande durante o verão. Com base nestes trabalhos, este estudo também utilizará a nova versão do RegCM4 que combina os esquemas Grell (continente) e Emanuel (oceano). 


\section{DADOS E METODOLOGIA}

\subsection{Modelo Climático Regional versão 4 - RegCM4}

Este estudo utilizou a quarta versão do Modelo Climático Regional (RegCM4 - Regional Climate Model version 4 ) descrita por Giorgi et al. (2012). O RegCM foi desenvolvido pelo National Center for Atmospheric Research-Pennsylvania State University (NCARPSU), a partir do modelo atmosférico Mesoscale Model version 4 (MM4, ANTHES et al., 1987). A história da evolução das versões do RegCM até a terceira versão é apresentada em Pal et al. (2007).

\subsubsection{Dinâmica do RegCM4}

A base da dinâmica do RegCM4 permaneceu semelhante ao RegCM versões 2 e 3 (GIORGI et al., 1993a; GIORGI et al., 1993b; PAL et al., 2007; GIORGI et al., 2012), ou seja, é um modelo hidrostático, compressível, em coordenada vertical sigma-p e grade Arakawa B, na qual o vento e as variáveis termodinâmicas são escalonadas horizontalmente.O RegCM4 utiliza um esquema de integração explícito "time-split" no qual os dois modos de gravidade mais rápidos são integrados com menor passo de tempo, o que permite passos no tempo maiores para os demais componentes do modelo. O RegCM4 é então muito semelhante a versão hidrostática do Modelo de Mesoescala versão 5 (MM5 PAL et al., 2007).

\subsubsection{Física do RegCM4}

Para a transferência radiativa o RegCM4 utiliza o mesmo esquema do modelo Community Climate Model version 3 do NCAR (CCM3; KIEHL et al., 1996). Este esquema calcula separadamente as taxas de aquecimento devido à onda curta e infravermelho do espectro, incluindo gases atmosféricos e aerossóis. Inclui também a contribuição dos gases de efeito estufa e CFCs e radiação solar. A absorção e o espalhamento da radiação solar por aerossóis são também incluidas e baseadas nas propriedades ópticas dos aerossóis. 
A interação entre radiação solar e nuvem foi modificada no RegCM4 para corrigir o problema de tratar as propriedades da nuvem como média na grade (GIORGI et al., 2012). O RegCM4 calcula primeiro a cobertura total de nuvem e então os fluxos na superfície separadamente para as partes nubladas e de céu claro na grade. A cobertura de nuvem na grade é obtida como a média entre o valor usando sobreposição aleatória (o qual maximiza a cobertura de nuvem) e aquele dado pela maior cobertura de nuvem na coluna vertical. Esta modificação considera a possibilidade de existir parte de céu claro na grade, fornecendo então fluxo de radiação solar em superfície mais realístico. O RegCM4 também modificou os cálculos de transferência radiativa considerando aerosóis, através da inclusão da contribuição no espectro infravermelho (GIORGI et al., 2012).

O esquema de camada limite planetária (ver HOLTSLAG et al., 1990 para detalhes) implementado no RegCM4 sofreu algumas alterações (GIORGI et al., 2012). O termo de fluxo contra-gradiente para o vapor de água foi removido, definiram condições "muito estáveis" quando a razão da altura da superfície sobre o comprimento do Monin-Obhukov é menor do que 1.0. Sob tais condições a difusão turbulenta e o termo de contra-gradiente foram considerados para todas as variáveis. Em testes preliminares, estas modificações reduzem o erro médio quente nas altas latitudes no inverno e permitem capturar inversões de superfície (GIORGI et al., 2012).

Para representar a convecção de cumulus no RegCM4, três opções estão disponíveis:

- esquema modificado de Anthes-Kuo (ANTHES, 1977): ativa a convecção quando a convergência de umidade na coluna excede um dado limiar. Esse esquema é pouco utilizado (GIORGI et al., 2012);

- esquema Emanuel (EMANUEL, 1991): a convecção é desencadeada quando o nível de flutuabilidade é mais alto do que o nível da base da nuvem, a mistura da nuvem é considerada episódica e não homogênea, e os fluxos convectivos são baseados em um modelo de corrente ascendente e descendente de subescala de nuvem. A precipitação resulta da autoconversão da água da nuvem em água de chuva e inclui processos simplificados de gelo. Este esquema foi implementado inicialmente no RegCM3 (PAL et al., 2007);

- esquema de Grell (GRELL, 1993): é uma parametrização de fluxo de massa de convecção profunda, onde as nuvens são consideradas como duas circulações em estado estacionário, incluindo uma corrente ascendente e uma corrente descendente. O esquema é desencadeado quando uma parcela levantada em uma corrente ascen- 
dente eventualmente atinge o nível de convecção úmida. Um modelo de nuvem é usado com entranhamento e desentranhamento somente no topo e na base da nuvem (GIORGI et al., 2012).

Com relação a convecção de cumulus, diferentemente das outras versões o RegCM4 pode utilizar diferentes esquemas de convecção sobre a terra e o oceano. Em testes preliminares a combinação de Emanuel no oceano e Grell sobre a terra se mostrou mais adequada e agora está implementada no RegCM4 (GIORGI et al., 2012).

Giorgi et al. (2012) discute que o esquema Grell é o mais utilizado atualmente. DA ROCHA et al. (2009) mostrou que o RegCM3 com este esquema simulou as principais características do ciclo diurno da precipitação sobre uma grande parte da AS, mas apresenta substimativa de chuva sobre os oceanos adjacentes. Portanto, o presente estudo utilizou os esquemas combinados de Grell e Emanuel, sobre o continente e oceano, respectivamente, para representar a convecção cumulus.

No RegCM4, a precipitação que é resolvida na escala da grade é representada pelo Subgrid Explicit Moisture Scheme (SUBEX; PAL et al., 2007). O SUBEX considera a variabilidade da nuvem em escala de subgrade e inclui autoconversão da água da nuvem em água da chuva, o acréscimo das gotículas de nuvem pelas gotas de chuva caindo, e a evaporação dessas gotas de chuva. A cobertura de nuvem é calculada a partir da umidade relativa e a nuvem se forma quando a umidade relativa excede um determinado limiar. Em adição, o limiar de água líquida na nuvem para formação de chuva é baseado em observações empíricas de quantidade de água líquida na nuvem.

O RegCM4 incluiu o esquema de interação biosfera-atmosfera o Biosphere-Atmosphere Transfer Scheme (BATS; DICKINSON et al., 1993) para representar processos de superfície, ou seja, interação solo-planta-atmosfera. O BATS descreve a transferência de energia, massa e momento entre a atmosfera e a biosfera. Nesta versão do modelo foram adicionadas ao BATS dois novos tipos de uso da terra para representar ambientes urbanos e suburbanos, e a opção do Community Land Model, uma parametrização baseada em biogeofísica para descrever as trocas de energia, momento, água e carbono entre terra e atmosfera (GIORGI et al., 2012).

\section{Radiação de onda longa}

O método empregado no CCM3 para representar transferência radiativa de onda longa é baseado em uma expressão de absortividade/emissividade (RAMANATHAN; DOWNEY, 1986 apud KIEHL et al., 1996), 


$$
\begin{gathered}
F^{\downarrow}(p)=B(0) \varepsilon(0, p)+\int_{0}^{p} \alpha\left(p, p^{\prime}\right) d B\left(p^{\prime}\right) \\
F^{\uparrow}(p)=B\left(T_{s}\right)-\int_{p}^{p_{s}} \alpha\left(p, p^{\prime}\right) d B\left(p^{\prime}\right)
\end{gathered}
$$

onde $B(T)=\sigma T^{4}$ é a relação de Stefan-Boltzmann, onde $\sigma=5,67051.10^{-8} \mathrm{Wm}^{-2} \mathrm{~K}^{-4}$. $\alpha$ e $\varepsilon$ são a absortividade e emissividade,

$$
\begin{gathered}
\alpha\left(p, p^{\prime}\right)=\frac{\int_{0}^{\infty}\left\{d B_{v}\left(p^{\prime}\right) / d T\left(p^{\prime}\right)\right\}\left(1-\tau_{v}\left(p, p^{\prime}\right)\right) d v}{d B\left(p^{\prime}\right) / d T\left(p^{\prime}\right)} \\
\varepsilon(0, p)=\frac{\int_{0}^{\infty} B_{v}\left(\tau_{\infty}\right)\left(1-\tau_{v}(0, p)\right) d v}{B(0)}
\end{gathered}
$$

onde a integração é sobre o número de onda, $v \cdot B_{v}(p)$ é a função de Planck, e $\tau_{v}$ é a transmissividade atmosférica. Então, para resolver os fluxos de cada camada do modelo é utilizada a seguinte solução,

$$
\int_{0}^{\infty}\left(1-\tau_{v}\right) F\left(B_{v}\right) d v
$$

onde $F\left(B_{v}\right)$ é a função de Planck para a emissividade, ou a derivada da função Planck em relação à temperatura para a absortividade.

Para o intervalo de número de ondas de interesse, de 500 a $1500 \mathrm{~cm}^{-1}$, definido através de demonstrações descritas em Kiehl et al. (1996), o fluxo radiativo é determinado em parte pela integral,

$$
\int_{500}^{1500}\left(1-\tau_{v}\right) F\left(B_{v}\right) d v
$$

\subsubsection{Simulações numéricas}

As simulações com o RegCM4 foram realizadas no contexto do projeto Climate Change Assessment and Impact Studies in La Plata Basin (CLARIS-LPB) e utilizaram a reanálise ERA-Interim (SIMMONS et al., 2007) como condições inicial e de fronteira. Esta reanálise possui 37 níveis de pressão na vertical e está disponível com uma resolução horizontal 1,5 . As simulações usaram a projeção de Mercator, com resolução de 50 km na horizontal (192 x 202 pontos de grade na direção leste-oeste e norte-sul, respectivamente) e 18 níveis sigma na vertical. Tanto as variáveis atmosféricas (altura geopotencial, temperatura, vento, 
umidade relativa e pressão) como a temperatura da superfície do mar foram fornecidas pela ERA-Interim. As simulações foram iniciadas no dia 01 de outubro e prosseguiram até o último dia de maio do ano seguinte. Foram então realizadas 6 simulações iniciadas em outubro de 1997, 1998, 1999, 2000, 2001 e 2002. Para o rastreamento dos SCMs utilizou-se a radiação de onda longa emergente (ROLE).

Muitos trabalhos rastrearam SCMs com intervalo de 3 horas entre imagens de satélite, contudo uma dificuldade desta resolução temporal é identificar com precisão o padrão do ciclo diurno, e outras estatíticas, tais como máxima extensão, tamanho e duração dos sistemas (DURKEE; MOTE; 2010), assim como os horários de início, máxima extensão e dissipação. No ForTraCC, devido à imposição de área mínima de sobreposição (MOREL; SENESI, 2002), quanto maior o intervalo de tempo entre as imagens menor quantidade de SCMs pode ser detectada (SEGALIN et al., 2011). Em virtude desses fatores utilizouse o intervalo de tempo de 1 hora nas simulações do RegCM4. O período de simulação inclui os meses de outubro a maio (estação quente austral), o que permite comparar as características cinemáticas e morfológicas dos CCMs com a recente climatologia de Durkee $\underline{\text { e Mote }} \underline{(2010)}$ para a AS, mas neste trabalho utilizou-se apenas os anos de 1997 a 2003.

\subsubsection{Validação da simulação do RegCM4}

Para validar a simulação do RegCM4 foram comparados os campos de precipitação média entre outubro-maio de 1997 a 2003 com o CPC Merged Analysis of Precipitation (CMAP) e o Tropical Rainfall Measuring Mission (TRMM). O CMAP é uma combinação de dados pluviométricos com estimativas de precipitação baseadas em algoritmos e estimativas de satélites no infravermelho e reanálise do National Center for Atmospheric Research do National Centers for Environmental Prediction (NCAR/NCEP), produzindo análises mensais de precipitação global com resolução de 2,5x 2, $5^{\circ}$ (XIE; ARKIN, 1997). O TRMM é um projeto de satélite lançado em 1997 para monitorar e estudar a precipitação na região tropical e subtropical, com varreduras desde $38^{\circ} \mathrm{N}$ até $38^{\circ} \mathrm{S}$ (KUMMEROW et al., 2000). Neste trabalho foi utilizado média mensal global de precipitação com resolução de $1^{\circ} \mathrm{X} 1^{\circ}$ (produto $\left.3 \mathrm{~B} 43\right)$.

As simulações de ROLE foram comparadas com a reanálise do NCEP/NCAR. Essa reanálise é um projeto que produz análises de campos atmosféricos desde 1948 até a atualidade, assimilando dados da superfície da terra, radiossondagens, satélite, navios, aeronaves, entre outros, e possui resolução horizontal de $210 \mathrm{~km}$ (T62) e 28 níveis verticais (KALNAY et al., 1996). As simulações de umidade específica, ventos em 850 e 200 hPa 
e temperatura do ar foram comparadas com a reanálise ERA-Interim (descrita no item $\underline{3.1 .3)}$.

\subsection{Programa ForTraCC}

A técnica de rastreamento conhecida como Forecasting and Tracking the evolution of Cloud Clusters (ForTraCC; VILA et al., 2008) é um algoritmo que permite o rastreamento das propriedades radiativas e morfológicas dos SCMs e previsões destas propriedades físicas, baseado na temperatura de brilho do topo das nuvens, usando imagens de satélite no canal infravermelho $(10,8 \mu \mathrm{m})$.

As principais etapas do ForTraCC são (VILA et al., 2008):

- Detecção de aglomerado de nuvens com base em limiares de tamanho e de temperatura de brilho.

- Módulo estatístico para identificar parâmetros morfológicos e radiativos de cada SCM.

- Técnica de rastreamento baseada em sobreposição de áreas de SCM entre imagens sucessivas.

- Módulo de previsão baseado na extrapolação das posições anteriores dos SCM.

O ForTraCC tem como base a utilização de três limiares de temperatura, $250 \mathrm{~K}$ e 235 K para a detecção precoce dos SCMs e $235 \mathrm{~K}$ e $210 \mathrm{~K}$ para o rastreamento dos SCMs (dois intervalos fixos com um valor de temperatura em comum), o valor mais frio é para delimitar as células convectivas (CCs) inseridas nos SCMs. Machado et al. (1998) sugerem como limiares de temperatura $245 \mathrm{~K}$ para rastrear SCMs e $218 \mathrm{~K}$ para CCs, contudo após a analise de trabalhos com diferentes limiares (feita por VILA et al., 2008) o ForTraCC tem como limiares padrões as temperaturas de $235 \mathrm{~K}$ para SCMs e $210 \mathrm{~K}$ para CCs, pois esses limiares se mostraram adequados para detectar nuvens associadas com convecção em diferentes regiões da AS.

Para cada SCM primeiramente são calculados diversos parâmetros (tamanho, temperatura mínima, excentricidade, etc.), em seguida verifica-se a sobreposição das áreas do SCM original e do sistema candidato na imagem seguinte, calculando a fração desta sobreposição, a velocidade e direção de propagação e determinando a continuação de cada $\mathrm{SC}$. 


\section{Parâmetros dos SCMs}

O SCM pode ser rastreado durante todo seu ciclo de vida, o que permite estudar a evolução de suas propriedades morfológicas e radiativas. Os parâmetros morfológicos dos SCMs são calculados segundo a metodologia de Machado et al. (1998):

- Tamanho do SCM em número de pixels.

- Raio efetivo do SCM, ou seja, o raio de um círculo com a mesma área do SCM, dado pela equação (3.7):

$$
R=\sqrt{\frac{\text { area }}{\pi}}
$$

- Excentricidade do SCM $\epsilon$ é definida através do seguinte procedimento. Primeiramente, nas coordenadas da imagem é ajustada uma linha reta pelo método do mínimo quadrado para a posição de todos os pixels do SCM. Esta linha torna-se a ordenada do novo eixo de coordenada. Em seguida, projeta-se a latitude $\left(L A T_{i}\right)$ e longitude $\left(L O N_{i}\right)$ para o novo eixo $\left(x x_{i}\right.$ e $\left.y y_{i}\right)$ através das equações:

$$
\begin{gathered}
x x_{i}=L O N_{i} \cos \beta+L A T_{i} \sin \beta \\
y y_{i}=L O N_{i} \sin \beta+L A T_{i} \cos \beta \\
\beta=\tan ^{-1} \alpha \\
\alpha=\frac{\left(N \sum L A T_{i} L O N_{i}-\sum L A T_{i} \sum L O N_{i}\right)}{N \sum L A T_{i}^{2}-\left(\sum L A T_{i}\right)^{2}}
\end{gathered}
$$

Então $\epsilon$ é computada como a razão entre o intervalo de valores da abcissa pelo da ordenada (equações $(\underline{3.12})$ ou (3.13)) . $\epsilon$ é menor ou igual a 1, sendo um círculo quando é igual a 1.

$$
\epsilon=\left|\frac{x x(\max )-x x(\min )}{y y(\max )-y y(\min )}\right|
$$

$\mathrm{Ou}$

$$
\epsilon=\left|\frac{y y(\max )-y y(\min )}{x x(\max )-x x(\min )}\right|
$$


- Inclinação do SCM é dada por $\beta$ (equação (3.10)). Quando $\epsilon<0.5, \beta$ indica a orientação do SCM, que pode estar relacionada com a orientação de uma frente fria, mas quando $\epsilon>0.5$ indica formas aproximadamente circulares para as quais o eixo de orientação não é muito significativo.

Os parâmetros radiativos calculados pelo ForTraCC são temperatura média e mínima do SC, variação da temperatura, e temperatura média das cinco maiores CCs. E os parâmetros de localização são as coordenadas do centro geométrico do SCM e das cinco maiores CC, e data e hora (UTC).

\section{A técnica de rastreamento}

A metodologia de rastreamento do ForTraCC é baseada no algoritmo de rastreamento de Mathon e Laurent (2001b) que é um método de rastrear nuvens convectivas baseado na área de sobreposição semelhante ao descrito por Williams e Houze (1987). Esta técnica assume que a nuvem no tempo $t+\Delta t$ corresponde a nuvem do tempo $t$ quando há pixels em comum em ambas as imagens. Segundo Mathon e Laurent (2001b), para detectar e identificar os diferentes possíveis casos que podem ser obtidos desse algoritmo, são computados o rastreamento "forward"e "backward". O rastreamento "forward" consiste em, para um dado cluster no tempo $t$, encontrar dentre vários clusters no tempo $t+\Delta t$ aquele com a maior área de sobreposição. O rastreamento "backward" consiste no processo contrário, ou seja, para um dado cluster no tempo $t+\Delta t$ deve-se encontrar dentre vários no tempo $t$ aquele com a maior área de sobreposição. Há cinco possíveis situações de desenvolvimento de aglomerados convectivos que podem ser identificados pelo ForTraCC (MATHON; LAURENT, 2001b; VILA et al., 2008):

1. Geração espontânea: o SCM na imagem $t+\Delta t$ não estava presente na imagem $t$ ou não há sobreposição entre os SCMs das duas imagens.

2. Dissipação natural: o SCM na imagem $t$ não está presente na imagem $t+\Delta t$ ou não há sobreposição entre os SCMs das duas imagens.

3. Continuidade: há área de sobreposição em somente um par de SCMs, em "forward"e "backward"(figura 1a).

4. Divisão: o primeiro SCM em $t$ tem área de sobreposição com mais do que um SCM em $t+\Delta t$. O SCM, em $t+\Delta t$, com maior área de sobreposição será escolhido como continuação e os outros representarão o início de um novo SCM (figura $\underline{1 b}$ ). 


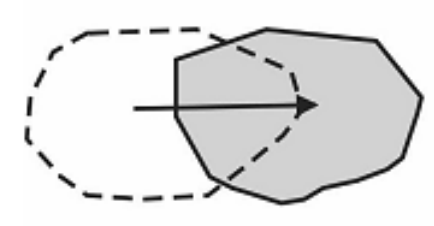

(a)

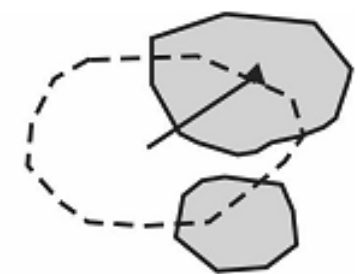

(b)

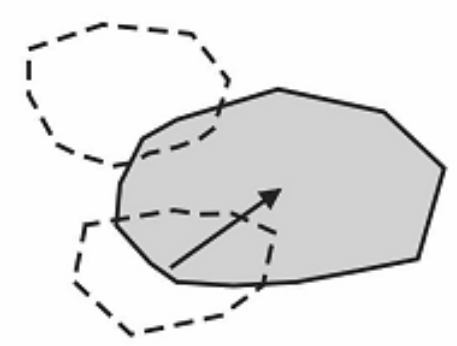

(c)

Figura 1: Representação esquemática das situações de rastreamento. As figuras brancas com contorno tracejado são os SCMs no instante $t$ e as figuras cinzas são os SCMs no tempo $t+\Delta t$. As setas representam a evolução do SCM para um caso de continuidade (a), divisão (b) e fusão (c) (VILA et al., 2008).

5. Fusão: há mais do que um SCM em $t$ com área de sobreposição com o mesmo SCM em $t+\Delta t$. Este SCM é considerado continuação do SCM em $t$ com maior área de sobreposição com ele. O outro SCM em $t$ (ou mais, se houverem), representará a dissipação do seu próprio ciclo de vida (figura $\underline{1 c}$ ).

A área de sobreposição é calculada no ForTraCC considerando a hipótese de Morel e Senesi (2002) de que a área mínima de sobreposição entre duas imagens com intervalo de tempo de 30 minutos é de $25 \%$ do tamanho do sistema. Considerando uma excentricidade de 0,5 (valor médio), de acordo com a figura 2 , a área de sobreposição resultante é de 150 pixels na imagem de satélite com resolução de 4 km ((VILA et al., 2008)).

\section{A técnica de previsão}

Baseado no critério de máxima sobreposição e de identificação do mesmo SCM em $t-2 \Delta t, t-\Delta t$ e $t$, para os limiares de $250 \mathrm{~K}$ e $235 \mathrm{~K}$, a velocidade estimada é calculada considerando o deslocamento do centro de massa entre $t-2 \Delta t$ e $t-\Delta t\left(\vec{V}_{h}(t-1)\right)$. Considerando $\vec{V}_{h}(t-1)$ constante em módulo e direção é gerada uma velocidade prevista $\vec{V}_{h} P(t)$ (MACEDO et al., 2004; VILA et al., 2008).

O crescimento e decaimento do SCM é avaliado segundo a metodologia de Machado e Laurent (2004) através da normalização da área de expansão que é dada pela equação 


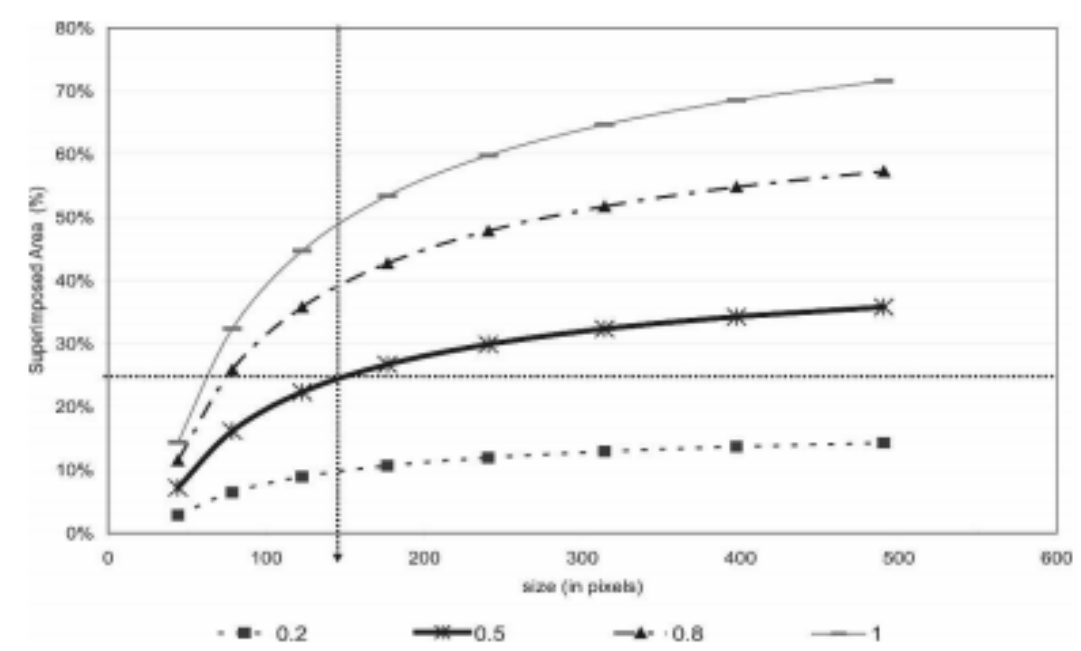

Figura 2: Porcentagem de área de sobreposição entre duas elipses com diferentes excentricidades como uma função do tamanho da elipse. Excentricidade igual a 1 significa um circulo perfeito (VILA et al., 2008).

$\underline{(3.14)}$ :

$$
\Delta E=\frac{1}{A}\left(\frac{\delta A}{\delta t}\right)
$$

Valores positivos (negativos) indicam crescimento (decaimento) do tamanho do SCM. Contudo, somente SCMs com geração espontânea e dissipação natural, sem fusão e divisão, são usados para obter valores médios de $\Delta E$. Segundo Machado e Laurent (2004) o ciclo de vida de um SCM pode ser estimado usando a equação (3.15):

$$
A(t)=\alpha e^{a t^{2}+b t+c}
$$

Baseado na equação (3.16), $\Delta E$ é tipicamente uma linha reta:

$$
\Delta E=\frac{1}{A}\left(\frac{\delta A}{\delta t}\right)=a t+b
$$

onde $A(t)$ é a área do SCM no tempo $t$ do ciclo de vida e $a, b$ e $c$ são parâmetros definidos de acordo com a duração do ciclo de vida do SCM.

Em casos de faltar imagens (o tempo entre as imagens é superior ao $\Delta t$ definido no arquivo de entrada) ou quando há falhas em 10\% ou mais da imagem o ForTraCC utiliza a imagem virtual prognosticada no tempo anterior para continuar o rastreamento. Uma das vantagens de se usar as saídas do RegCM4 é que não há imagens faltando ou com 
falhas.

\subsection{Código do ForTraCC}

O código do ForTraCC está escrito em Fortran 70, opera em ambiente LINUX, e está operacional na Divisão de Satélites e Sistemas Ambientais (DSA) do Centro de Previsão do Tempo e Estudos Climáticos (CPTEC) do Instituto Nacional de Pesquisas Espaciais (INPE; GOMES, 2007; FERNANDES, 2010).

O ForTraCC foi desenvolvido em duas partes, uma é operacional, rastreia os SCMs e realiza prognósticos de sua evolução e a outra parte é não operacional e objetiva somente fazer diagnósticos. A versão do ForTraCC utilizada neste trabalho é a mesma que foi aplicada por Fernandes (2010), para caracterizar tempestades no sudeste da AS. Neste trabalho será utilizada e adaptada apenas a parte não operacional do ForTraCC.

O ForTraCC é composto por dois códigos fontes o fortracc.f e o family.f. O fortracc.f é o programa principal que apresenta a seguinte estrutura (também esquematizada na figura 3 -MACEDO et al., 2004):

- fortracc.ins : arquivo de parâmetros utilizados no fortracc.f.

- read_input_file.f : lê os parâmetros iniciais do arquivo fortracc_input.txt, onde estão contidos os limiares de temperatura mínima, tamanho mínimo (em pixels), hora, dia, mês e ano iniciais e finais, intervalo de tempo entre as imagens, imagens faltantes (nulo no caso das saídas do RegCM4) e número de linhas e colunas da imagem.

- getnav_ch4.f : lê os arquivos de latitude e longitude e carrega-os numa matriz. Além disso, gera uma matriz com o tamanho de cada pixel.

- read_goes_ch4.f : lê os arquivos de imagens de satélite, e após a adaptação, lê saídas de modelos numéricos. Preenche linhas com falhas nas imagens de satélites (com até 3 linhas falhas consecutivas). Saídas de modelos não possuem linhas falhas.

- read_raw.f : lê a imagem virtual criada no tempo anterior.

- cprod.f : identifica os pixels que estão entre os limiares de temperatura e atribui um número para cada aglomerado desses pixels (SC). Gera arquivos já com os clusters classificados segundo o limiar de temperatura mínima definido em fortracc_input.txt. 
- cstat.f : calcula a quantidade de pixels de cada cluster e o centro geométrico do SCM e verifica suas coordenadas de latitude e longitude. Delimita os clusters maiores e elimina os clusters menores que o limiar de tamanho mínimo, definido em fortracc_input.txt.

- clesize.f : calcula a temperatura média do SCM e define um parâmetro de peso para os pixels mais frios, definindo o centro de massa e cria uma matriz com latitude, longitude, centro de massa do SC.

- track.f : é a parte principal do ForTraCC, onde recalcula o tamanho dos clusters (em pixels) e os centros geométricos e verifica se o tamanho do SCM é maior que o tamanho mínimo admitido (definido em fortracc_input.txt). Verifica se há superposição entre um cluster da imagem atual e outro da imagem anterior procurando os pixels em comum entre a imagem anterior e a atual. Para um SCM ser considerado como continuidade de um da imagem anterior, a área de sobreposição entre os clusters deve ser no mínimo de 150 pixels, para imagens de satélite, como visto na figura 2. O track.f guarda o número de identificação do cluster na imagem anterior que continua na atual para montar o histórico do SCM. Atribui número de identificação a SCMs novos ou provenientes de fusão ou divisão. Calcula variáveis que descrevem a evolução do SCM, tais como o tempo de vida, temperatura mínima, tamanho, velocidade, expansão, entre outros.

- forecast.f : é o arquivo referente a parte operacional do ForTraCC e não será utilizado neste trabalho.

O programa family.f lê os parâmetros iniciais do arquivo family_input.txt, onde estão contidos o mês e ano inicial e final das imagens de satélite a serem rastreadas pelo FroTraCC. O family.f utiliza os parâmetros contidos em family.ins e organiza as famílias de SCMs conforme o seu ciclo de vida, a partir dos resultados gerados pelo fortracc.f.

\subsubsection{Adaptação do ForTraCC}

Para adaptar o ForTraCC para rastrear SCMs nas saídas de ROLE do modelo RegCM4 foi necessário alterar parte de alguns dos programas supracitados, principalmente as funções e variáveis referentes a resolução espacial e temporal, pois há grande diferença entre as imagens de satélite (resolução de 4km e intervalo de tempo de 30 minutos) e as saídas do modelo (resolução de $50 \mathrm{~km}, 12,5$ vezes maior, e intervalo de tempo de 1). 


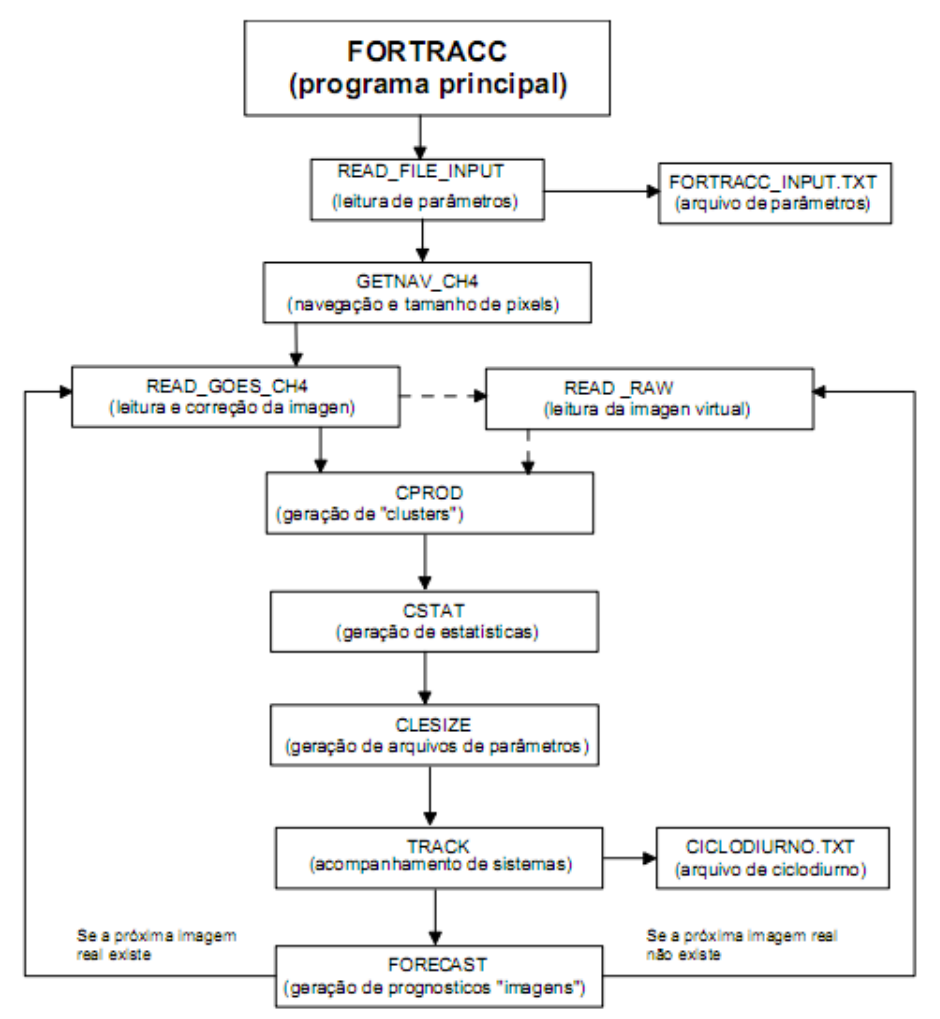

Figura 3: Esquema da estrutura do algoritmo fortracc.f (MACEDO et al., 2004).

Como o RegCM4 não simula a temperatura de brilho de topo de nuvem, para rastrear os SCMs foram utilizadas as saídas de ROLE. Para transformar a ROLE em temperatura de brilho utilizou-se a equação de Stefan-Boltzman, conforme feito por Gomes (2007). Essa equação estabelece que a irradiância emitida por um corpo negro é proporcional à sua temperatura à quarta potência:

$$
B(T)=\sigma T^{4}
$$

onde $\sigma=5,67051.10^{-8} W^{-2} K^{-4}$.

No programa principal, fortracc.f, foi introduzida a equação (3.17) para que os cálculos só fossem efetuados com a ROLE já convertida em temperatura de brilho. Foram alteradas também as funções DELTAT e XCONT2 relacionadas com o intervalo de tempo entre as imagens. Como a saída do RegCM4 já está em binário, não foram criados arquivos de navegação (latitude e longitude), com isso o arquivo getnav_ch4.f foi alterado para obter a latitude e longitude diretamente das saídas do modelo, sem precisar utilizar arquivos de navegação.

O arquivo read_goes_ch4.f foi alterado para ler diretamente a ROLE convertida em 
temperatura pelo fortracc.f. A parte desse algoritmo que faz o preenchimento de falhas se torna desnecessário, uma vez que as saídas de modelo não possuem falhas e nem há imagens faltantes. No arquivo clesize.f a variável iflon, referente a posição do satélite, foi anulada. Neste arquivo também foi alterado o escalar zsiz referente ao tamanho do pixel que de $16 \mathrm{~km}^{2}$ na imagem de satélite passou a ter $2500 \mathrm{~km}^{2}$ nas simulações do RegCM4.

No arquivo track.f foram alteradas variáveis que eram função do intervalo de tempo entre as imagens, como DELTAT1, ID, JD, R1, R_EST, T_REMAIN e T_TOTAL, onde o intervalo de tempo de 30 minutos entre as imagens de satélite passou a ser de 1 hora para as simulações do RegCM4. Neste arquivo também foram modificadas as funções TI_MIN e TI1_MIN que eram referentes à área de superposição mínima dos SCs. Nestas funções o valor de 150 pixels referente a sobreposição mínima dos sistemas (25\% do tamanho do SC) para um intervalo de tempo de 30 minutos entre as imagens de satélite foi alterado para 1 pixel $\left(2500 \mathrm{~km}^{2}\right)$ para os SCMs (valor mínimo possível) e 5 pixels $\left(12.500 \mathrm{~km}^{2}\right.$ ) para os CCMs. Esse valor de sobreposição de CCMs foi calculado considerando-se que para 1 hora entre as saídas do modelo tem-se metade da área de sobreposição $(12,5 \%)$ que teria em 30 minutos entre imagens de satélite (25\%).

\subsection{Rastreamento dos SCMs e CCMs}

Os SCMs foram rastreados a partir da conversão da ROLE em temperatura de brilho de topo de nuvem pelo ForTraCC usando o limiar de $235 \mathrm{~K}\left(-38^{\circ} \mathrm{C}\right)$, já que este limite seria adequado para a detecção de nuvens associadas com convecção em diferentes regiões da AS (VILA et al., 2008). O rastreamento dos SCMs obteve limiar de tamanho mínimo de 4 pixels $\left(10.000 \mathrm{~km}^{2}\right)$. Esse valor é mais alto do que o usual (MOREL; SENESI, 2002, SAKAMOTO, 2009, SAKAMOTO et al., 2011) devido ao pixel $\left(2.500 \mathrm{~km}^{2}\right)$ da simulação do RegCM4 ser muito maior do que a imagem de satélite $\left(16 \mathrm{~km}^{2}\right)$ e também pelo critério de área mínima de sobreposição de 25\% do tamanho do SCM (MOREL; SENESI, 2002).

O ForTraCC rastreia o SCM considerando seu início quando atinge uma área maior ou igual a 4 pixels com no mínimo $235 \mathrm{~K}$. A dissipação ocorre quando esses critérios não são mais satisfeitos. Depois de finalizado o rastreamento as saídas do ForTraCC foram filtradas para se obter somente os SCMs com tempo de vida maior ou igual a 6 horas, assim como em Sakamoto (2009) e Eichholz (2011).

Os CCMs foram identificados através dos critérios definidos por (MADDOX, 1980):

1. Área de $100.000 \mathrm{~km}^{2}$ ou mais com temperatura menor ou igual a $241 \mathrm{~K}\left(-32^{\circ} \mathrm{C}\right)$. 
2. Tempo de vida maior ou igual a 6 horas.

3. Excentricidade (eixo menor/eixo maior) maior ou igual a 0,7 no momento de máxima extensão.

Os critérios de núcleo de CCMs com temperatura menor ou igual a $221 \mathrm{~K}\left(-52^{\circ} \mathrm{C}\right)$ e área igual ou maior que $50000 \mathrm{~km}^{2}$ definidos por Maddox (1980) não foram utilizados, pois o RegCM4 não simulou topos de "nuvens"muito frios, o que pode estar associado ao esquema de convecção testado. Essas modificações produzem precipitação antes de a "nuvem" atingir maiores altitudes, logo as "nuvens" não são muito profundas e apresentam topo mais quente.

O ForTraCC rastreia os CCMs através do critério (1), considerando o início do CCM quando este critério é satisfeito e dissipação quando não é mais satisfeito. Após esse rastreamento as saídas do ForTraCC são filtradas utilizando os critérios de tempo de vida e de excentricidade, (2) e (3), respectivamente. Dessa maneira os resultados do ForTraCC permitem análises da morfologia e cinemática dos SCMs e CCMs simulados.

\subsubsection{Regiões de estudo}

Os SCMs foram rastreados em duas áreas distintas da AS (figura $\underline{4 a}$ ), uma sobre a região tropical, de agora em diante denominada AMZ (entre as latitudes 15 e $5^{\circ} \mathrm{S}$ e as longitudes 67,5 e $48,5^{\circ} \mathrm{W}$ ), e outra na região subtropical, doravante BP (entre as latitudes 32,5 e $20^{\circ} \mathrm{S}$ e as longitudes 63 e $49^{\circ} \mathrm{W}$ ), com o intuito de analisar as diferenças e semelhanças entre os SCMs dessas regiões. Após essa análise regional os SCMs foram rastreados em toda a $\mathrm{AS}$ (entre as latitudes $45^{\circ} \mathrm{S}$ e $10^{\circ} \mathrm{N}$ e as longitudes 90 e $20^{\circ} \mathrm{W}$ ), incluindo a parte costeira dos oceanos Atlântico e Pacífico, buscando características gerais comuns à todos os tipos de SCMs (tropicais e subtropicais, continentais e oceânicos).

A região de estudo dos CCMs (entre as latitudes 10 e $45^{\circ} \mathrm{S}$ e as longitudes 75 e $30^{\circ} \mathrm{W}$ - figura 4b) é similar à que Durkee e Mote (2010) utilizaram para fazer a climatologia de CCMs com imagens de satélites na AS. Essa região abrange toda a Bacia do Prata que é o segundo maior sistema fluvial da AS depois do Bacia do Amazonas (DEMARIA et al., $\underline{2011)}$. 


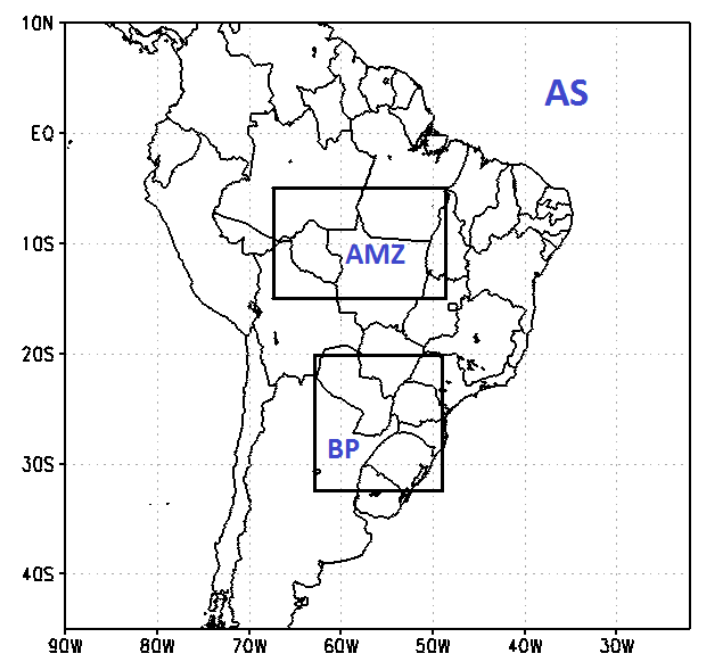

(a)

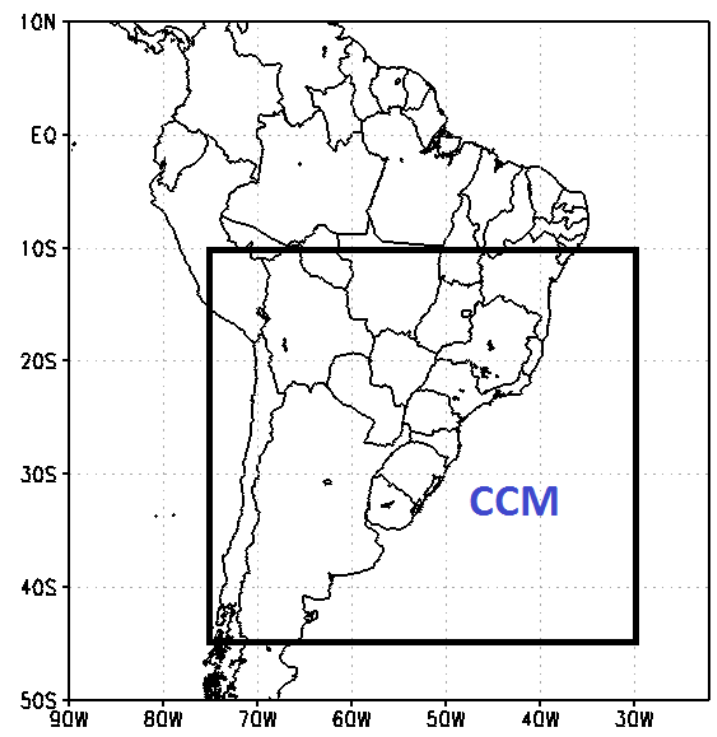

(b)

Figura 4: Região de estudo dos SCMs (4a) na AS (entre as latitudes $45^{\circ} \mathrm{S}$ e $10^{\circ} \mathrm{N}$ e as longitudes 90 e $20^{\circ} \mathrm{W}$ ) e nas regiões tropical AMZ (entre as longitudes 67,5 e $48,5^{\circ} \mathrm{W}$ e as latitudes 15 e $5^{\circ} \mathrm{S}$ ) e subtropical $\mathrm{BP}$ (entre as longitudes 63 e $49^{\circ} \mathrm{W}$ e as latitudes 32,5 e $20^{\circ} \mathrm{S}$ ) e região de estudo dos CCMs (CCM - 4b - entre as longitudes 75 e $30^{\circ} \mathrm{W}$ e as latitudes 10 e $\left.45^{\circ} \mathrm{S}\right)$. 


\section{RESULTADOS E DISCUSSÕES}

\subsection{Validação do ForTraCC}

Para verificar se as adaptações feitas no ForTraCC estão corretas foi realizada uma validação através do acompanhamento do centro geométrico dos SCMs rastreados sobrepostos à ROLE simulada pelo RegCM4. Para o mesmo instante de tempo, a latitude e longitude do centro geométrico dos SCMs são plotadas juntamente com a ROLE e depois essas variáveis mudam ao longo do tempo. Esta validação inclui o tamanho, em pixels, que o SCM possui naquele instante de tempo, buscando verificar a coerência entre o tamanho na figura e aquele calculado pelo ForTraCC. Para a validação do ForTraCC foram escolhidos dois SCMs rastreados em janeiro de 2001 na região da BP e com gênese na Argentina.

A figura $\underline{5}$ apresenta o primeiro exemplo de SCM, doravante denominado SCM1. Esta figura apresenta o início do sistema às 09 UTC do dia 13 de janeiro de 2001 (figura $\underline{5 a}$ ) no noroeste da Argentina, cujo centro está marcado com o sinal "+" em $28,25^{\circ} \mathrm{S}$ e $61,25^{\circ} \mathrm{W}$. O número abaixo desse sinal indica o tamanho (em pixels) do SCM naquele momento. O SCM1 é um evento simples com geração espontânea e dissipação natural sem apresentar fusão ou divisão durante seu ciclo de vida. O SCM1 dissipou-se às 23 UTC (figura 5p) do dia 13, próximo à divisa da Argentina com o Uruguai, com centro geométrico em $30,8^{\circ} \mathrm{S}$ e 58,60 W. O momento de máxima extensão do SCM1 ocorreu às 12 UTC (figura $\underline{5 \mathrm{~d}}$ ) com tamanho de 11 pixels e excentricidade de 0,48. A temperatura mínima atingiu 226 K às 19 UTC (figura 51 - o valor não aparece na escala da figura). O SCM1 apresentou tamanho médio de 7,07 pixels e tempo de vida de 14 horas.

O segundo SCM utilizado como exemplo para a validação do ForTraCC, denominado SCM2, foi simulado no dia 19 de janeiro de 2001. Neste exemplo, o SCM2 além de apresentar geração espontânea e dissipação natural sofreu fusões e divisões ao longo do seu ciclo de vida. O SCM2 iniciou-se às 06 UTC do dia 19 de janeiro de 2001 na Argentina (figura 6 a), com centro geométrico em $29,38^{\circ} \mathrm{S}$ e $62,25^{\circ} \mathrm{W}$. A primeira fusão do sistema 


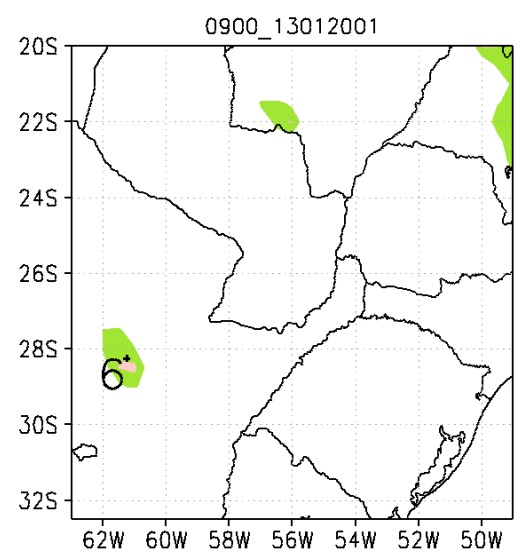

(a)

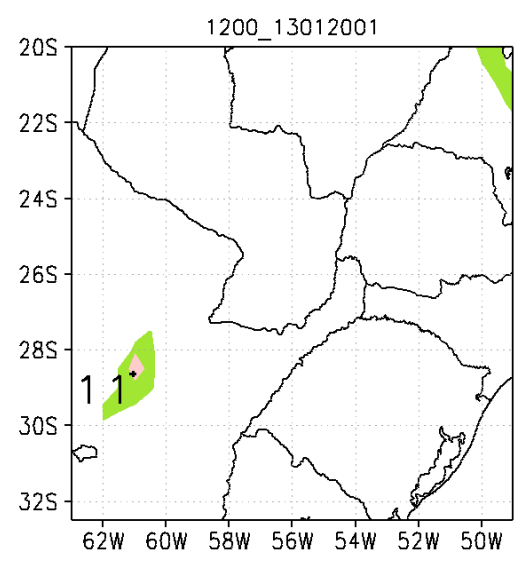

(d)

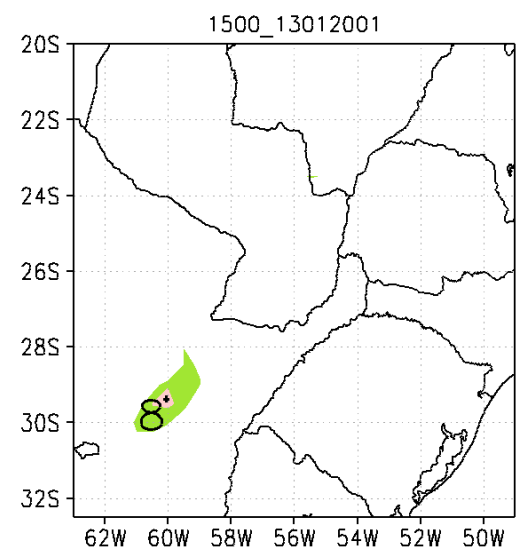

(g)

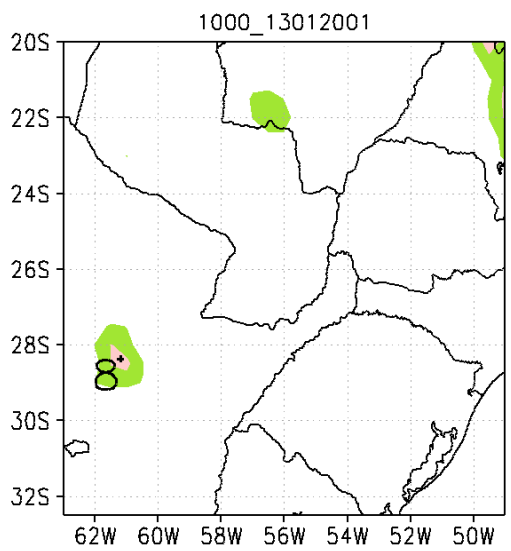

(b)

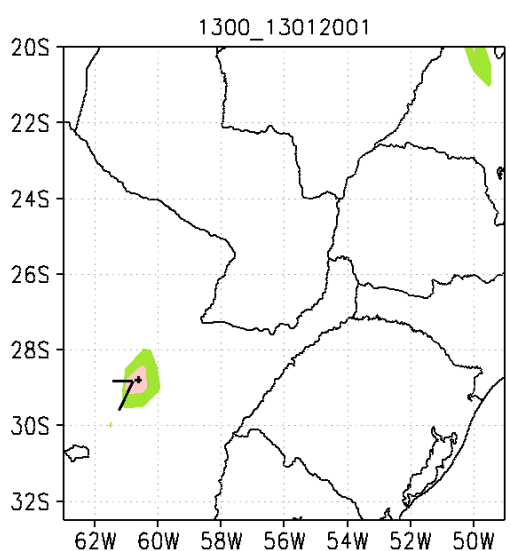

(e)

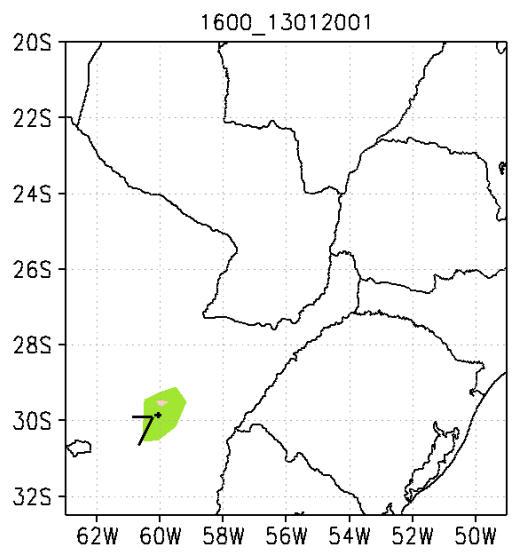

(h)

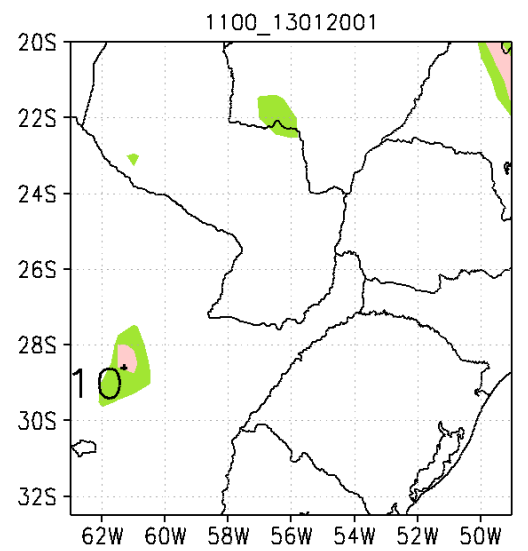

(c)

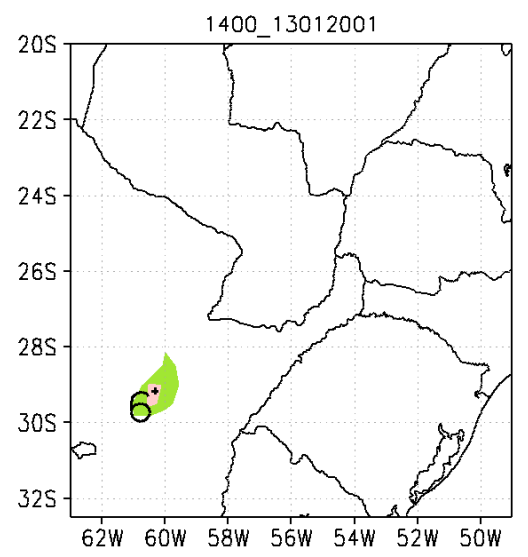

(f)

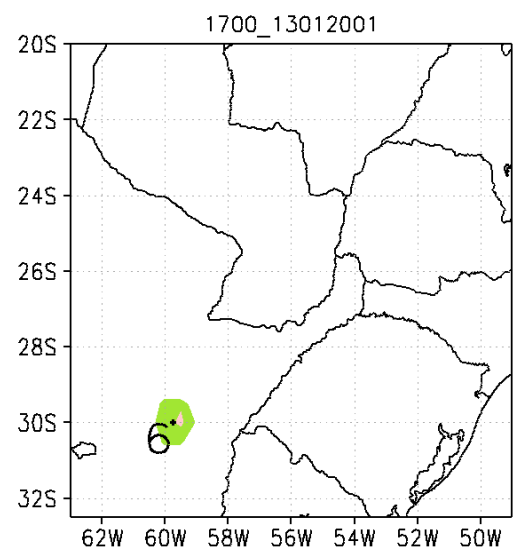

(i)

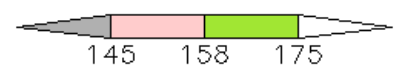

Figura 5: Ciclo de vida do SCM1, entre 09-23 UTC de 13 de janeiro de 2001, rastreado pelo ForTraCC, na simulação do RegCM4. Os limiares de ROLE 145, 158 e 175 W.m ${ }^{-2}$ se referem às temperaturas de $-48{ }^{\circ} \mathrm{C},-43{ }^{\circ} \mathrm{C}$ e $-38{ }^{\circ} \mathrm{C}$, respectivamente. $\mathrm{O}$ sinal "+" indica o centro geométrico do SCM1, e o número abaixo deste indica o tamanho do SCM1 em pixels. 


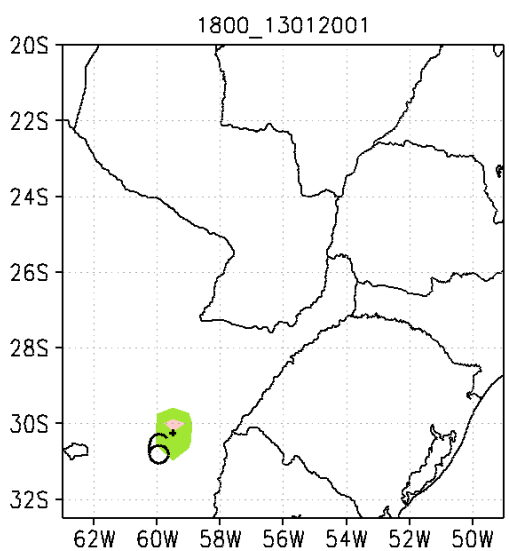

$(\mathrm{k})$

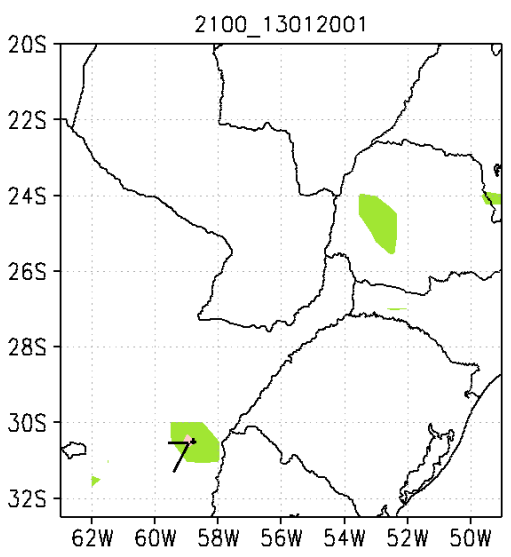

(n)

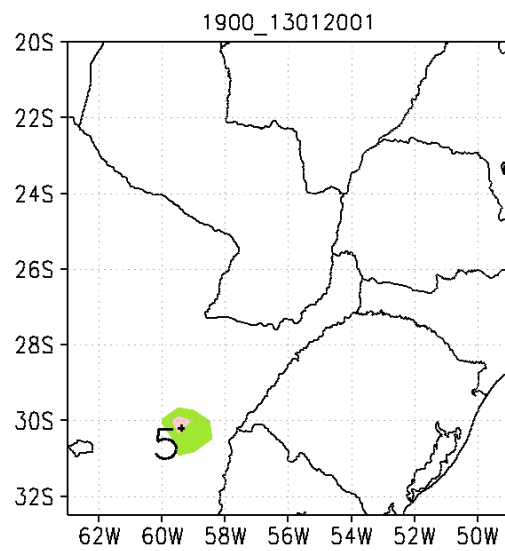

(l)

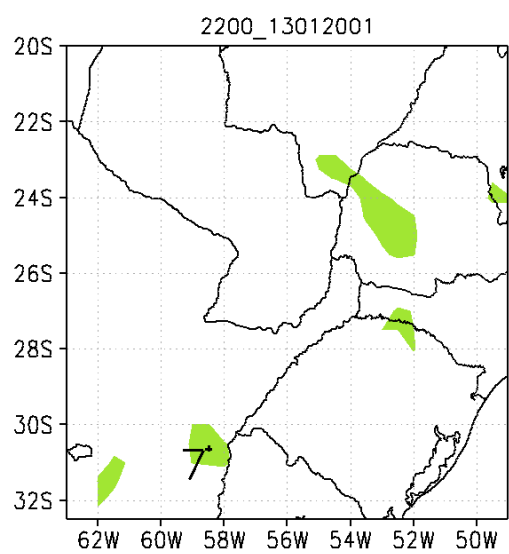

(o)

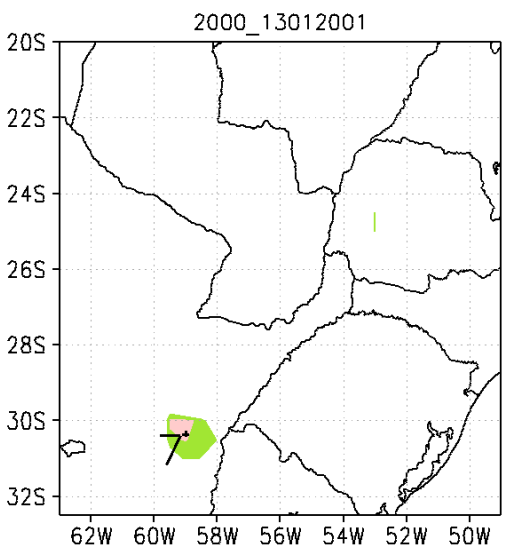

$(\mathrm{m})$

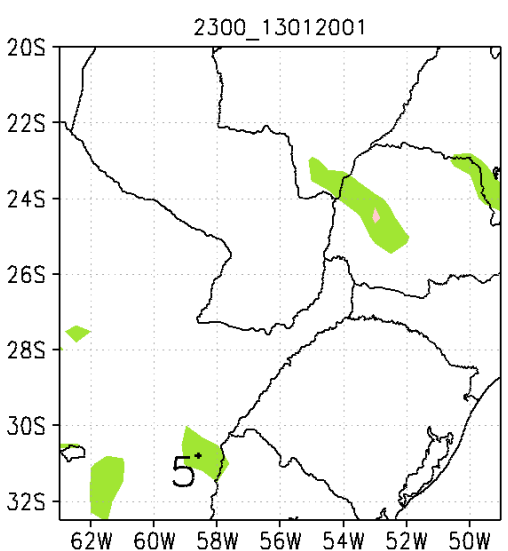

(p)

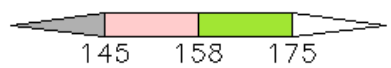

Figura 5: Continuação.

ocorreu após 2 horas de vida (figura 6b) com um sistema que estava a sudeste às 06 UTC (figura 6a). Essa fusão praticamente triplicou o tamanho do SCM2, que de 8 pixels passou para 23 pixels. Na hora seguinte houve uma nova fusão e o sistema dobrou de tamanho, chegando a 47 pixels (figura 6c). O SCM2 atingiu 136 pixels no momento de máxima extensão, às 14 UTC do dia 19, com 0,37 de excentricidade (figura 6i). O SCM2 é 12 vezes maior que o SCM1 (figura 5d), o que mostra que a fusão favorece o desenvolvimento de SCMs grandes.

A primeira divisão do SCM2 ocorreu às 19 UTC do dia 19 de janeiro de 2001 (figura 6o), o que reduziu o tamanho do sistema de 115 à 87 pixels. O SCM2 apresentou outras divisões até sua dissipação à 01 UTC do dia seguinte (dia 20). Esse sistema teve tempo de vida de 19 horas, 5 horas mais duradouro que o SCM1. O tamanho médio do SCM2 foi de 68,3 pixels, ou seja, 9,7 vezes maior que o SCM1. O SCM2 apresentou temperatura 


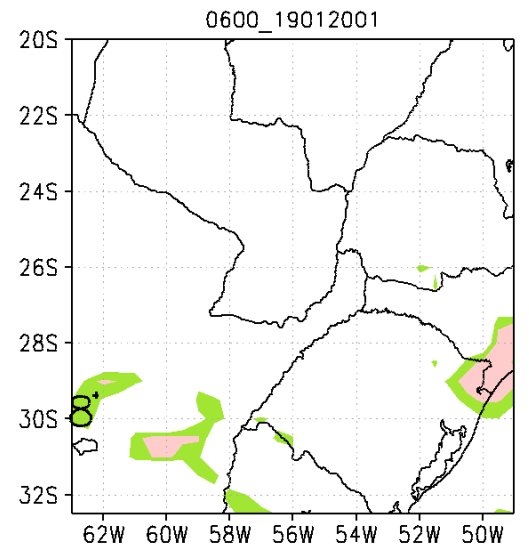

(a)

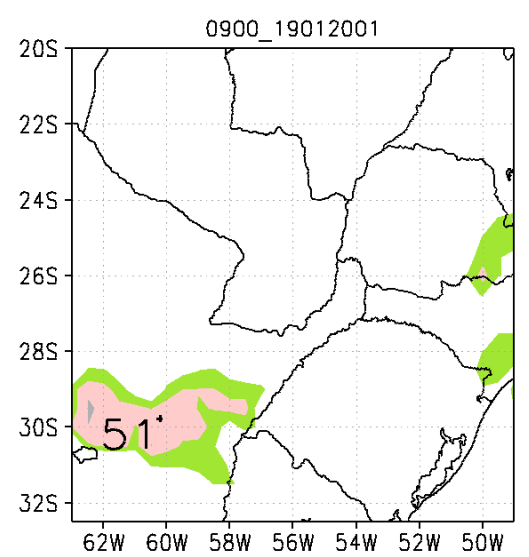

(d)

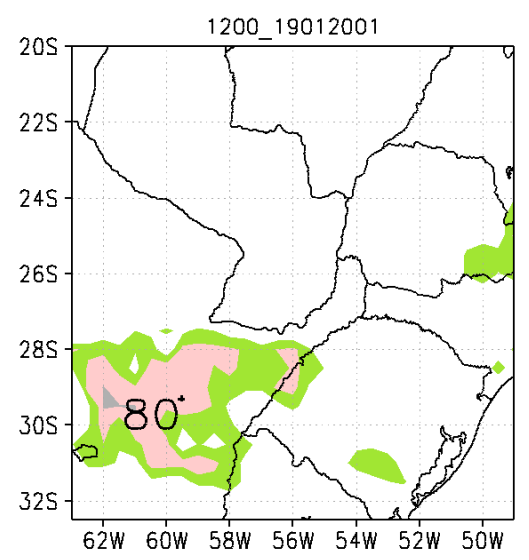

(g)

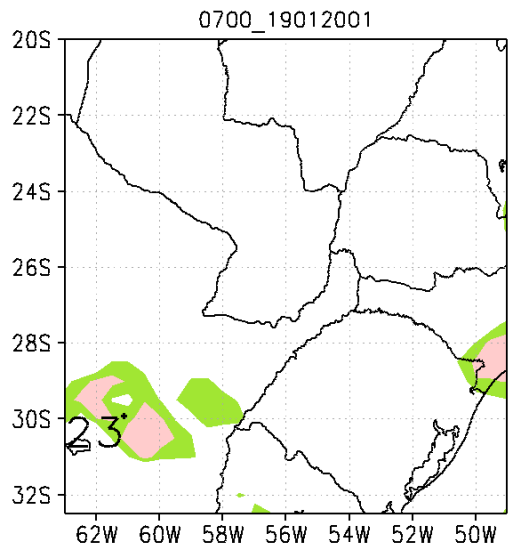

(b)

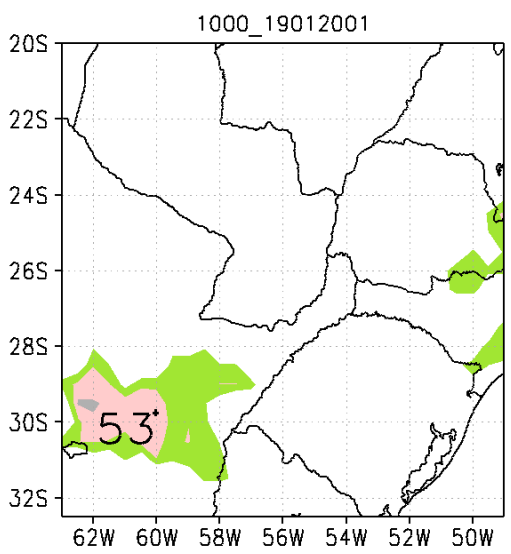

(e)

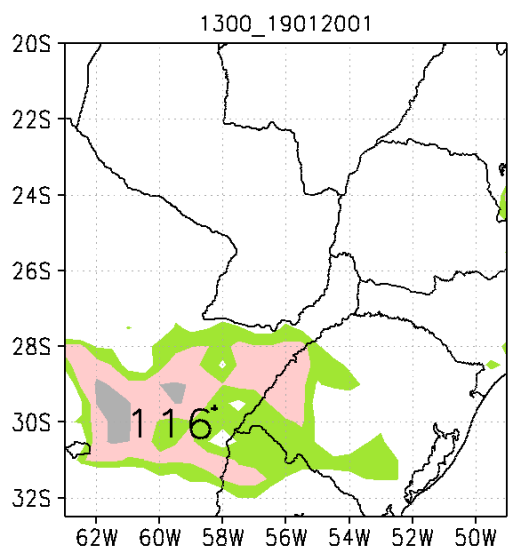

(h)

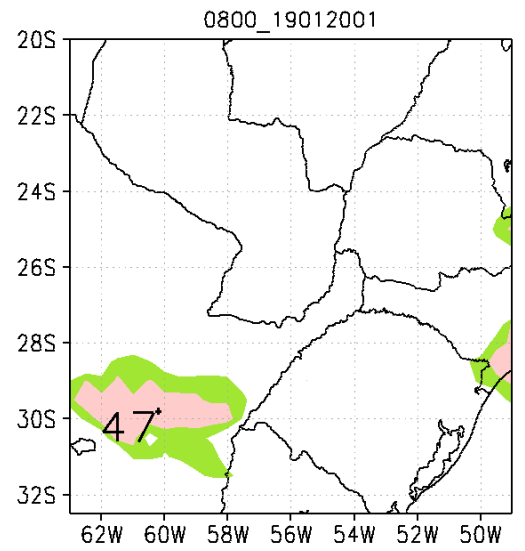

(c)

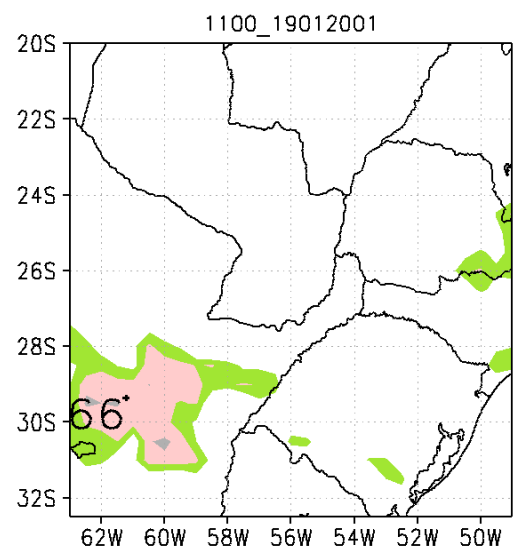

(f)

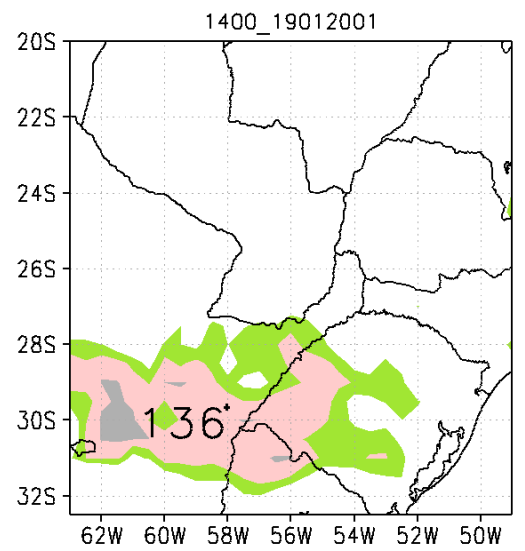

(i)

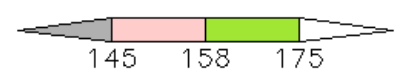

Figura 6: Semelhante a figura $\underline{5}$, mas para o SCM2 simulado pelo RegCM4 entre 09 UTC do dia 19 e 01 UTC do dia 20 de jañeiro de 2001, e apresentou fusão e divisão em seu ciclo de vida.

mínima de $223 \mathrm{~K}$ às 21 UTC do dia 19 (figura 6q - o valor não aparece na escala da figura), $3 \mathrm{~K}$ mais frio que o SCM1. O fato de o SCM2 apresentar maior duração e tamanhos médio e máximo, e menor temperatura mínima em comparação com o SCM1, seria devido à sua 


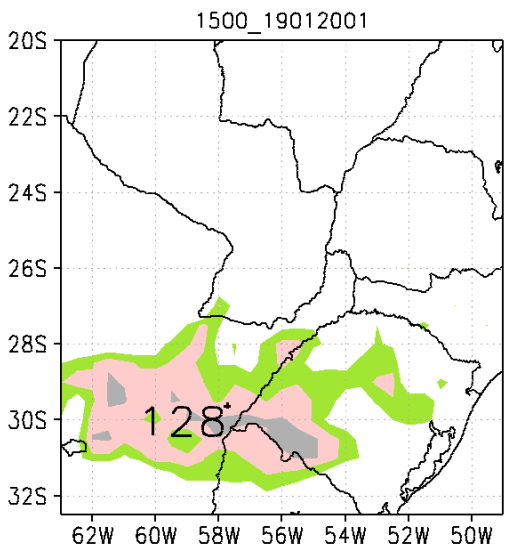

$(\mathrm{k})$

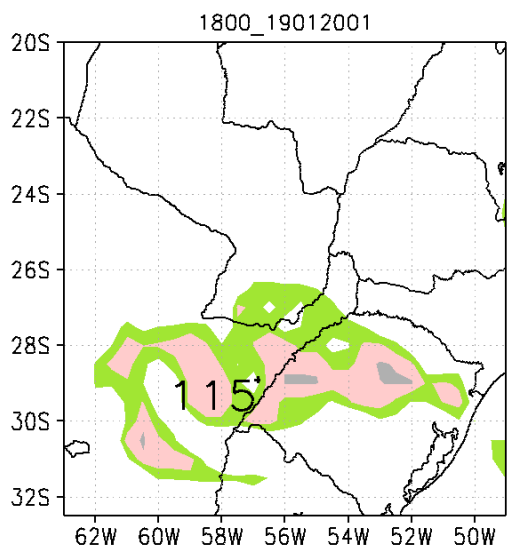

(n)

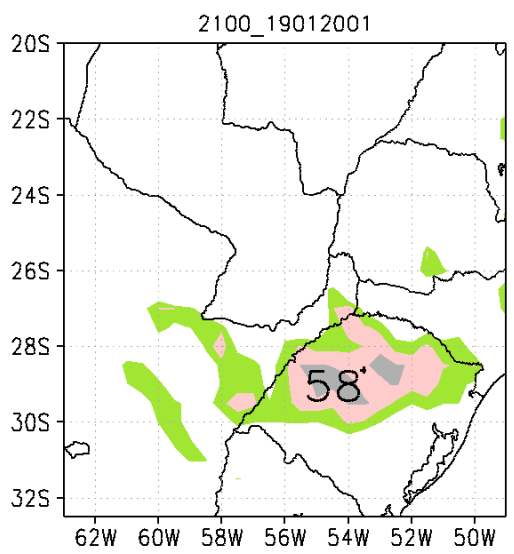

(q)

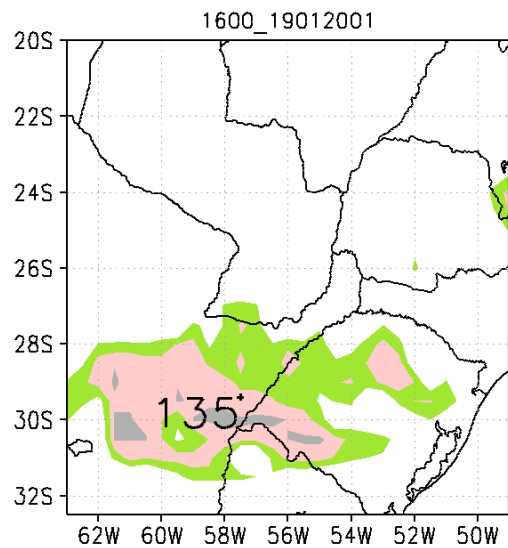

(l)

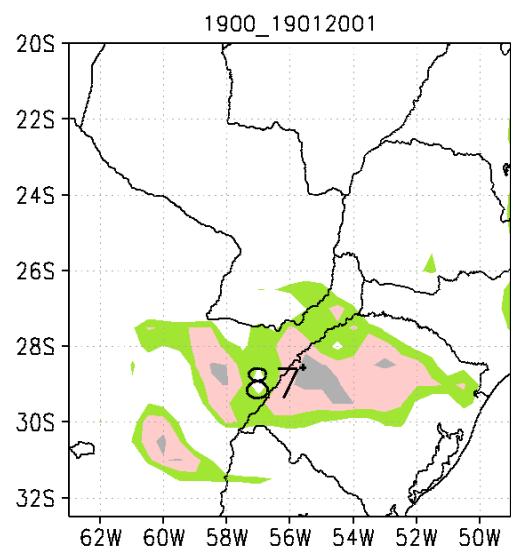

(o)

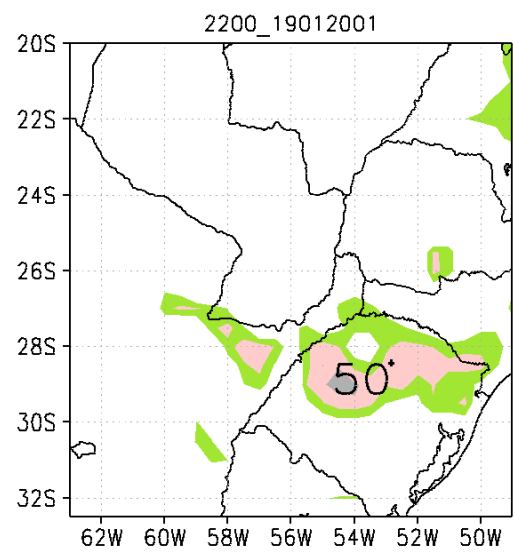

(r)

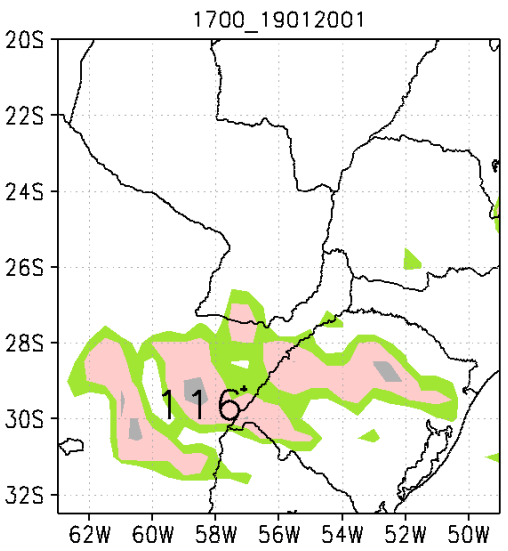

(m)

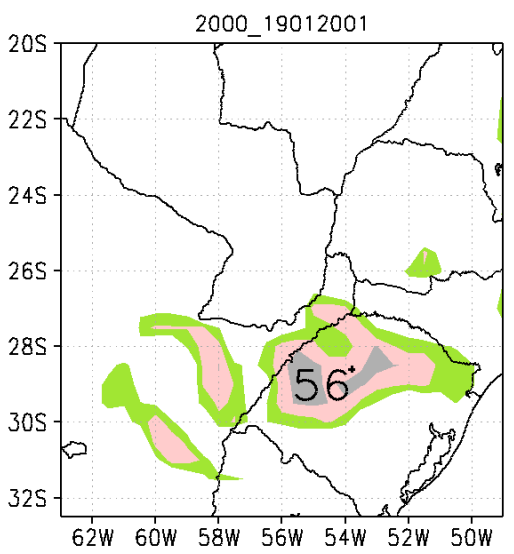

(p)

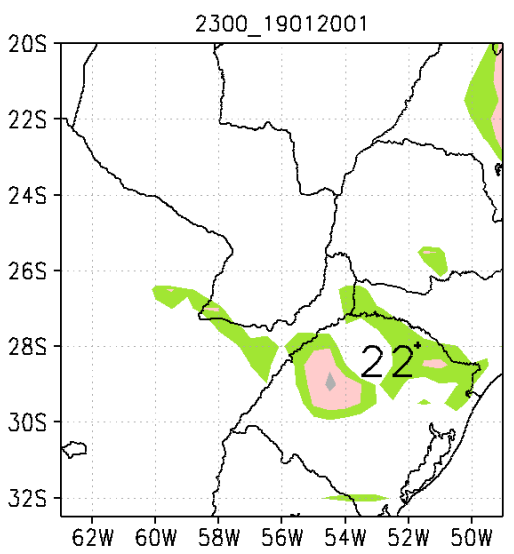

(s)

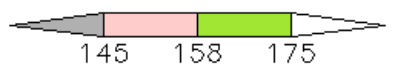

Figura 6: Continuação.

fusão com outros sistemas, re-intensificando o seu desenvolvimento.

A figura 7 apresenta as trajetórias de deslocamento (em linhas retas) do SCM1 e SCM2. Observa-se que o SCM1 tem deslocamento para sudeste da região de gênese, 


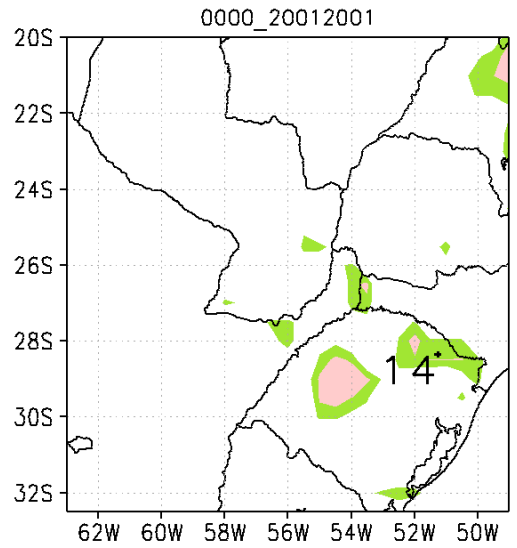

(u)

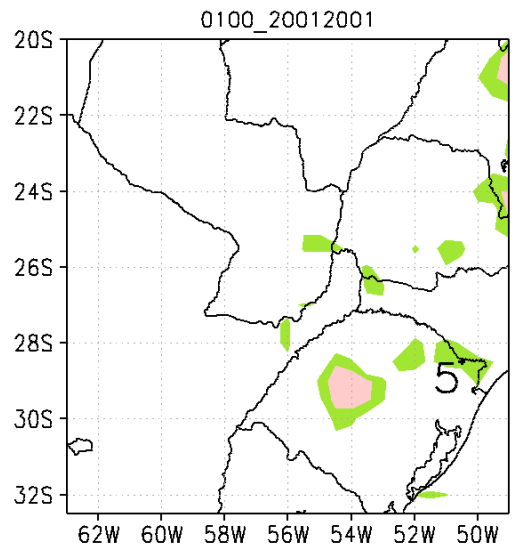

(v)

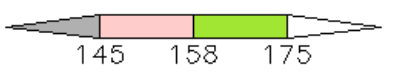

Figura 6: Continuação.

enquanto o SCM2 possui movimento para nordeste. Essas trajetórias mostram que o deslocamento efetivo do SCM2 é consideravelmente maior do que o do SCM1. Essa trajetória mais longa pode também estar associada ao fato de que o SCM2 sofreu fusões com outros sistemas durante seu ciclo de vida, aumentando assim o seu tempo de vida e também a sua trajetória.

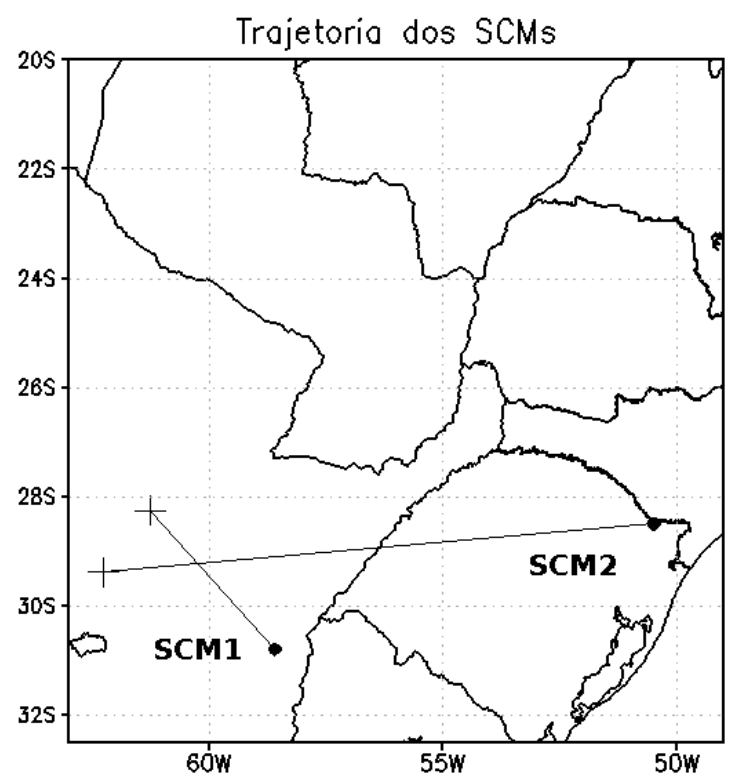

Figura 7: Trajetórias, em linha reta, do SCM1 e SCM2 a partir do momento de início, representado pelo sinal "+", até a dissipação marcada pelo ponto. 


\subsection{Climatologia - RegCM4}

Nesta seção são apresentadas as climatologias das simulações do RegCM4 e comparadas com dois produtos de reanálises (ERA-Interim e NCEP) e dois produtos provenientes de composição de dados observados com sensoriamento remoto (TRMM e CMAP). Aqui são consideradas climatologias as médias de outubro a maio do ano subsequente, de 1997 a 2003. Os períodos são referenciados utilizando os dois últimos dígitos do ano que inicia, em outubro, agregado com os dois últimos dígitos do ano que termina, em maio. Por exemplo, o período de outubro de 1997 a maio de 1998 será referenciado como 9798.

A figura $\underline{8}$ mostra as climatologias de precipitação de outubro a maio, de 1997 a 2003, obtidas do RegCM4 (8a), CMAP (b) e TRMM (두). O regime de precipitação sobre os oceanos no CMAP e no TRMM apresenta valores baixos na costa do Pacífico leste e valores mais altos no oceano Atlântico oeste, o que pode estar relacionado com a maior intensidade dos anticiclones subtropicais nos oceanos (figura 14). Esse padrão é representado pelo RegCM4, com valores de precipitação mais próximos aos do CMAP. O TRMM mostra chuva em torno de $2 \mathrm{~mm} /$ dia maior que o CMAP nos oceanos. Isto ocorre também em praticamente todo o continente sul-americano.

Os valores máximos de precipitação média no CMAP (8b) e TRMM (8c) estão nos oceanos, entre $5^{\circ} \mathrm{N}$ e $10^{\circ} \mathrm{N}$ norte, na Guiana Francesa, Suriname, Colômbia, Venezuela e nos estados brasileiros Amapá, norte do Pará e Amazonas, com taxa de precipitação máxima até $4 \mathrm{~mm} /$ dia a mais na climatologia do TRMM. O RegCM4 representa esse padrão, mas com valores menores nos oceanos e mais altos no continente, principalmente no Suriname, Guiana Francesa, Amapá e Pará. No RegCM4 há máximos de precipitação também na costa do oceano Atlântico e ao longo (do lado leste) da Cordilheira dos Andes não presentes no CMAP e TRMM. Segundo Figueroa (1997) sobre a região dos Andes a superestimativa da precipitação pelo modelo regional pode ser uma resposta a erros numéricos na representação da topografia severa (FIGUEROA, 1997 apud ALVES, 2007). 


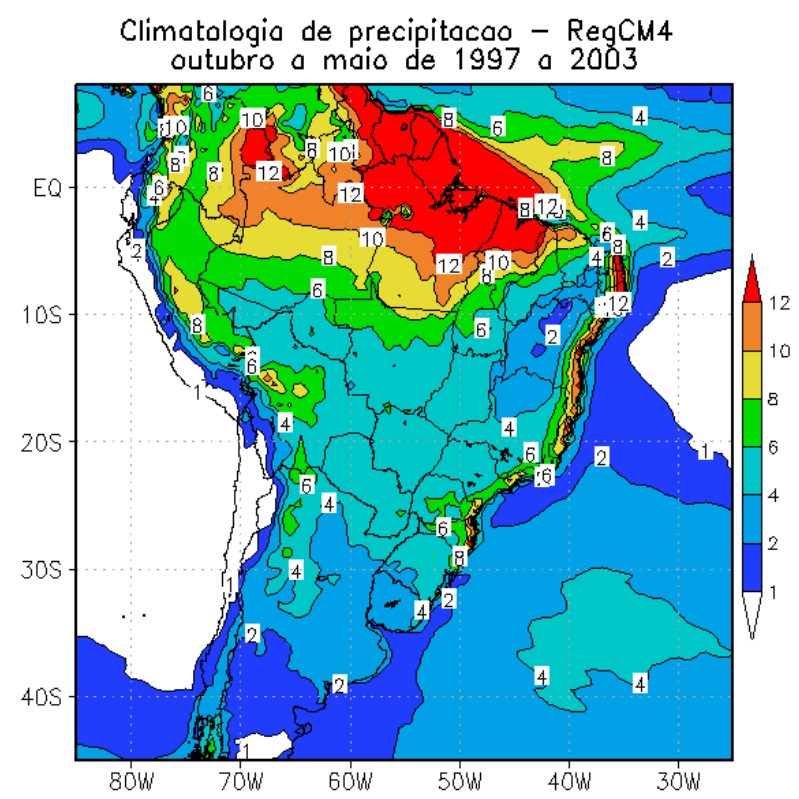

(a)

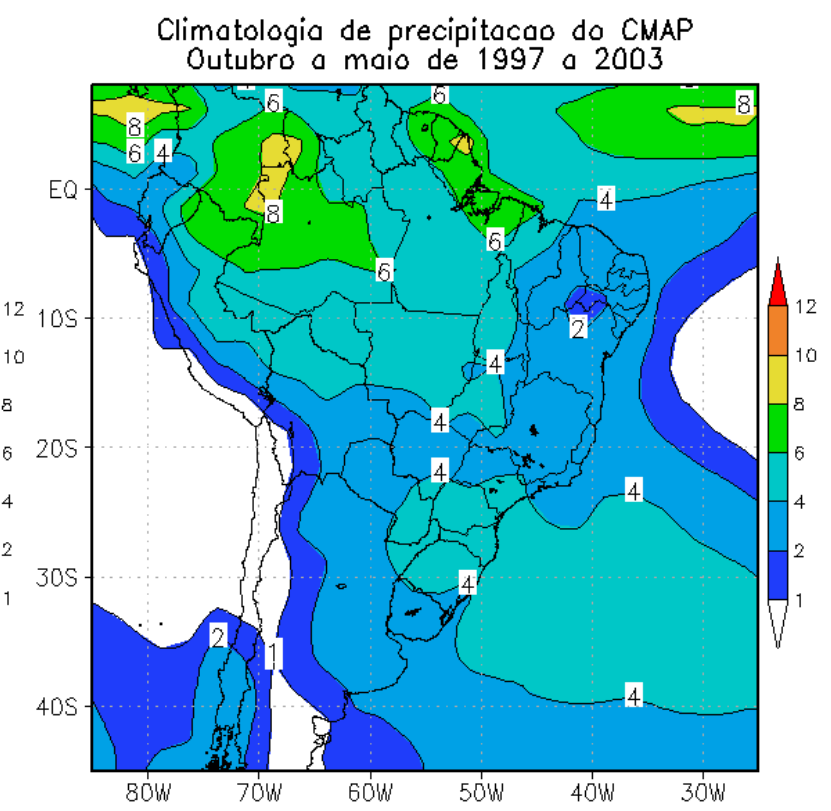

(b)

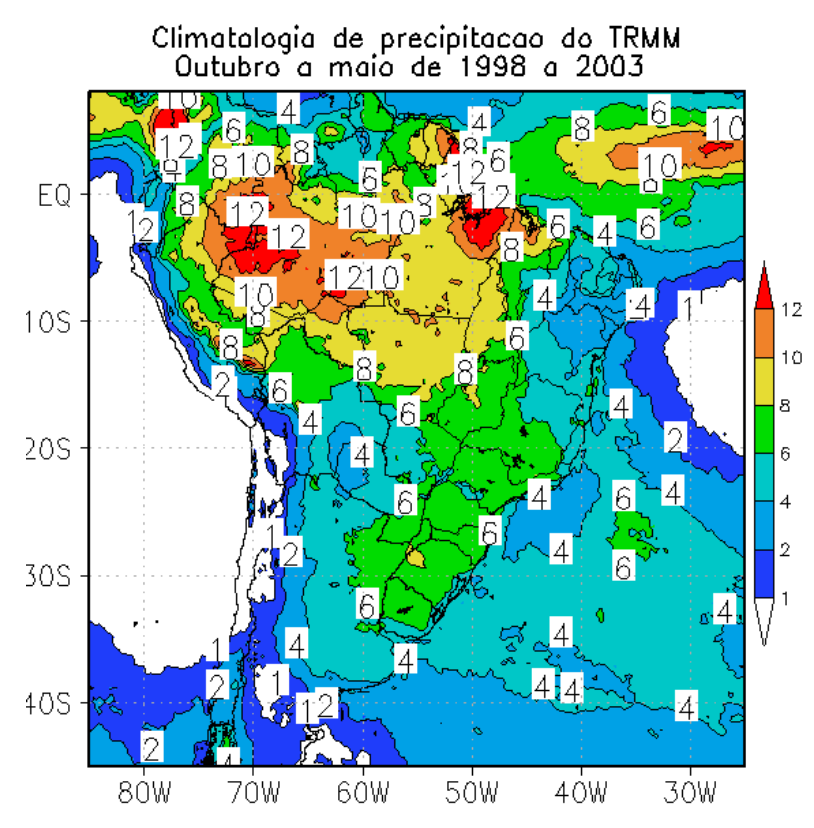

(c)

Figura 8: Climatologia de precipitação média diária (mm/dia) do RegCM4 (8a) e do CMAP (8b) de outubro a maio de 1997 a 2003, e do TRMM (8c) de outubro a maio de 1998 a 2003.

Outra característica da precipitação média diária presente tanto no CMAP (figura 8b) quanto no TRMM (figura 8c) é o sinal da presença da Zona de Convergência do Atlântico Sul (ZCAS), que se estende com orientação noroeste-sudeste, desde o sul da região Amazônica até o centro do Atlântico Sul (KOUSKY, 1988). Novamente o TRMM apresenta precipitação mais intensa do que o CMAP nesta área, em torno de $4 \mathrm{~mm} /$ dia na Amazônia e 2 mm/dia na região sul do Brasil e Paraguai, leste da Argentina, e Uruguai. 
Pinto et al. (2009) apresentou médias anuais de 2000 a 2004 e também encontrou que o TRMM superestima a precipitação nessa região. Os autores explicam que uma das possíveis causas para isso está associada à metodologia utilizada no algoritmo 3B43, que utiliza somente informação da região espectral do infravermelho. Eles comentam também que a região extratropical é frequentemente afetada por fenômenos atmosféricos como a ZCAS, SCMs e frentes frias, que produzem grande convecção, o que também gera nuvens do tipo cirrus, compostas basicamente por gelo, e este fenômeno pode estar relacionado à superestimativa de precipitação que o TRMM apresenta nesta região.

O RegCM4 não simula adequadamente o padrão da ZCAS, contudo na região sul a simulação se assemelha ao CMAP, exceto por uma maior precipitação no Paraná e Santa Catarina que pode estar relacionada aos SCMs, além do efeito orográfico da Serra do Mar. Este máximo também está presente no TRMM mas deslocado para o oeste do Rio Grande do Sul e com maior intensidade. Os máximos de precipitação no noroeste do Rio Grande do Sul, oeste de Santa Catarina, sudoeste do Paraná, nordeste da Argentina e sudeste do Paraguai são fortemente influenciados pelos CCMs (CAVALCANTI et al., 2009).

Segundo OYAMA (2006) os erros sistemáticos na precipitação na região tropical da AS podem estar relacionados aos esquemas de convecção (microfísica e/ou convecção profunda) adotados, ou seja, no presente estudo a combinação de Grell sobre o continente e Emanuel sobre o oceano explicaria os máximos mais intensos de precipitação no RegCM4. Por outro lado, a superestimativa da precipitação pode também estar associada a erros na própria circulação atmosférica do RegCM4, como o deslocamento da máxima precipitação da Amazônia para a região do Amapá, Guiana Francesa, Suriname e Pará representando um erro no posicionamento e/ou intensificação da Zona de Convergência Intertropical (ZCIT). O deslocamento para norte e intensificação na precipitação nas simulações, não representando a banda de precipitação da ZCAS também foi encontrado por Gomes (2007), no RegCM3. As alterações na nova versão, o RegCM4, combinando os esquema de convecção Grell e Emanuel não corrigiram esse problema.

Para uma análise mais regional, a precipitação média diária para cada período (outubromaio de 1997-2003) é apresentada na figura $\underline{9}$ para a AMZ e a BP (figura $\underline{4 a}$ ). A figura apresenta a média e o desvio padrão para cada período do RegCM4 (vermelho), CMAP (azul) e TRMM (verde - não há dados para o período de outubro de 1997 a maio de 1998). Na AMZ (figura 9a) a precipitação do RegCM4 e do CMAP são semelhantes, com média em torno dos $7 \mathrm{~mm} /$ dia em quase todos os períodos, com desvios padrões maiores nas simulações do RegCM4. A precipitação média diária é menor em 9798 do que nos 
demais anos devido ao forte El Niño que ocorreu nesse período (GRIMM et al., 1998b; MCPHADEN, 1999). O RegCM4 simulou essa redução da precipitação na região causada pelo El Niño.

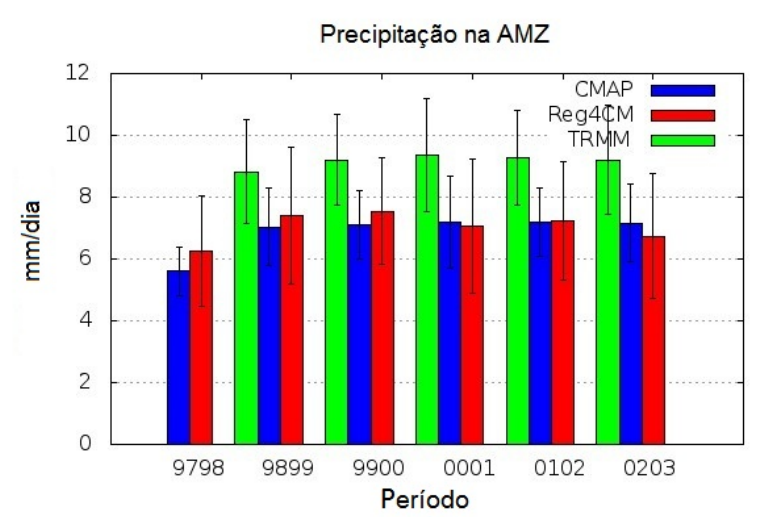

(a)

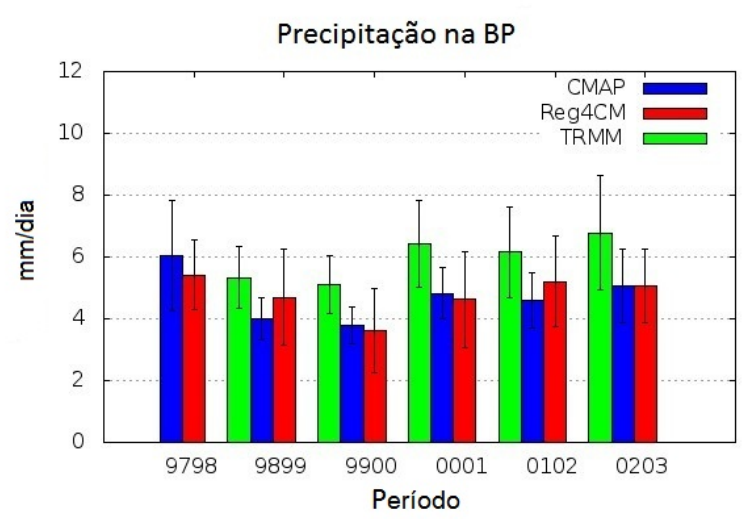

(b)

Figura 9: Precipitação média diária ( $\mathrm{mm} /$ dia) e desvio padrão de outubro a maio do ano subsequente de 1997 a 2003, no CMAP (azul), RegCM4 (vermelho) e TRMM (verde) para as regiões AMZ (9a) e BP (9b).

Na BP (figura 9b) a precipitação apresenta maior variabilidade interanual do que na AMZ, mas os desvios padrões são menores, mostrando maior variabilidade de chuvas entre os períodos e menor diferença na quantidade de precipitação entre os meses em comparação com AMZ. Há maior precipitação nos anos de 9798 também devido ao El Niño, que tem sinal contrário ao da AMZ, atuando para aumentar a precipitação na BP (GRIMM et al., 1998a). Nos períodos de 9899 e 9900 a precipitação diminui e volta a aumentar nos anos seguintes. O RegCM4 apresenta pequena superestimativa nos momentos em que a precipitação diminuiu no CMAP (9899 e 9900), aproximando-se do TRMM em 9899. uQando a precipitação aumenta ocorre o contrário, o RegCM4 é mais próximo do CMAP, subestimando a precipitação com relação ao TRMM. Em ambas as regiões o TRMM apresenta maior taxa de precipitação, em concordância com o discutido na figura $\underline{8}$.

A figura 10 apresenta a climatologia de radiação de onda longa emergente (ROLE) do RegCM4 (10a) e da reanálise $\operatorname{NCEP}(\underline{10 b})$ de outubro a maio de 1997 a 2003 . A ROLE no NCEP apresenta um mínimo de $210 \mathrm{Wm}^{-2}$ numa vasta área do noroeste da AS, englobando a Amazônia, Peru e Colômbia, que indica convecção profunda e está condizente com os máximos de precipitação do TRMM e CMAP (figuras 8c e 8b). No RegCM4 essa região apresenta valores bem mais altos, em torno de $240 \mathrm{Wm}^{-2}$, valor este que em geral não é encontrado no extremo noroeste da AS, pois esta região não 
apresenta estação seca (MARENGO et al., 2001). O mínimo de ROLE no RegCM4 é um pouco mais alto $\left(220 \mathrm{Wm}^{-2}\right)$ que o NCEP e está deslocado para a região do Suriname, Guiana Francesa, Pará e Amapá. Essa diferença pode ser devido à intensificação da ZCIT na região e/ou diferente representação da convecção por causa do esquema convectivo adotado no RegCM4. Essas alterações fazem com que as "nuvens" não tenham topos muito altos e, portanto, com ROLE mais alta do que se esperaria para a convecção profunda na AMZ.

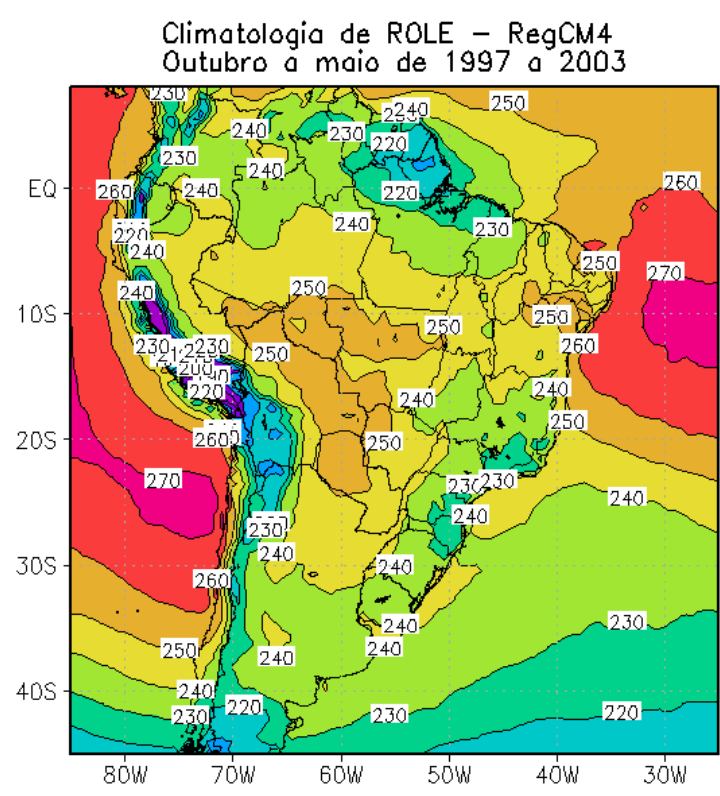

(a)

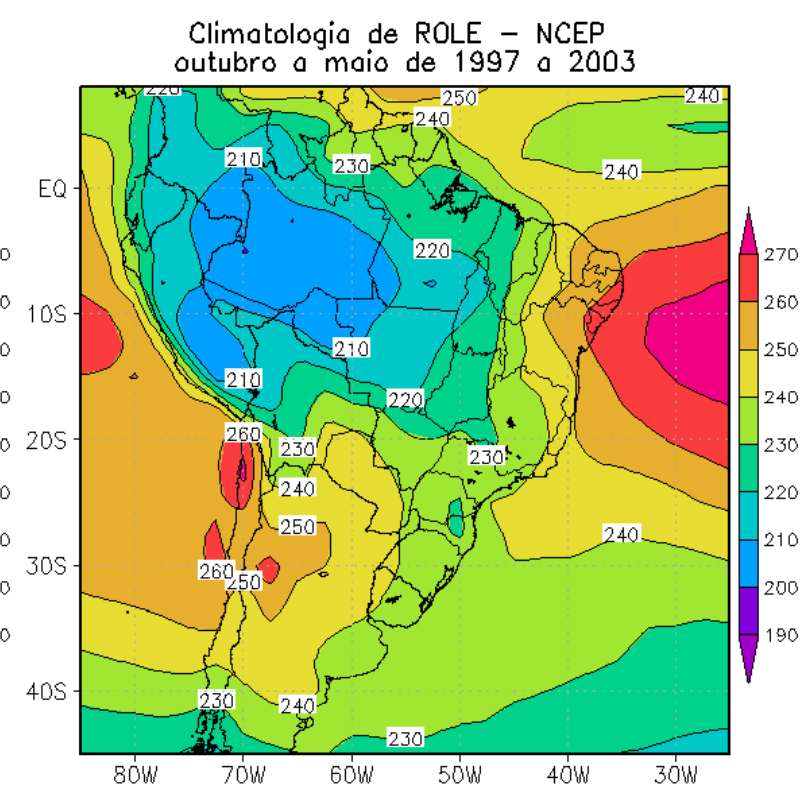

(b)

Figura 10: Climatologia de radiação de onda longa emergente $\left(\mathrm{Wm}^{-2}\right)$ do $\operatorname{RegCM} 4$ (10a) e do NCEP (10b) de outubro a maio de 1997 a 2003.

Os oceanos apresentam os maiores valores de ROLE no NCEP (figura 10b), o que condiz com os mínimos de precipitação observados nessas regiões (figura 8). O RegCM4 (figura 10a) reproduz esse padrão de ROLE nos oceanos, mas apresenta valores maiores no oceano Pacífico. Os valores mais baixos de ROLE no sul e sudeste do Brasil no RegCM4 estão em conformidade com os do NCEP e são possivelmente devido aos SCMs. O RegCM4 apresenta mínimo mais intenso de ROLE nos Andes e não representa corretamente a ZCIT no Atlântico equatorial, onde o mínimo de ROLE se restringe às proximidades da costa do norte do Brasil. No RegCM4 há uma extensa região com ROLE mais alta, entre 240 e $260 \mathrm{Wm}^{-2}$, que se estende desde $5^{\circ} \mathrm{S}$ até $30^{\circ} \mathrm{S}$, no centro do continente. No NCEP valores mais altos de ROLE estão presentes somente no Paraguai, Argentina e em uma estreita faixa no nordeste do Brasil.

Assim como para a precipitação, aqui também o enfoque é para a ROLE na AMZ e 


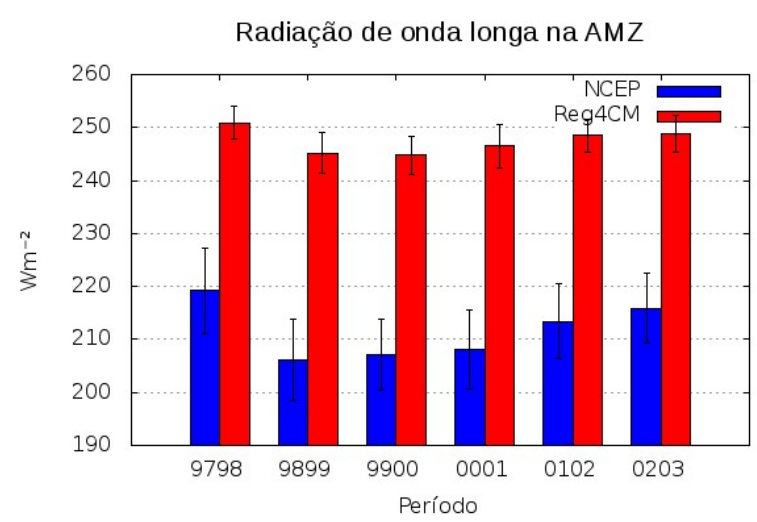

(a)

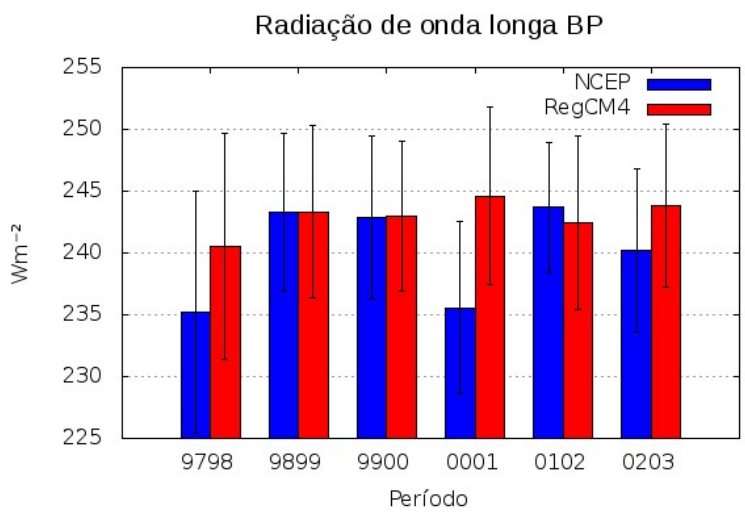

(b)

Figura 11: Radiação de onda longa emergente $\left(\mathrm{Wm}^{-2}\right)$ média e desvio padrão de outubro a maio do ano subsequente de 1997 a 2003, no CMAP (azul), RegCM4 (vermelho) e TRMM (verde) para as regiões da AMZ (11a) e da BP (11b).

na BP, sendo apresentada na figura 11 a média e desvio padrão de ROLE da reanálise do NCEP (azul) e da simulação do RegCM4 (vermelho). Para a região AMZ (figura 11a) a ROLE é mais alta em 9798, pois o forte El Niño que ocorreu nesse período reduziu a convecção na região. A ROLE diminui em 9899 e depois aumenta gradativamente. O RegCM4 simula esse padrão, mas superestima muito a magnitude de ROLE em todos os períodos analisados. Na BP o RegCM4 acompanha a magnitude da ROLE do NCEP, com pequena subestimativa nos períodos de 9798 e 0001 quando ocorrem os mínimos de ROLE do NCEP na região da BP.

A figura 12 mostra a climatologia de umidade específica simulada pelo RegCM4 (12a) e da reanálise ERA-Interim (12b) para a AS de outubro a maio de 1997 a 2003. Na ERAInterim, a umidade específica é máxima na região equatorial devido à maior evaporação, decrescendo de forma gradativa na direção sul do continente (figura 14b). O RegCM4 simula essa distribuição de forma coerente ao sul de $20^{\circ} \mathrm{S}$, mostrando somente o oceano Pacífico um pouco mais seco do que a ERA-Interim. Contudo ao norte de $20^{\circ} \mathrm{S}$ existem problemas semelhantes aos da precipitação (figura 8a). A umidade específica é mais baixa no noroeste da AS na simulação do RegCM4, apresentando subestimativa de até 2 g/kg em relação à ERA-Interim na Amazônia, Rondônia, Acre, Colômbia, Peru e norte da Bolívia. O RegCM4 simula o máximo de umidade específica (figura 12a) no oceano Atlântico Equatorial, próximo à costa do Pará e do Amapá. Este máximo de umidade específica está aproximadamente na região central do máximo de precipitação do RegCM4 (figura $\underline{8 \mathrm{a}}$ ), mostrando forte relação entre a umidade específica e a precipitação simulada.

A figura 13 mostra as climatologias do vento em 200 hPa na AS simulada pelo RegCM4 


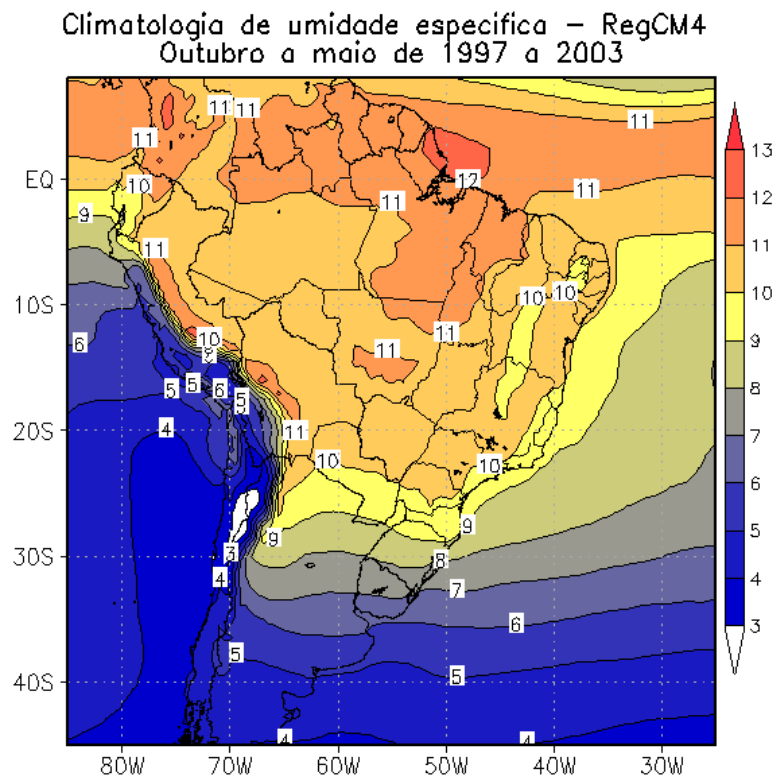

(a)

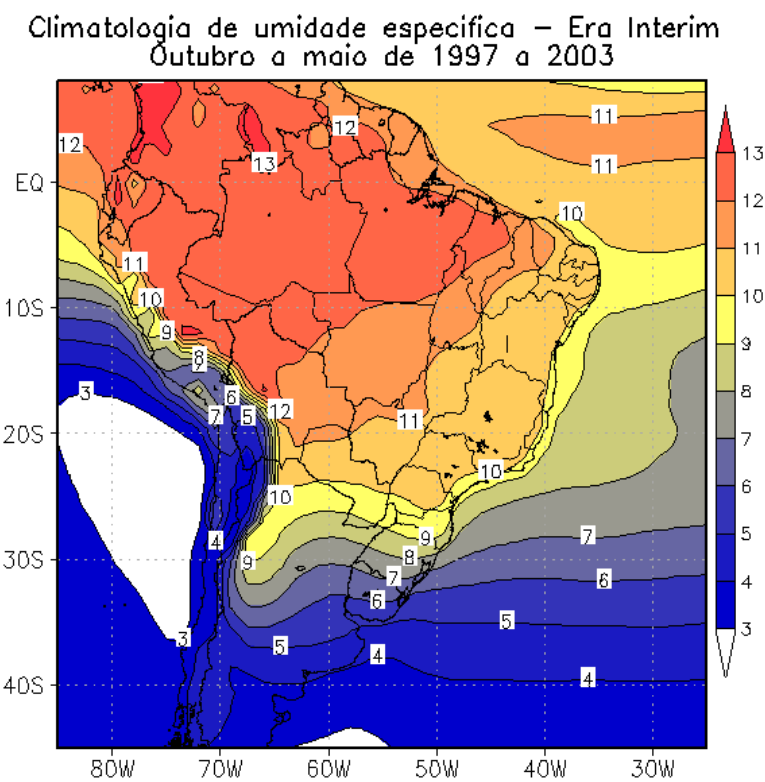

(b)

Figura 12: Climatologia de umidade específica (g/kg) em 850 hPa do RegCM4 (12a) e reanálise do ERA-Interim (12b) de outubro a maio de 1997 a 2003.

(13a) e obtida da ERA-Interim (13b). Há uma circulação anticiclônica, conhecida como Alta da Bolívia (AB), bem definida no campo da ERA-Interim, com centro na divisa da Bolívia com o estado brasileiro de Rondônia (aproximadamente $12^{\circ} \mathrm{S}$ e $64^{\circ} \mathrm{W}$ ). A formação da $\mathrm{AB}$ é normalmente atribuída à liberação de calor latente nos principais centros de precipitação durante a monção sul-americana (LENTERS; COOK, 1997). Mesmo as simulações apresentando os centros de máxima precipitação deslocados na região tropical (figura 8), o RegCM4 simula a posição da $\mathrm{AB}$, com o centro deslocado levemente para sudoeste (aproximadamente $13^{\circ} \mathrm{S}$ e $65^{\circ} \mathrm{W}$ ), similar ao observado na ERA-Interim.

O RegCM4 também simula o cavado no nordeste do Brasil (figura 13a), contudo o seu eixo (no oceano Atlântico Equatorial) tem orientação mais meridional do que o da ERAInterim que está orientado sudeste-noroeste. Entre $25^{\circ} \mathrm{S}$ e $45^{\circ} \mathrm{S}$ os ventos são predominante zonais e de oeste em ambos os campos, contudo o RegCM4 simula ventos de oeste com menor intensidade. O núcleo do Jato de Altos Níveis (JAN) na ERA-Interim se estende de $75^{\circ} \mathrm{W}$ a $25^{\circ} \mathrm{W}$, orientado noroeste-sudeste e ao sul de $26^{\circ} \mathrm{S}$, sobre o Chile, Argentina, Uruguai e o estado do RS, se estendendo ao oceano Atlântico Sul, com velocidade superior a $35 \mathrm{~m} / \mathrm{s}$. O JAN simulado pelo RegCM4 está deslocado para sudeste com núcleo mais intenso ao sul de $35^{\circ} \mathrm{S}$ sobre o sudeste da Argentina e Oceano Atlântico Sul, contudo o RegCM4 simula mesma magnitude do JAN da reanálise ERA-Interim.

Para outubro a maio de 1997 a 2003, a figura 14 apresenta as climatologias do vento 


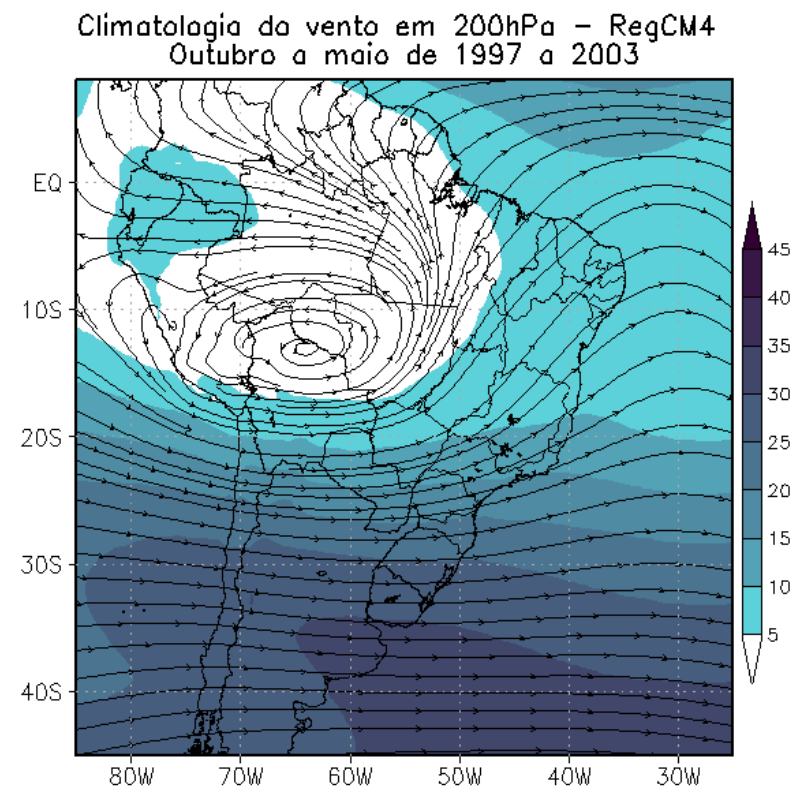

(a)

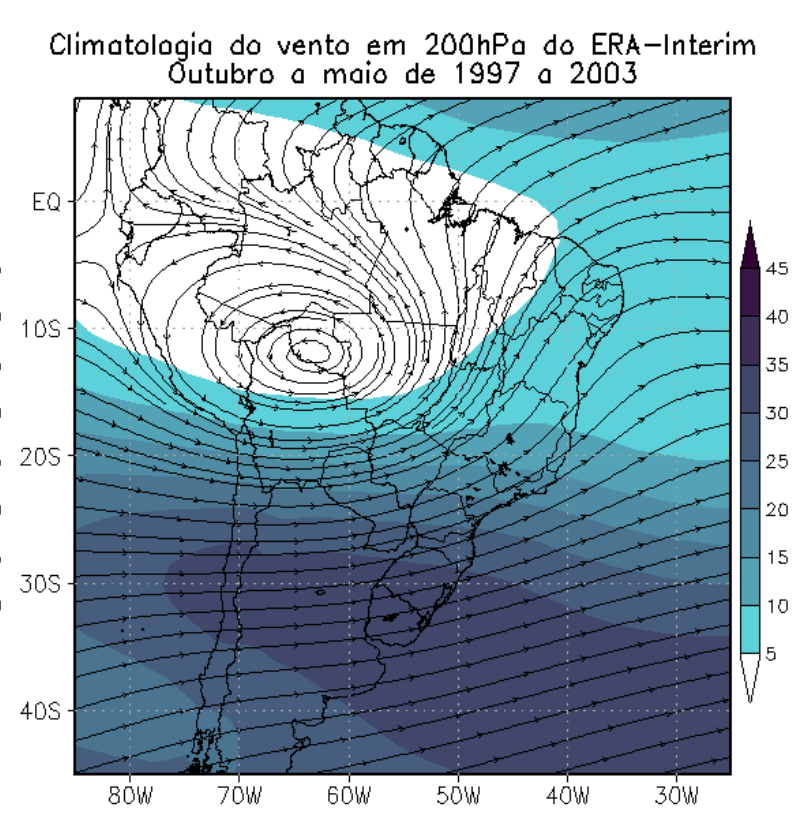

(b)

Figura 13: Climatologia de vento (linhas de corrente e intensidade em m/s) em $200 \mathrm{hPa}$ do RegCM4 (13a) e reanálise do ERA-Interim (13b) de outubro a maio de 1997 a 2003.

em 850 hPa do RegCM4 (figura 14a) e da ERA-Interim (figura 14b). A AS está entre duas circulações anticiclônicas (figura 14b), a alta pressão do Pacífico Sul (ASPS) e a do Atlântico Sul (ASAS). O RegCM4 simula a ASAS e a ASPS com maior intensidade do que na ERA-Interim. A Cordilheira dos Andes e o planalto da Bolívia limitam a atuação dos ventos do Pacífico em baixos níveis, fazendo com que a ASAS tenha maior influência sobre o continente, e esse padrão é simulado pelo RegCM4. Os ventos da ASAS em baixos níveis (figura 14a), em conjunto com a orografia favorecem a precipitação na região costeira, notadamente na costa leste da região sul o efeito orográfico da Serra do Mar, contribui significativamente para a precipitação, principalmente no Paraná (figura 8a).

Os ventos de nordeste e depois noroeste transportam umidade desde a região tropical até a região sul (figuras $\underline{14}$ e $\underline{12}$ ) e frequentemente desenvolve-se um JBN sobre a Bolívia, com máximo entre $12^{\circ} \mathrm{S}$ e $15^{\circ} \mathrm{S}$, que aumenta esse transporte de umidade dos trópicos para os subtrópicos (MARENGO et al., 2004). O JBN não está presente na climatologia da ERA-Interim (figura 14b), mas é visto na simulação do RegCM4 através dos máximos de vento de noroeste ao longo dos Andes. Isso pode ser devido à maior resolução do RegCM4 e/ou à representação de efeitos orográficos. Na ERA-Interim o vento mostra uma curvatura ciclônica desde a Bolívia até o norte da Argentina, apresentando um máximo no oeste da Argentina. Essa circulação ciclônica, juntamente com a ASAS, geram uma 


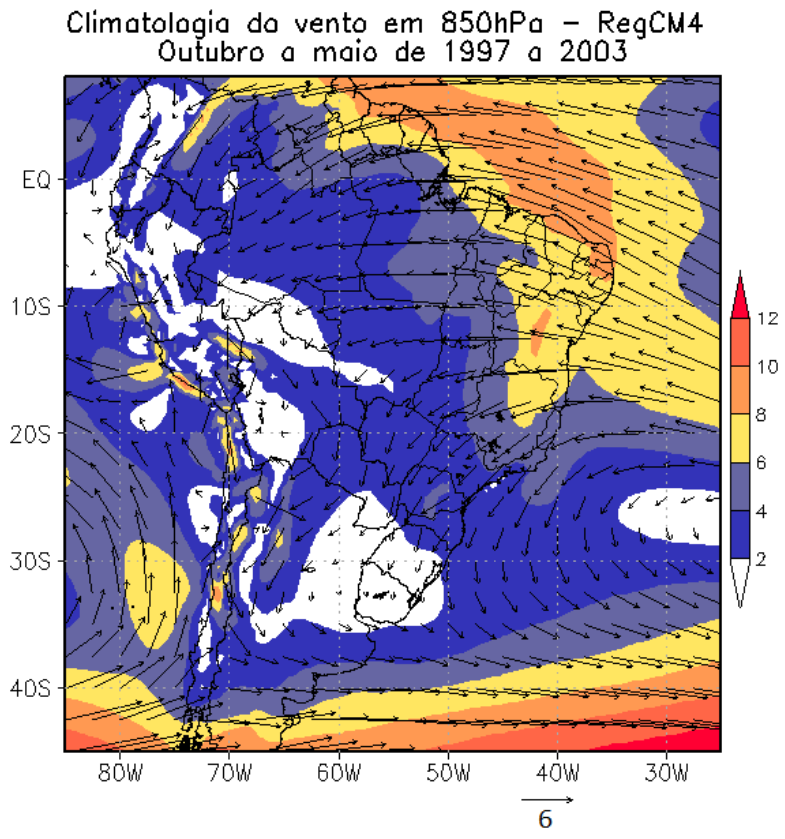

(a)

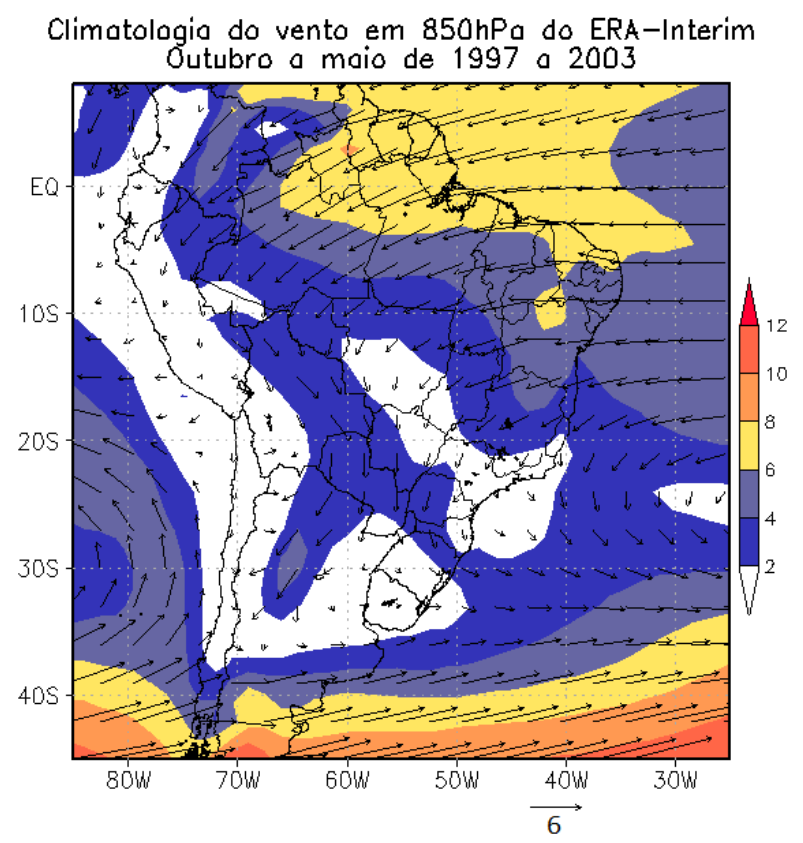

(b)

Figura 14: Climatologia de vento (vetor e intensidade em m/s) em $850 \mathrm{hPa}$ do RegCM4 (14a) e reanálise ERA-Interim (14b) de outubro a maio de 1997 a 2003.

forte componente de norte no vento na região sul da $\mathrm{AS}$, que se desintensifica no leste da Argentina, RS (exceto o nordeste) e Uruguai. Esse padrão de circulação é simulado pelo RegCM4. Os ventos simulados no norte e nordeste do Brasil estão mais intensos (em torno de $2 \mathrm{~m} / \mathrm{s}$ ) e menos zonais (de sudeste) do que na climatologia do ERA-Interim.

As climatologias da temperatura em $850 \mathrm{hPa}$ na AS obtidas pelo RegCM4 e pela reanálise ERA-Interim para o período de estudo (outubro-maio de 1997-2003) são apresentadas na figura 15 . O modelo (figura $\underline{15 \mathrm{a}}$ ) posiciona a região mais quente da $\mathrm{AS}$, no Brasil, em posição similar à da reanálise (figura 15b) e que se estende desde o norte do estado do Mato Grosso do Sul até Pernambuco, contudo o RegCM4 subestima em $1^{\circ} \mathrm{C}$ a temperatura do ERA-Interim. Essa subestimativa da temperatura ocorre em toda a AS, continente e oceanos, desde $25^{\circ} \mathrm{S}$ a $10^{\circ} \mathrm{N}$, chegando a uma diferença de $-2^{\circ} \mathrm{C}$ no noroeste do Brasil e países vizinhos. Na reanálise, a região sul apresenta gradiente de temperatura, com direção meridional, devido à variação de radiação solar recebida com a latitude. O RegCM4 reproduz esse processo.

As regiões sul/sudeste do Brasil também apresentam forte componente zonal do gradiente da temperatura (figura 15). Fatores que influenciam essa componente zonal são a advecção de ar quente do norte durante praticamente todo o período (figura 14a), diferenças entre o aquecimento do continente e do oceano e a topografia, sendo esta última 


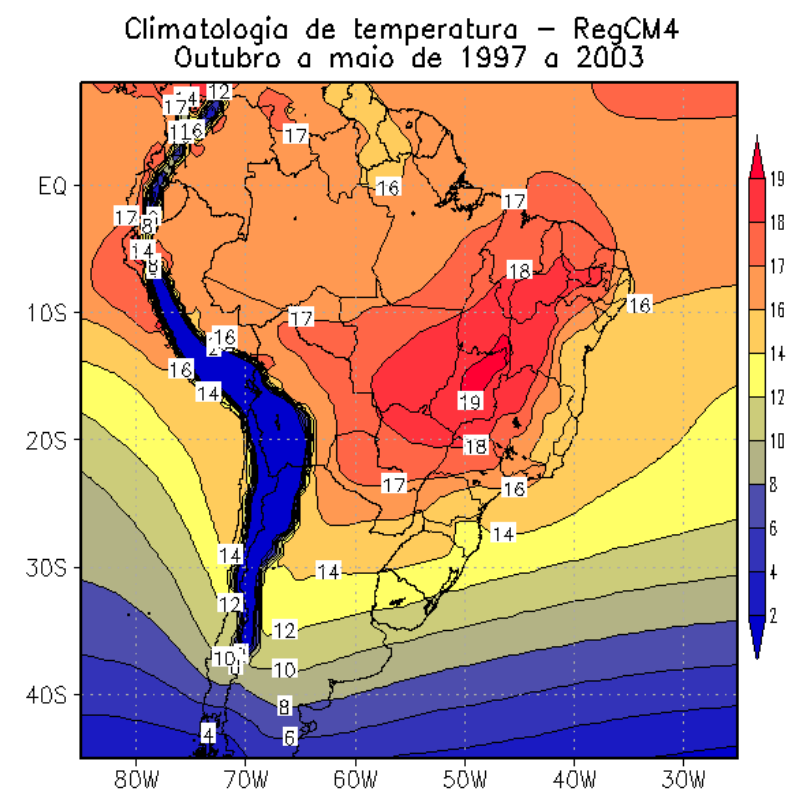

(a)

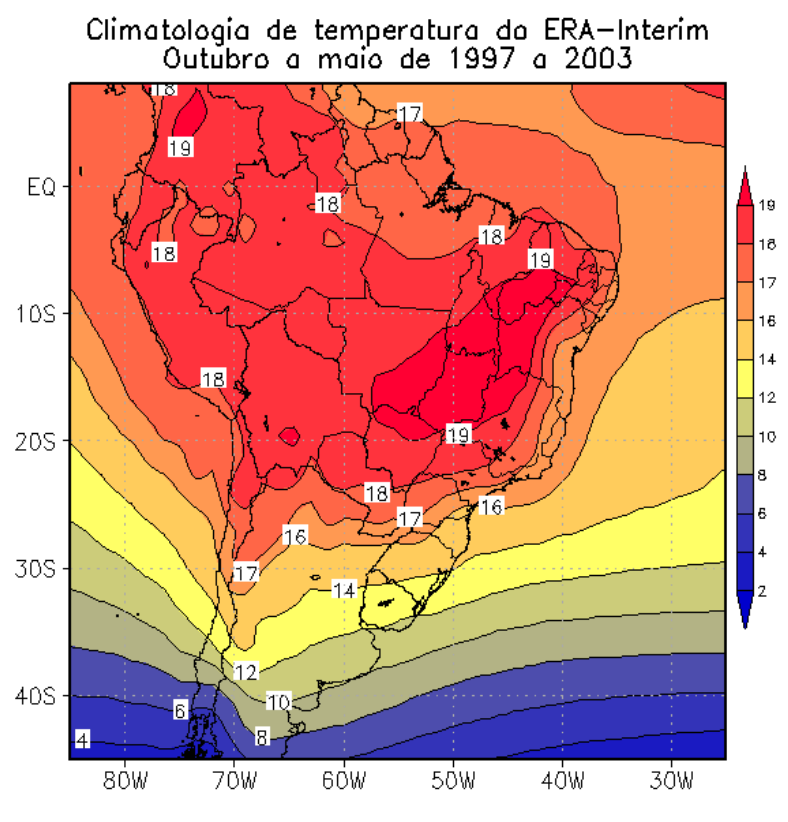

(b)

Figura 15: Climatologia de temperatura $\left({ }^{\circ} \mathrm{C}\right)$ em $850 \mathrm{hPa}$ do RegCM4 (15a) e do ERA-Interim (15b) de outubro a maio de 1997 a 2003.

a principal responsável pela componente zonal do gradiente de temperatura em todas as estações do ano (CAVALCANTI et al., 2009). O RegCM4 simula essa estrutura de temperatura nestas regiões, o que indica que representa adequadamente esses fatores, exceto sobre topografia acentuada, como é o caso dos Andes onde o RegCM4 é muito mais frio do que a reanálise. No entanto, isto resulta principalmente do método utilizado para a extrapolação dos dados uma vez que o nível de 850 hPa não é real na maior parte dos Andes.

A análise das variáveis climatológicas mostra que o RegCM4 simula os principais padrões atmosféricos da AS. A simulação apresenta uma melhora considerável na representatividade da atmosfera mais ao sul, semelhante ao encontrado por Reboita et al. (2006) que concluiu que o RegCM3 simula melhor as variáveis nos extratrópicos.

\subsection{Sistemas Convectivos de Mesoescala na AMZ e na BP}

O ForTraCC rastreou 686 SCMs na AMZ e 687 na BP (figura 4a), nas simulações de outubro a maio de 1997 a 2003 do RegCM4. Embora o modelo tenha simulado praticamente a mesma quantidade de SCMs nas duas regiões, as características morfológicas e cinemáticas dos sistemas rastreados na região tropical (AMZ) são diferentes dos da região subtropical (BP). 
A figura 16 mostra a distribuição dos SCMs ao longo dos meses de outubro a maio do ano subsequente para a AMZ (figura 16a) e para a BP (figura 16b). Na região tropical o número de ocorrências de SCMs apresenta oscilações, sendo que em outubro há menor frequência de SCMs e praticamente dobra em novembro que se caracteriza como o mês de maior ocorrência de SCMs. No mês subsequente (dezembro), a frequência de formação de SCMs volta a diminuir, aumentando novamente em janeiro, e continua oscilando dessa forma até maio. Na região subtropical (figura 16b) a ocorrência de SCMs apresenta padrão diferente, com valores máximos semelhantes em janeiro e fevereiro (125 e 123 SCMs, respectivamente), redução em abril e mínimo em maio (41 SCMs), o que pode ser explicado pela redução na atividade convectiva organizada em SCMs, à medida que avança para o outono. Os demais meses apresentaram número semelhante de SCMs (80-90 sistemas), com leve redução de outubro a dezembro.

A ocorrência de SCMs simulados pelo RegCM4 na BP (figura 16b) acompanha a precipitação mensal (mm/dia) observada na Bacia do Prata por Pinto et al. (2009), indicando a influência desses sistemas na precipitação da região. Os valores máximos de ocorrência de SCMs na BP podem ser favorecidos pela atividade convectiva na ZCAS, que em janeiro e fevereiro apresenta posicionamento preferencial ao sul da posição climatológica (ANDRADE, 2011), e também por maior ocorrência de JBN. O JBN a leste dos Andes representa um aspecto relevante da circulação em baixos níveis na estação quente (SUGAHARA et al., 1994; MARENGO et al., 2004; REBOITA et al.,2010). Este JBN atua transportando ar quente-úmido dos trópicos para os subtrópicos da AS (MARENGO et al., 2004) e influencia os SCMs subtropicais principalmente na primavera e verão (SALIO et al., 2007). Para os SCMs da AMZ (figura 16a) há maior relação com a ZCAS em novembro quando a ZACS está ao norte de sua posição climatológica. Esses máximos na AMZ podem também estar associados à menor ocorrência de JBN, pois os SCMs tropicais são mais frequentes durante dias sem JBN (SALIO et al., 2007).

O número de SCMs rastreados por períodos anuais é apresentado na figura $\underline{17}$. A ocorrência de SCMs tropicais (figura 17a) aumenta até o período de 9900, quando ocorre o máximo de 157 SCMs. Há uma diminuição no número de SCMs até 0102, onde o mínimo é de apenas 75 SCMs, e em 0203 volta a aumentar. Para os SCMs subtropicais ocorre padrão quase inverso, onde o mínimo é em 9900 (73) e o máximo é em 0203 (146). Esta evolução temporal de maior (menor) número de SCMs acompanha o aumento (redução) na precipitação simulado pelo RegCM4 mostrado na figura $\underline{9}$, com maior evidência na BP. Isso mostra que os SCMs são grandes responsáveis pela precipitação nestas regiões. Além disso, indica variabilidade interanual de convecção que quando reduz (aumenta) na região 


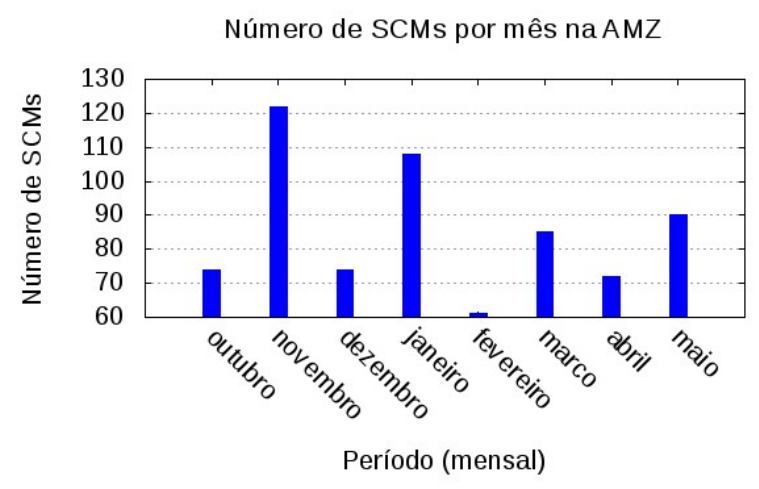

(a)

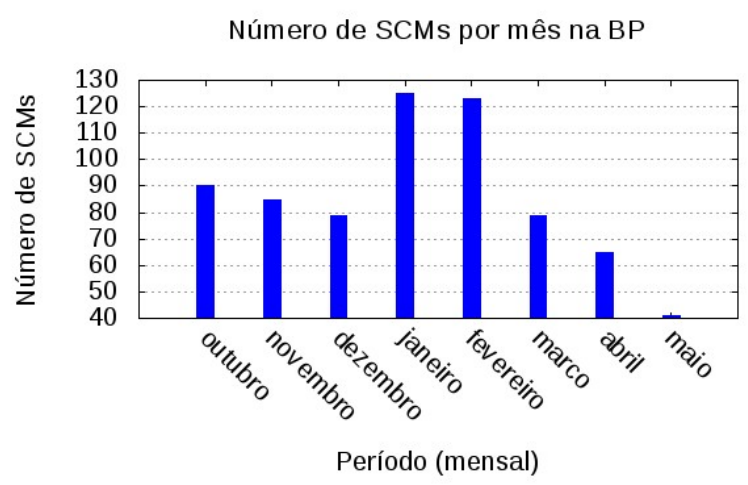

(b)

Figura 16: Número de SCMs rastreados por mês na AMZ (16a) e na BP (16b) de outubro a maio de 1997 a 2003.

tropical aumenta (diminui) a frequência na região subtropical. Esse padrão interanual de aumento (redução) na formação de SCMs na BP (AMZ) pode também estar associado a maior presença (ausência) de JBN (SALIO et al., 2007).

O padrão de maior/menor número de SCMs na BP em 9798/9899, com relação a AMZ, também foi encontrado em análises de imagens de satélite feitas por Ferreira et al. (2003) em regiões semelhantes, contudo somente para os meses de janeiro, fevereiro e março. Isso ocorre devido a atuação do El Niño e da La Niña, respectivamente, pois a AMZ e a BP são parte do dipolo de precipitação entre o sul da AS e a região tropical associado à variabilidade do El Niño Oscilação Sul (ZHOU; LAU, 2001).

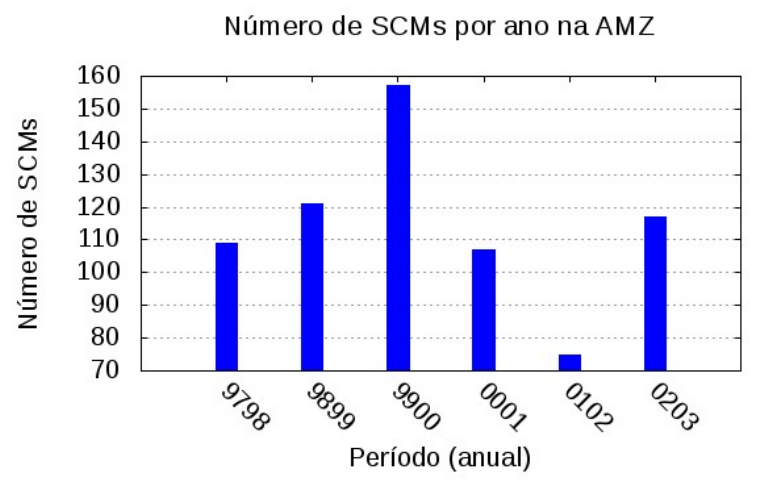

(a)

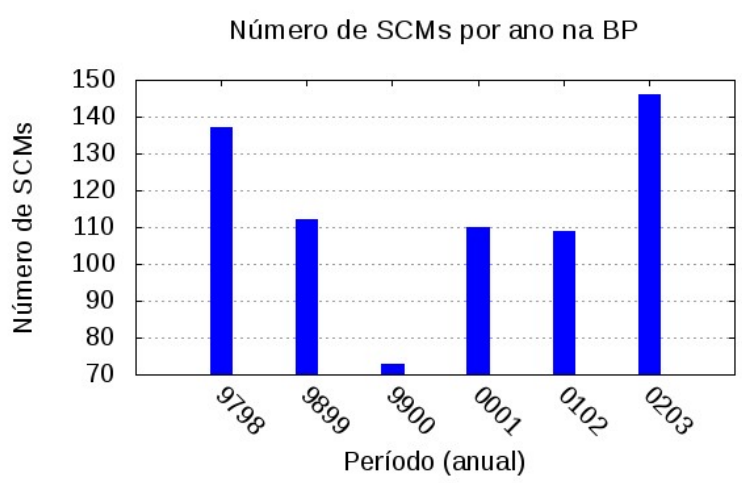

(b)

Figura 17: Número de SCMs rastreados por mês na AMZ (17a) e na BP (17b) de outubro a maio de 1997 a 2003.

A figura 18 apresenta a distribuição de frequência dos horários de início (azul), máxima extensão (vermelho) e dissipação (verde) dos SCMs rastreados pelo ForTraCC na AMZ e 
na BP, considerando todo o período de estudo. Os SCMs na AMZ (figura 18a) apresentam um padrão sequencial com início preferencial às 03 UTC, máxima extensão às 06 UTC (três horas após seu início) e dissipação nas 6 horas seguintes, com dissipação máxima às 12 UTC. Esse intervalo de 6 horas entre máxima extensão e dissipação também foi encontrado por Salio et al. (2007). Contudo, o ciclo apresenta os picos horários muito defasados em relação aos descritos na literatura, em várias regiões do mundo, onde a maioria dos SCMs iniciam-se durante a tarde, atingem máxima extensão durante a noite e dissipamse durante a manhã (GRAY; JACOBSON, 1977; MATHON; LAURENT,2001a; LAURENT; MACHADO,2002; LAURENT et al.,2002; SALIO et al.,2007; SAKAMOTO,2009; GOYENS et al., 2011; DEMARIA et al.,2011).

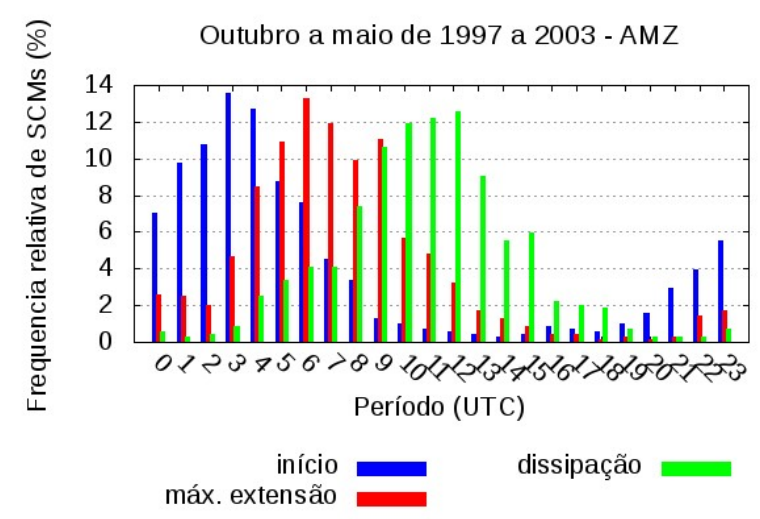

(a)

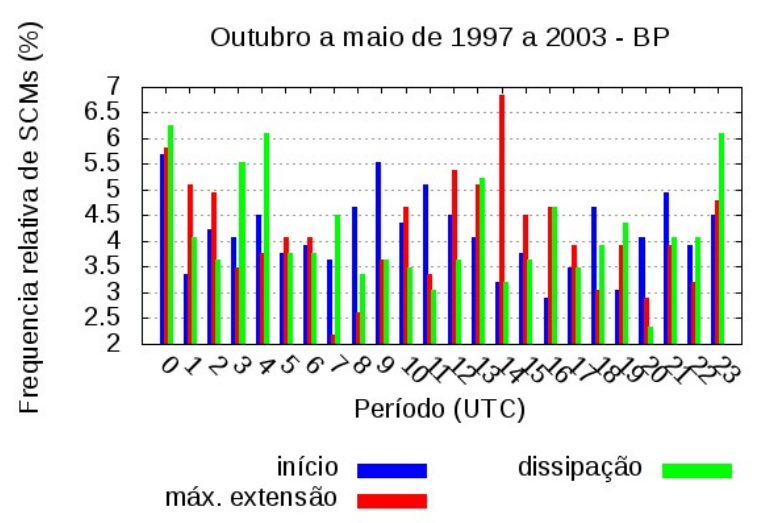

(b)

Figura 18: Distribuição de frequência (em porcentagem) de SCMs na AMZ (18a) e na BP (18b) com relação ao horário de início (azul), máxima extensão (vermelho) e dissipação (verde), de outubro a maio de 1997 a 2003.

O comportamento dos SCMs na AMZ (figura 18a) é muito semelhante aos SCMs oceânicos rastreados pelo ForTraCC na AS ao sul de $20^{\circ} \mathrm{S}$ (SAKAMOTO, 2009) e na Colômbia (SAKAMOTO et al., 2011). Segundo Gray e Jacobson (1977) os máximos de convecção profunda ou precipitação intensa durante a madrugada e a manhã observados nos oceanos tropicais e subtropicais, também são observados em algumas áreas continentais (GRAY; JACOBSON, 1977 apud SAKAMOTO, (2009). A principal causa dos máximos de chuva noturna seria o aumento (diminuição) da água precipitável disponível durante a noite (dia) devido ao ciclo de resfriamento/aquecimento radiativo com a consequente alteração da umidade relativa troposférica (SUI et al., 1997).

Segundo Soden (2000), variações no vapor de água e nas nuvens na troposfera tropical superior ocorrem (grosseiramente) em fase com mudanças na convecção profunda sobre o continente, mas aproximadamente 12 horas fora de fase com a convecção profunda 
sobre os oceanos. Um erro de fase do modelo RegCM4 na variação do vapor de água e nuvens na troposfera tropical superior sobre o continente, explicaria a diferença de aproximadamente 12 horas no horário mais frequente de início dos SCMs na AMZ e os reportados na literatura.

Outro fator que pode influenciar nas diferenças de gênese e dissipação dos SCMs simulados e observados é a metodologia aplicada para o rastreamento, uma vez que os SCMs simulados são rastreados a partir de um limiar de tamanho maior que os observados devido à resolução espacial do modelo ser menor que a da imagem de satélite. Desta forma os SCMs simulados atingiriam o tamanho mínimo para rastreo mais tarde e dissipariam mais cedo, que os rastreados em imagens de satélite.

Os SCMs subtropicais (figura 18b) apresentam distribuição de frequência de início, máxima extensão e dissipação sobre uma vasta gama de horas, indicando que há diferentes fatores que favorecem a formação e manutenção desses sistemas na BP. Segundo Romatschke et al. (2009), o aquecimento diurno juntamente com a topografia e forçantes sinóticas favorecem o desenvolvimento dos SCMs nas vizinhanças da Cordilheira dos Andes. A maior formação de SCMs ocorre às 09 UTC, horário que pode estar relacionando com a maior frequência e intensidade dos JBNs entre as 06 e 12 UTC (MARENGO et al., 2004) indicando que a forçante do JBN é mais importante do que o ciclo diurno de aquecimento (SALIO et al.,2007), em contraste com os SCMs tropicais. Isso mostra que para a BP, embora o RegCM4 possa também apresentar os problemas discutidos na AMZ, este teria efeito menor, uma vez que outros fatores influenciam mais o desenvolvimento dos SCMs subtropicais, como os JBN (SALIO et al., 2007).

\subsubsection{Características morfológicas dos SCMs na AMZ e BP}

Nesta seção serão analisadas as distribuição de frequência das características morfológicas dos SCMs rastreados pelo ForTraCC nas simulações do RegCM4, de outubro a maio de 1997 a 2003, nas regiões AMZ e BP. Essas características morfológicas são o tempo de vida, tamanho máximo, excentricidade no momento de máxima extensão e temperatura mínima dos SCMs.

A distribuição de frequência do tempo de vida dos SCMs é apresentada na figura 19, para as regiões AMZ (figura 19a) e BP (figura 19b), de outubro a maio de 1997 a 2003. Na AMZ a maioria dos SCMs tem tempo de vida menor que 12 horas $(92,3 \%)$, com máxima frequência em 6 horas $(28,3 \%)$, resultado semelhante ao encontrado por Machado et al. (1998) e Laurent et al. (2002). Vale lembrar que 6 horas é o tempo de vida mínimo 
usado como critério para classificar um aglomerado convectivo em SCM. Com isso, e através da curva de decaimento, infere-se que sistemas com menos de 6 horas de duração podem ser ainda mais frequentes, como encontrado por Morel e Senesi (2002) e Li et al. (2012). A curta duração desses sistemas sugere que resultaram principalmente do ciclo de aquecimento radiativo (SALIO et al., 2007). Esses SCMs tropicais apresentam tempo de vida médio de 8 horas, com desvio padrão de 2,15 horas. A distribuição de frequência de tempo de vida dos SCMs apresenta um decréscimo aproximadamente logarítmico, com os sistemas mais duradouros, com 19 horas, representando uma porcentagem pequena $(0,3 \%)$ do total de sistemas rastreados na AMZ. Isto indica que SCMs de longa duração são raros nesta região. Estas características dos SCMs simulados pelo RegCM4 na AMZ se assemelham às encontradas no Sahel através de imagens de satélite (GOYENS et al., 2011).

Os eventos extremos simulados pelo RegCM4 possuem duração (figura 19) de apenas metade do tempo de vida dos eventos extremos de longevidade de SCMs encontrados por Salio et al. (2007). Segundo Sakamoto (2009) SCMs com ciclo de vida mais longo são gerados em um ambiente onde as forçantes sinóticas e de mesoescala são mais definidas. Isso indica que o RegCM4 não simulou essas condições de forma mais definida na AMZ. Contudo, o RegCM4 pode estar simulando cisalhamento do vento em baixos níveis menos intenso durante o início dos SCMs, e/ou fornecendo menos umidade e calor latente através da evapotranspiração durante a evolução dos SCMs, o que reduz o tempo de vida dos SCMs, pois estas características se apresentam mais intensas em SCMs com maior duração (SAKAMOTO, 2009). Esses fatores também explicam a maior frequência de SCMs de curta duração.

Os SCMs subtropicais (figura 19b) também apresentam curva de decaimento logarítmico com máxima frequência de tempo de vida em 6 horas $(24,75 \%)$, semelhante ao encontrado por Mathon e Laurent (2001a), Punkka e Bister (2005), Salio et al. (2007), $\underline{\text { Sakamoto }} \underline{(2009)}$ e Eichholz $\underline{(2011)}$. Contudo, a maioria dos SCMs na BP tem tempo de vida menor que 16 horas (91,3\%). Os SCMs subtropicais tendem a durar mais que os SCMs tropicais, cuja maioria apresenta ciclo de vida menor que 12 horas, e também apresentam extremos com maior longevidade, que chegam a durar até 49 horas. Embora esses eventos extremos na BP representem apenas 0,15\% do total de SCMs rastreados, isto representa duração maior que o dobro dos eventos extremos tropicais.

Ferreira et al. (2003) e Salio et al. (2007) também encontraram que os SCMs subtropicais apresentam tempo de vida maior que os tropicais. Isso devido à presença do 
JBN e de sistemas sinóticos que fornecem suporte dinâmico e termodinâmico (como por exemplo, advecção de ar quente e úmido e convergência de massa em baixos níveis) para a manutenção prolongada dos SCMs subtropicais. Os SCMs na BP também apresentam tempo de vida médio maior que os da AMZ, com 9,7 horas e desvio padrão de 4,8 horas, já que eventos extremos de maior duração foram simulados pelo RegCM4. Essa média é menor do que a de 12,3 horas encontrada por Sakamoto (2009) devido aos SCMs de longevidade extrema observados serem maiores do que os simulados pelo RegCM4.

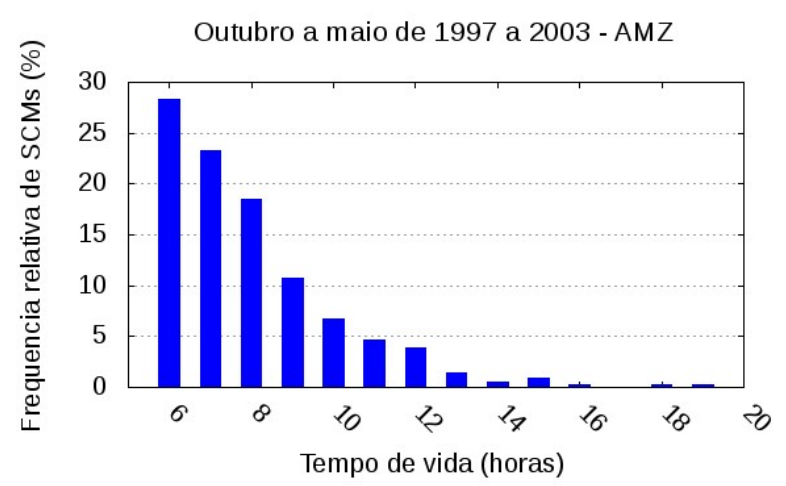

(a)

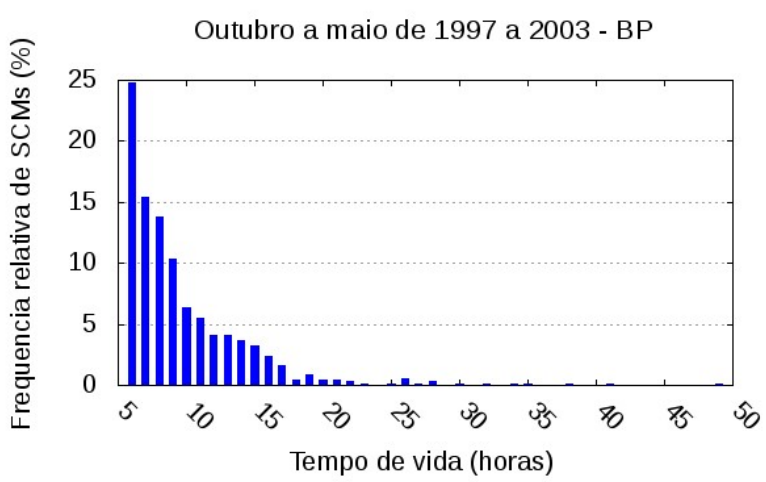

(b)

Figura 19: Distribuição de frequência (em porcentagem) do tempo de vida dos SCMs simulados pelo RegCM4 na AMZ (19a) e na BP (19b) de outubro a maio de 1997 a 2003.

A figura 20 apresenta a distribuição de frequência para o tamanho máximo dos SCMs simulados na AMZ (figura 20a) e na BP (figura 20b), e uma ampliação do intervalo entre 0 e 50 pixels de ambas as regiões (figuras 20c e 20d), de outubro a maio de 1997 a 2003. Para as duas regiões a maioria dos SCMs possui tamanho entre 07 e 50 pixels. No RegCM4, o tamanho máximo que um SCM tropical atinge é de 350 pixels, enquanto no subtropical esse máximo é de 700 pixels, ou seja, SCMs subtropicais atingem tamanhos extremos que podem ser até duas vezes maiores que os tropicais.

A curva de decaimento do número de SCMs em função do tamanho do SCMs tem forma aproximadamente logarítmica para as regiões AMZ e BP (figura 20). Isso indica que SCMs com tempo de vida longo são mais raros, principalmente na região tropical (figura 20a), onde os tamanhos máximos são menores que nos subtrópicos (figura 20b). Embora os SCMs possam atingir valores altos de tamanho, praticamente metade dos SCMs tropicais (51\%) possui entre 10 e 24 pixels, com maior frequência em 16 pixels $(4,81 \%)$, e os subtropicais $(52,2 \%)$ estão entre 12 e 31 pixels, com maior frequência em 14 pixels (4,51\%). Os tamanhos médio e médio máximo dos SCMs da AMZ são de 16,6 e 31 pixels, com desvio padrão de 14,1 e 31,4 pixels, respectivamente. Isto indica o quão 
variável é a amostra de tamanhos dos SCMs simulados pelo RegCM4. O mesmo ocorre para os SCMs da BP cujos tamanhos médio e médio máximo são de 22,8 e 42,8 pixels com desvio padrão de 27,2 e 49,5 pixels, respectivamente. Estes valores mostram que os SCMs subtropicais são maiores e possuem também maior variabilidade de tamanho.

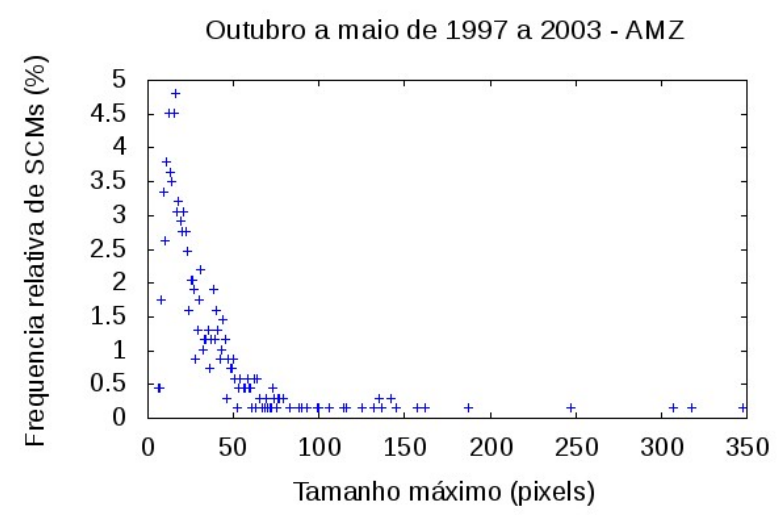

(a)

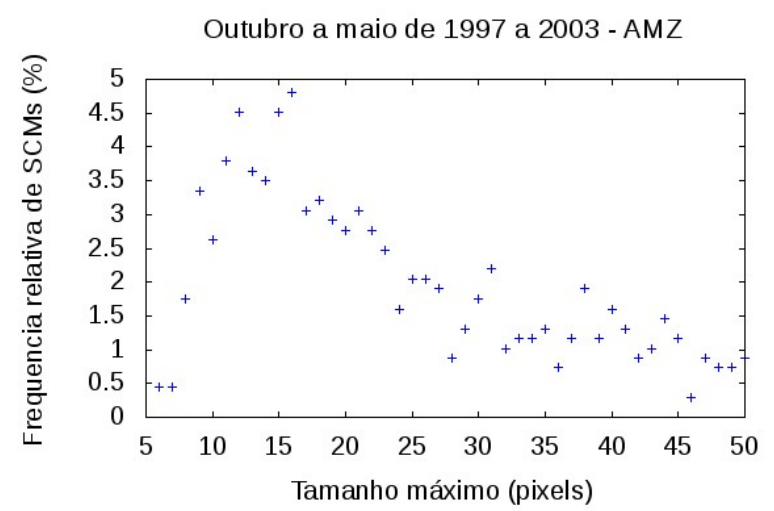

(c)

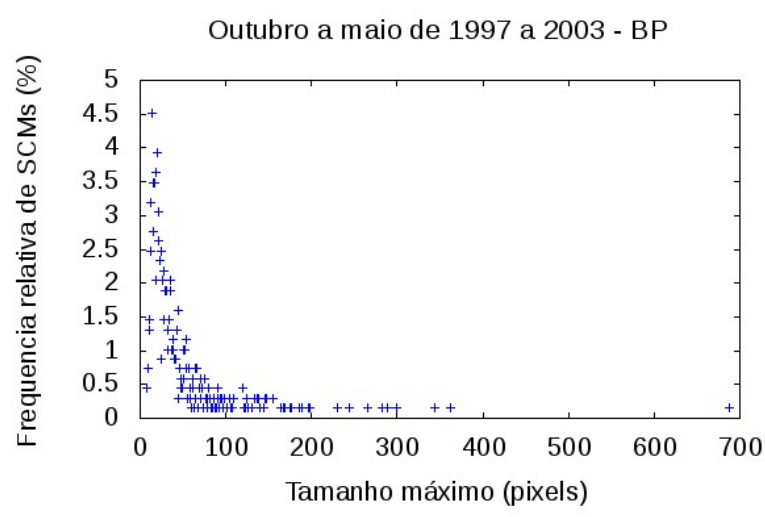

(b)

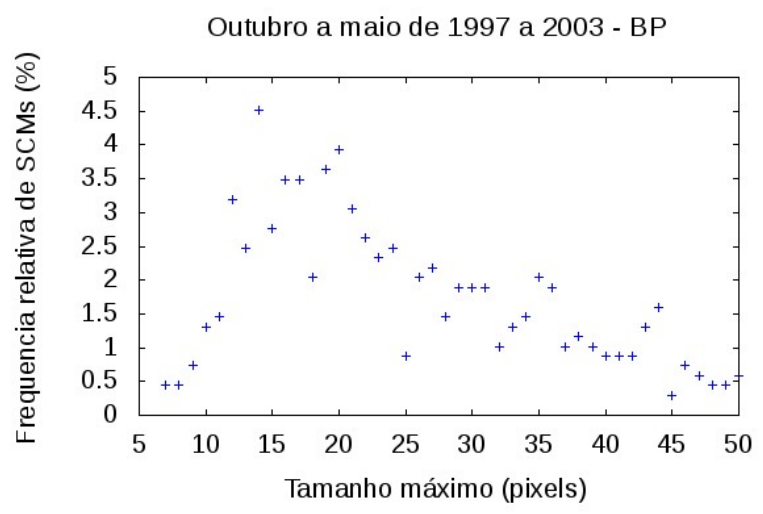

(d)

Figura 20: Distribuição de frequência (em porcentagem) de tamanho dos SCMs simulados pelo RegCM4 na AMZ (20a) e na BP (20b), e uma ampliação para o intervalo de 0 a 50 pixels de ambas as regiões $(2 \overline{0 \mathrm{c} \mathrm{e}} 20 \mathrm{~d})$, de outubro a maio de 1997 a 2003.

A análise da distribuição de frequência de excentricidade (figura 21) dos SCMs no momento de máxima extensão, para o período de outubro a maio de 1997 a 2003, mostra que as regiões tropicais e subtropicais apresentam padrão semelhante. Na AMZ (figura 21a) aproximadamente metade dos $\mathrm{SCMs}(57,1 \%)$ têm excentricidade entre 0,3 e 0,6, com máxima frequência em 0,5 (15,2\%). O mesmo ocorre na BP (figura 21b) com cerca de $58,8 \%$ com excentricidades entre 0,3 e 0,6 , mas com pico em 0,4 (17,6\%), levemente mais linear que os SCMs rastreados no Rio Grande do Sul por Eichholz (2011), cujo trabalho mostrou máxima frequência em 0,5 .

Em ambas as regiões a frequência de SCMs com forma mais circular, como os CCMs 
(excentricidade maior ou igual a 0,7), situa-se em torno de $28 \%$ (figura 21). SCMs praticamente circulares (excentricidade 1,0) são raros em ambas as regiões e representam apenas $1 \%$ e $0,9 \%$ dos SCMs na $\mathrm{AMZ}$ e na $\mathrm{BP}$, respectivamente. Isso mostra que os SCMs, em ambas as regiões, são em sua maioria mais alongados, como encontrado por

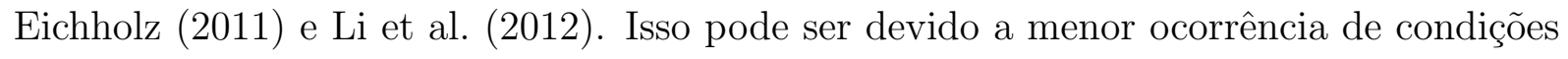
responsáveis pelo formato quase circular dos SCMs, como circulações de mesoescala geradas convectivamente (MADDOX, 1980) e regiões de vorticidade ciclônica em baixos níveis e anticiclônica em altos níveis (DA ROCHA, 1992).

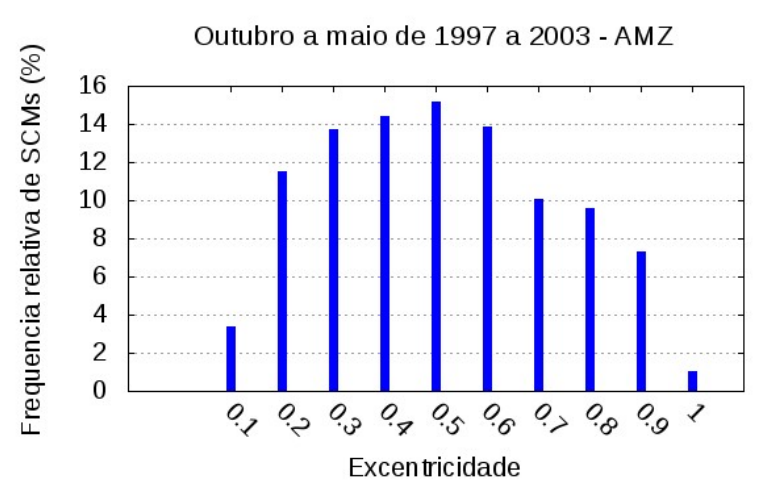

(a)

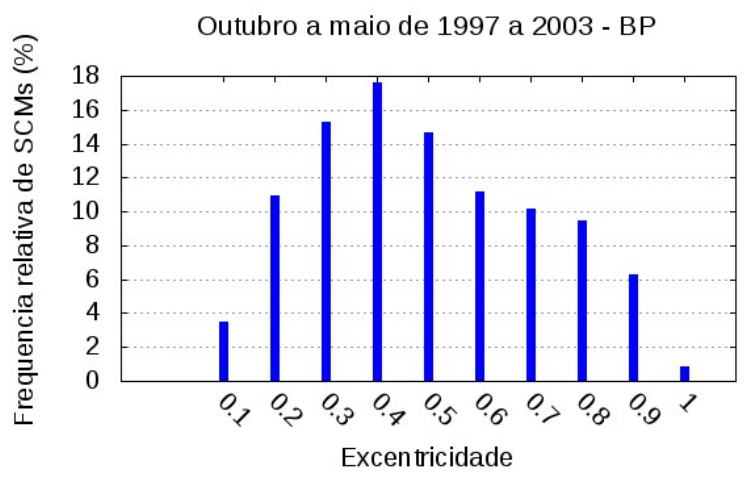

(b)

Figura 21: Distribuição de frequência (em porcentagem) de excentricidade dos SCMs simulados pelo RegCM4, no momento de máxima extensão, na AMZ (21a) e na BP (21b), de outubro a maio de 1997 a 2003.

A distribuição de frequência de temperatura mínima dos SCMs é apresentada na figura 22. A temperatura mínima dos SCMs varia de 232 a $223 \mathrm{~K}$ na AMZ com pico máximo em 229 K (17,6\%) e um secundário em 226 K (15,2\%). Os SCMs tropicais são distribuídos de forma semelhante entre sistemas mais frios, menor ou igual a $227 \mathrm{~K}$, com $52,9 \%$ e SCMs mais quentes, maior ou igual a $228 \mathrm{~K}$, com 47,1\%. Na BP a temperatura mínima varia entre 233 e $222 \mathrm{~K}$, apresentando SCMs mais quentes e mais frios que os da AMZ. Os sistemas subtropicais apresentam um pico de máxima ocorrência em $226 \mathrm{~K}$ $(18,3 \%)$ e maior frequência de SCMs mais frios que nos trópicos, pois $68,2 \%$ dos SCMs subtropicais apresentam temperatura mínima menor ou igual a $227 \mathrm{~K}$.

Segundo Eichholz (2011), SCMs apresentam temperatura mínima mais baixa devido à instabilidade associada à grande disponibilidade de umidade e calor na baixa troposfera, desenvolvendo cumulonimbos mais profundos e com topos mais frios. A ocorrência de JBN em eventos de SCMs subtropicais (SALIO et al., 2007) e/ou de sistemas frontais que são mais frequentes entre 40 e $35^{\circ} \mathrm{S}$ (nove por mês), e mais raros ao norte de $20^{\circ} \mathrm{S}$ (dois 
por mês - FEDOROVA et al., 2007) pode favorecer o desenvolvimento de topos mais frios na BP. Contudo, esses limiares mínimos de temperatura simulados pelo RegCM4 indicam SCMs mais quentes do que os reportados na literatura (MACHADO et al., 1998; VILA et al., 2006; SALIO et al., 2007; VILA et al., 2008, EICHHOLZ, 2011, GOYENS et al., 2011), isso seria atribuído ao esquema de convecção de cúmulos adotado no RegCM4, que reduz o desenvolvimento vertical das "nuvens".

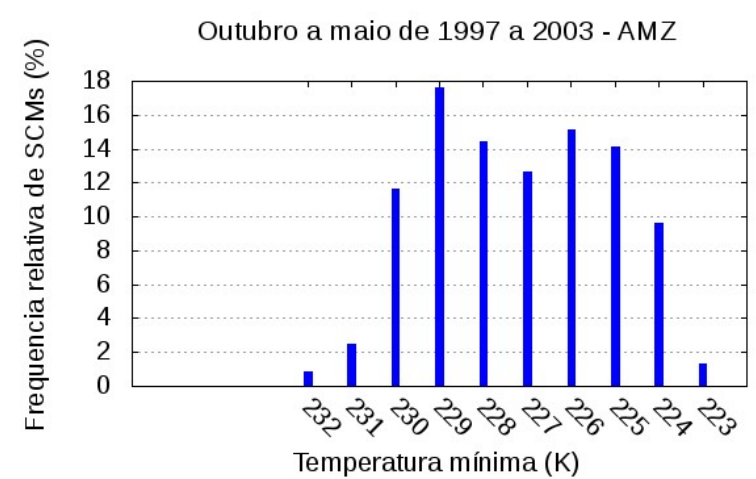

(a)

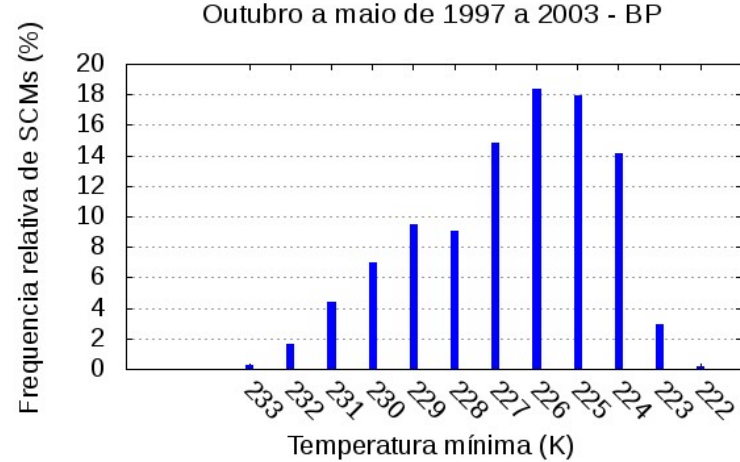

(b)

Figura 22: Distribuição de frequência (em porcentagem) de temperatura mínima dos SCMs na AMZ (21a) e na BP (22b), de outubro a maio de 1997 a 2003.

\subsubsection{Relação entre as características morfológicas dos SCMs}

Esta seção apresenta as relações entre as variáveis de características morfológicas do SCMs descritas na seção anterior em forma de distribuição de frequência. Serão analisadas as relações aos pares entre essas variáveis (tamanho máximo, tempo de vida, excentricidade no momento de máxima extensão e temperatura mínima).

A relação entre tamanho máximo e tempo de vida (figura 23 ), de outubro a maio de 1997 a 2003, mostra que a maioria dos SCMs tropicais (23a) e subtropicais (23b) são em geral pequenos e com tempo de vida menor. SCMs com tempo de vida longo e tamanho grande no momento de máxima extensão são bastante raros, principalmente na região tropical. Assim como SCMs duradouros são menos frequentes, os SCMs com grandes áreas no momento de máxima extensão também são mais raros. Estudos têm mostrado correlação entre o tempo de vida e o tamanho dos SCMs, de modo que há uma tendência de que quanto mais tempo dura o sistema, maior será o seu tamanho (MACHADO et al., 1998; MATHON; LAURENT, 2001a; VILA et al., 2004; SAKAMOTO, 2009; EICHHOLZ, 2011). O RegCM4 simula esse padrão embora com relação mais fraca que a obtida nesses trabalhos, principalmente para os SCMs tropicais. 


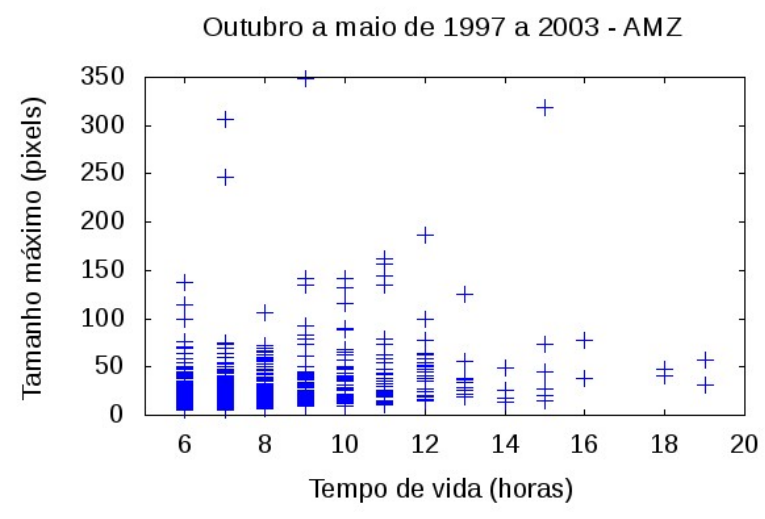

(a)

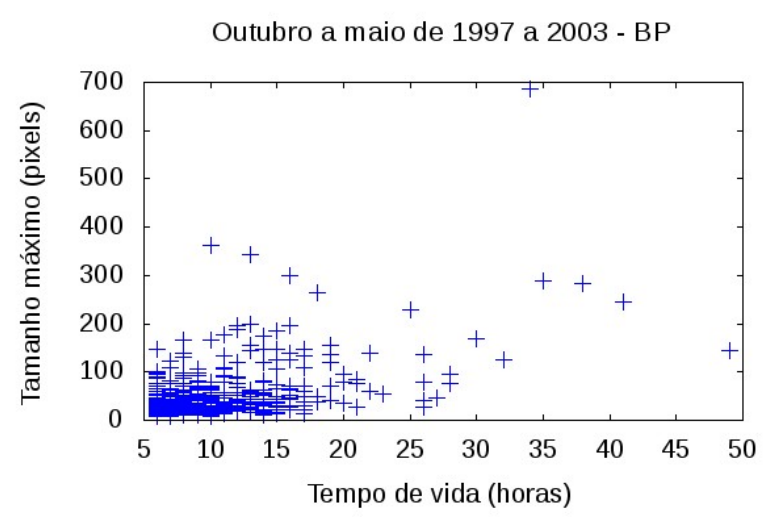

(b)

Figura 23: Relações entre tamanho máximo e tempo de vida dos SCMs simulados pelo RegCM4 na AMZ (23a) e na BP (23b) de outubro a maio de 1997 a 2003.

A figura 24 apresenta a relação entre tempo de vida e temperatura mínima dos SCMs. Nota-se correlação negativa, ou seja, quanto menor a temperatura mínima maior é o tempo de vida dos SCMs, como encontrado por vários autores (MACHADO et al., 1998; VILA et al., 2004; PALMEIRA, 2005; VILA et al., 2006). Embora os SCMs subtropicais (figura 24b) apresentem maior tempo de vida, a correlação negativa também ocorre nos SCMs tropicais (figura $24 \mathrm{a}$ ). A relação entre tempo de vida e temperatura mínima é praticamente inversa à obtida entre o tempo de vida e o tamanho máximo dos SCMs (figura 23), contudo o RegCM4 simulou mais claramente a relação com a temperatura mínima. Isto é um indicativo importante, uma vez que características de núcleo convectivo frio são mais importantes que as demais na previsão da precipitação do sistema (GOYENS et al., 2011).

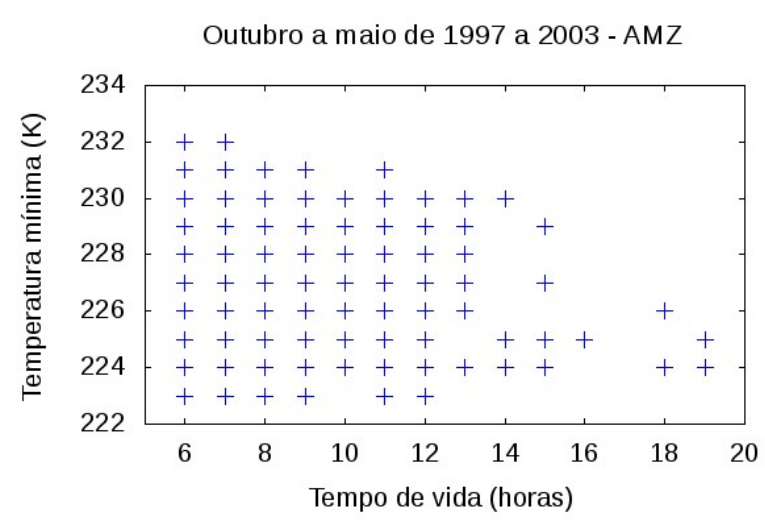

(a)

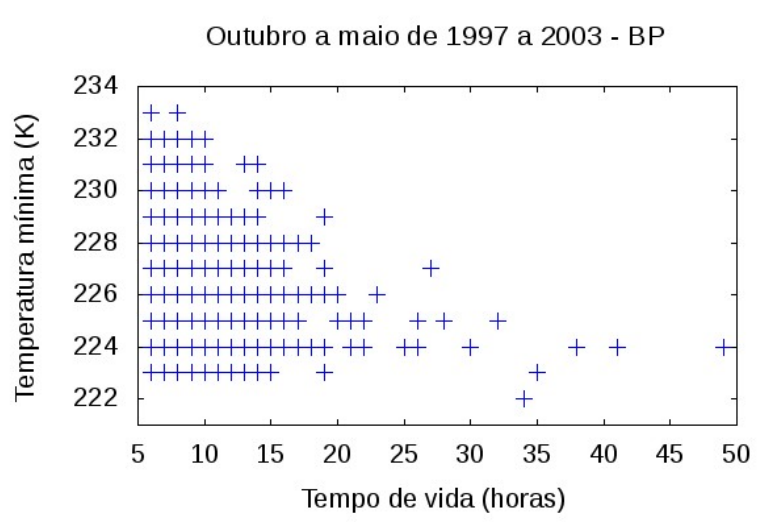

(b)

Figura 24: Relação entre tempo de vida e temperatura mínima dos SCMs na AMZ (24a) e na BP (24b) de outubro a maio de 1997 a 2003. 
A relação entre tamanho máximo e temperatura mínima (figura 25) apresenta decréscimo na temperatura mínima com o aumento do tamanho dos SCMs tropicais (figura 25a) e subtropicais (figura 25b). Segundo Machado e Rossow (1993) isso ocorre porque durante a etapa de formação, o SCM primeiro se resfria para em seguida se expandir durante a etapa de maturação (máxima extensão), logo quanto menor a temperatura mínima do sistema maior será seu tamanho horizontal, assim como seu desenvolvimento vertical (MACHADO et al., 1998). Estudos posteriores à Machado e Rossow (1993) também encontraram essa correlação negativa entre a temperatura mínima e tamanho máximo dos SCMs (VILA et al., 2004; VILA et al., 2006; SAKAMOTO, 2009; EICHHOLZ, 2011). Segundo Goyens et al. (2011) o máximo de precipitação ocorre após o mínimo de temperatura devido à forte corrente de ar ascendente, e em seguida o SCMs atinge sua máxima extensão.

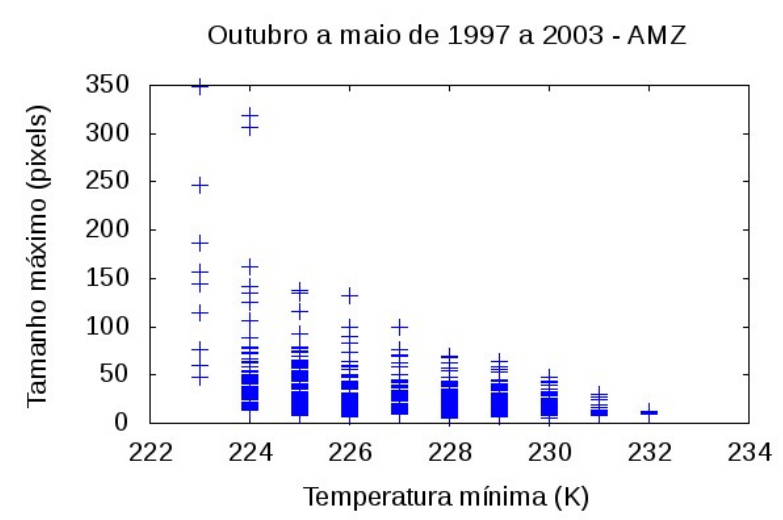

(a)

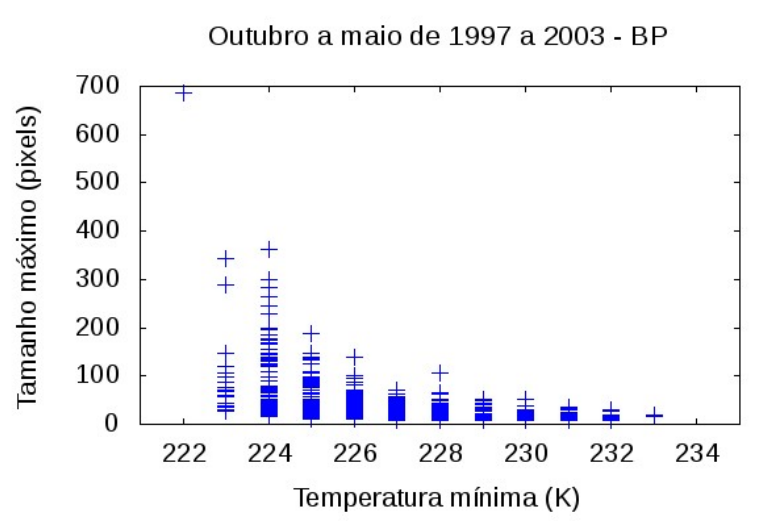

(b)

Figura 25: Relação entre temperatura mínima e tamanho máximo dos SCMs simulados pelo RegCM4 na AMZ (25a) e na BP (25b) de outubro a maio de 1997 a 2003.

Na simulação do RegCM4, as figuras que relacionam a excentricidade com o tempo de vida (figura $\underline{26}$ ), tamanho máximo (figura $\underline{27}$ ) e temperatura mínima (figura $\underline{28}$ ) dos SCMs não apresentaram nenhuma correlação evidente tanto na região tropical quanto na região subtropical. Embora Eichholz (2011) tenha encontrado que SCMs com formato mais circular no Rio Grande do Sul possuem maior atividade convectiva e maior tempo de vida, o RegCM4 não simulou essas relações, ou seja, na simulação a forma do SCM não tem influência clara no tamanho máximo, temperatura mínima e tempo de vida.

\subsubsection{Características cinemáticas dos SCMs na AMZ e na BP}

Esta seção apresenta algumas características cinemáticas dos SCMs simulados pelo RegCM4, como as posições iniciais (gênese), finais (dissipação) e trajetórias para os SCMs tropicais (AMZ) e subtropicais (BP) durante o período de outubro a maio de 1987 a 2003. 


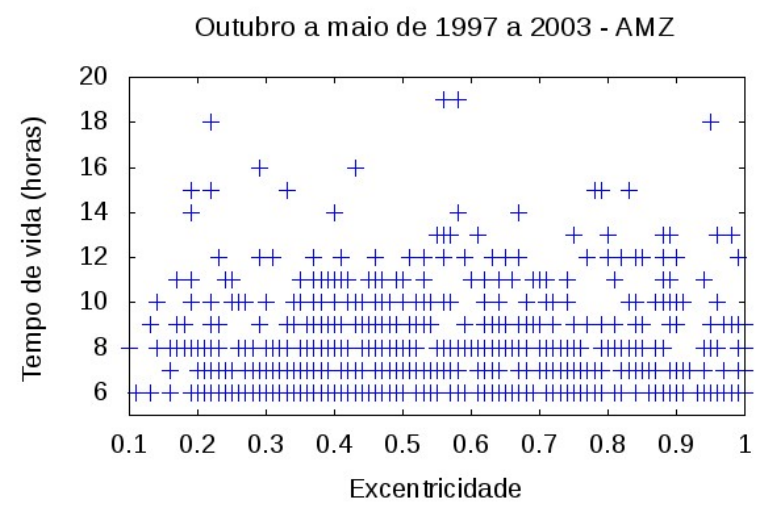

(a)

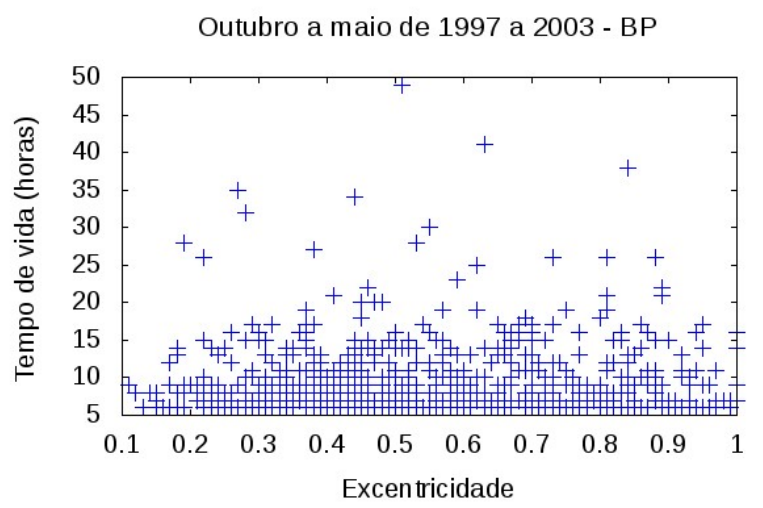

(b)

Figura 26: Relação entre temperatura mínima e tamanho máximo (26a) e tempo de vida e excentricidade (26b) dos SCMs simulados pelo RegCM4, de outubro a maio de 1997 a 2003.

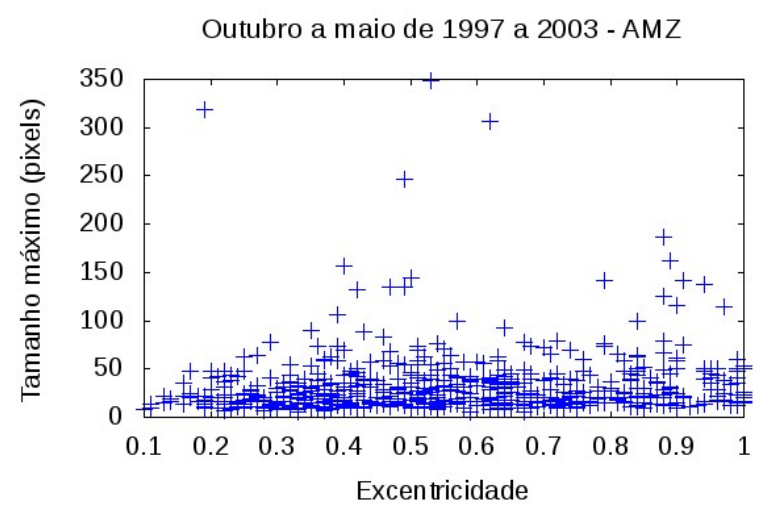

(a)

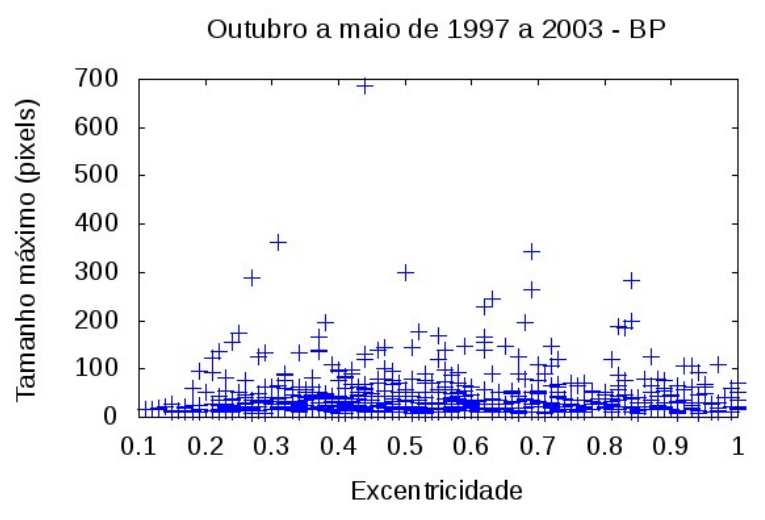

(b)

Figura 27: Relação entre excentricidade e tamanho máximo dos SCMs na AMZ (27a) e na BP (27b) de outubro a maio de 1997 a 2003.

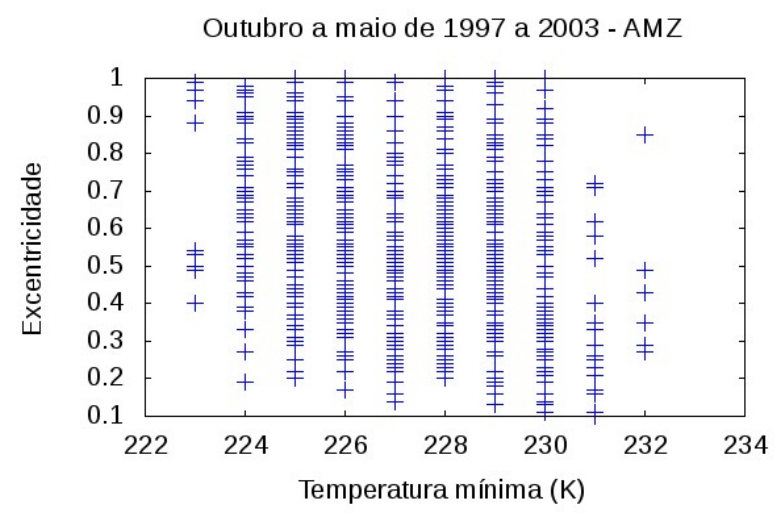

(a)

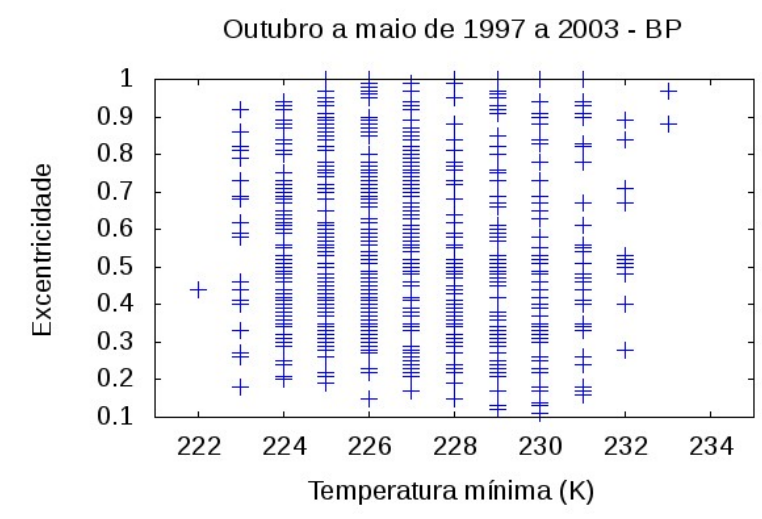

(b)

Figura 28: Relação entre excentricidade e temperatura mínima dos SCMs na AMZ (28a) e na BP (28b) de outubro a maio de 1997 a 2003. 
Os SCMs tropicais se iniciam (figura 29a) em qualquer local da AMZ, sem nenhuma região preferencial, o que também ocorre no momento de dissipação desses sistemas (figura 29b). A figura 31 mostram as trajetórias mensais dos SCMs de outubro a maio, de 1987 a 2003, reforçando o padrão de aleatoriedade dessas características cinemáticas dos SCMs tropicais, pois não é possível estabelecer um padrão predominante de trajetórias em nenhum dos meses analisados.

Os SCMs subtropicais também iniciam em qualquer posição da BP (figura 30a), mas mostram leve tendência de dissiparem-se no sul do Brasil, principalmente no norte do Rio Grande do Sul, em Santa Catarina e Paraná (figura 30b). Estudos como os de Gue-

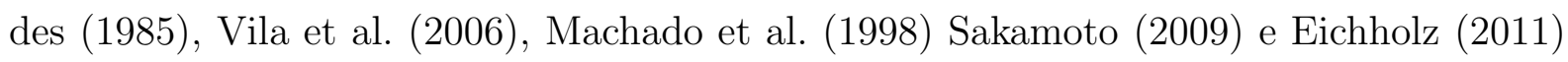
mostraram que os SCMs subtropicais se deslocam preferencialmente para leste, desde a gênese até a dissipação. De fato, a maioria dos SCMs na BP apresenta forte componente para leste durante o deslocamento (figura 32). O deslocamento preferencial dos SCMs na região subtropical ocorre devido ao escoamento de oeste em altos níveis (ROMATSCHKE; HOUZE JR, 2010). Além disso, estes SCMs são modulados por sistemas frontais e forçantes associadas com contrastes de temperatura e estratificação atmosférica de grande escala (SUGAHARA et al., 1996; citeauthorSiqueira2008, 2008).

Nos meses de outubro, novembro e dezembro (figuras 32a, 32b e 32c) a trajetória preferencial dos SCMs é para sudeste, os sistemas que se formam no norte da Argentina e no Paraguai se movem preferencialmente para o Rio Grande do Sul, Santa Catarina e Paraná, percorrendo distâncias maiores que SCMs com outras trajetórias. Nos meses de janeiro, fevereiro e março (figuras $32 \mathrm{~d}, 32 \mathrm{e}$ e $32 \mathrm{f}$ ) os SCMs apresentam maior diversidade nas suas trajetórias. Em maio (figura $32 \mathrm{~h}$ ) as trajetórias são mais zonais e mais curtas que nos demais meses. Os SCMs com maior deslocamento são os que se originam na Argentina, em todos os meses analisados.

As diferenças de trajetórias dos SCM podem ser devido aos diferentes tamanhos de SCMs simulados pelo RegCM4, uma vez que a interação dos SCMs com a circulação de grande escala difere em função do tamanho dos mesmos (MACHADO et al., 1998). Segundo Vila et al. (2004) os SCMs com deslocamento mais rápido estão associados à sistemas frontais. SCMs mais zonais ocorrem devido ao escoamento acima de $500 \mathrm{hPa}$ ser predominantemente zonal (SIQUEIRA; MARQUES, 2008). Alguns SCMs possuem trajetórias com componente de leste para oeste, devido a influência de forçantes termodinâmicas da região, como brisa marítima. Contudo estes são em menor quantidade, pois a influência dinâmica é mais forte que a termodinâmica na trajetória desses sistemas 
(SIQUEIRA; MARQUES, 2008).

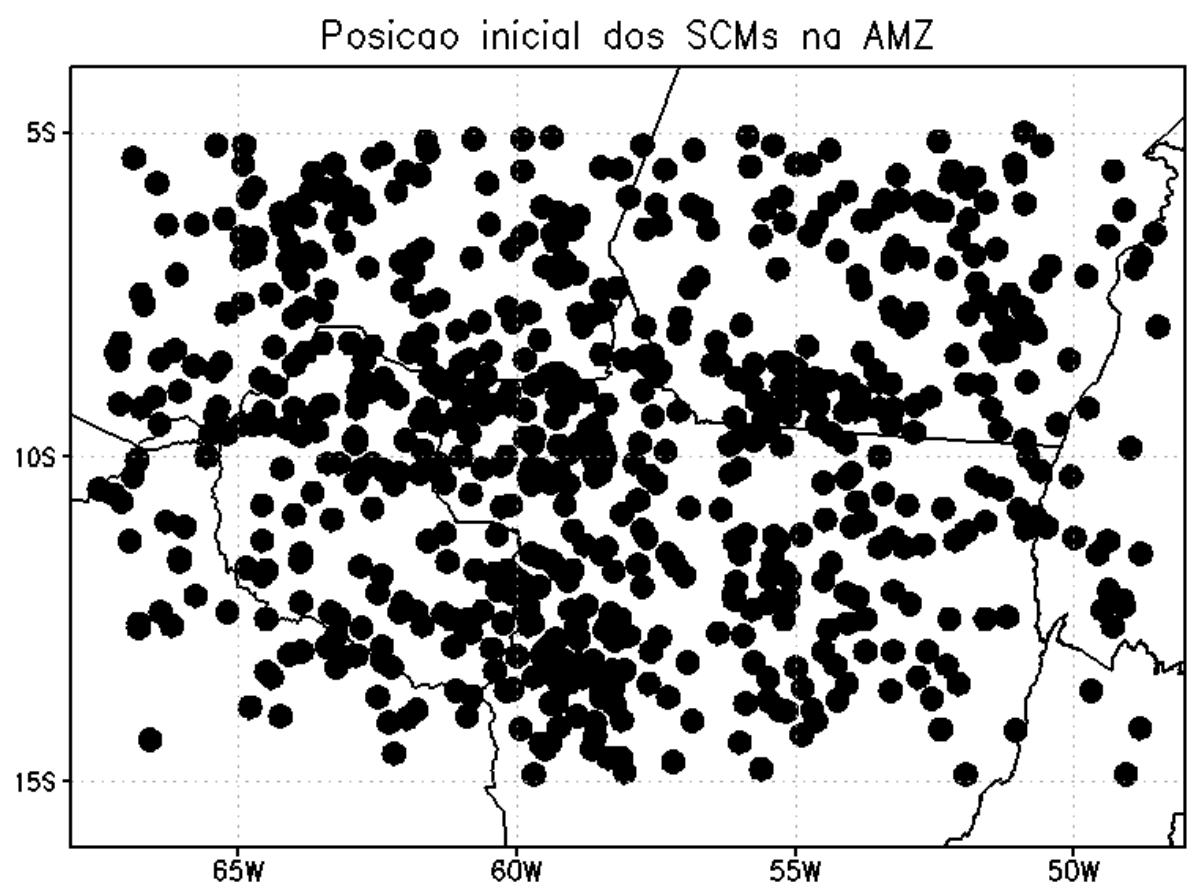

(a)

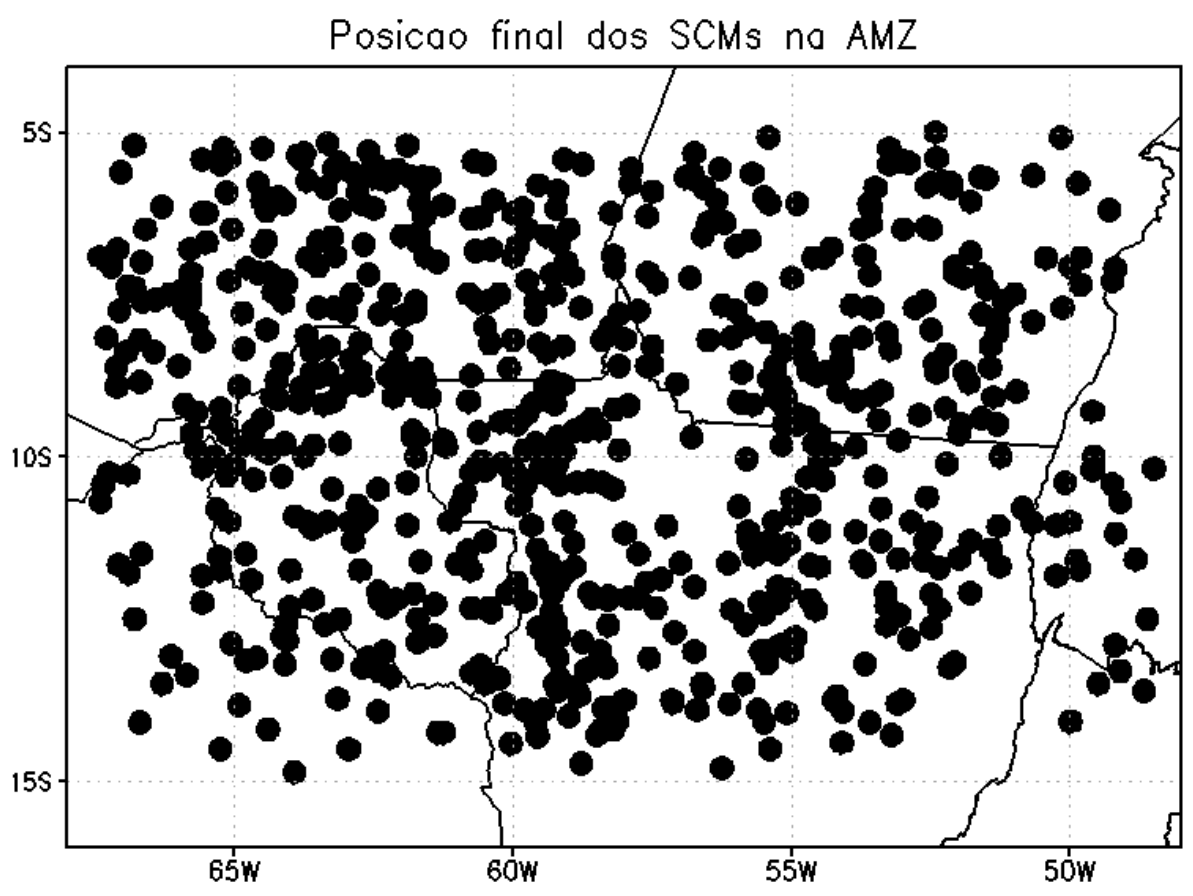

(b)

Figura 29: Posição inicial (29a) e final dos SCMs (29b) simulados pelo RegCM4 na AMZ de outubro a maio de 1997 a 2003. 


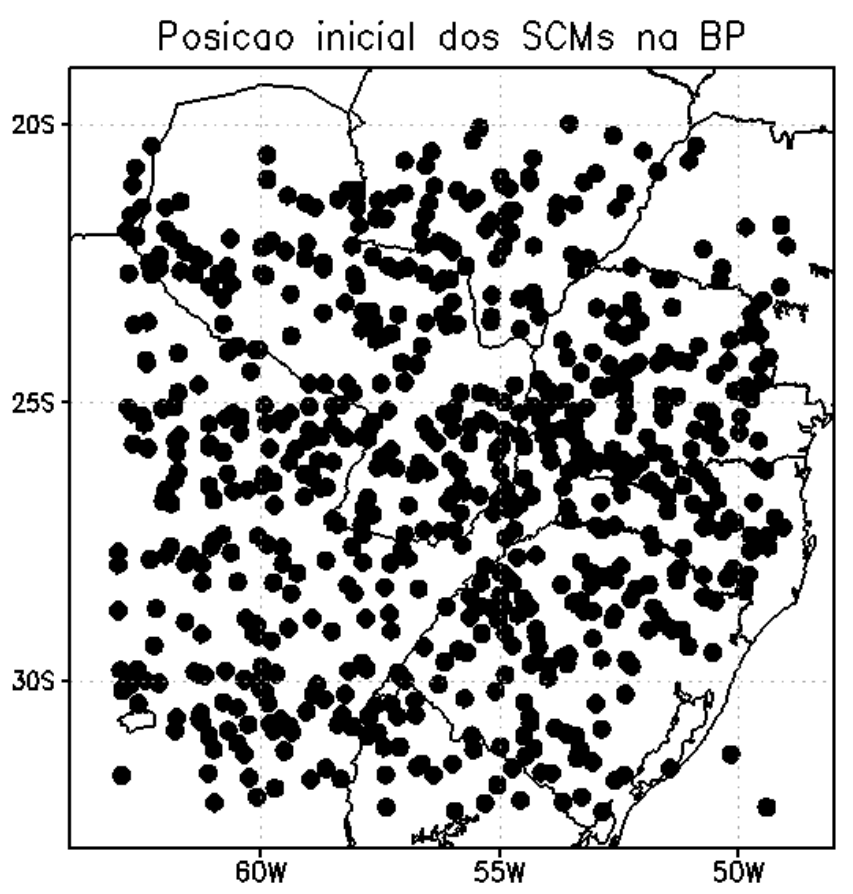

(a)

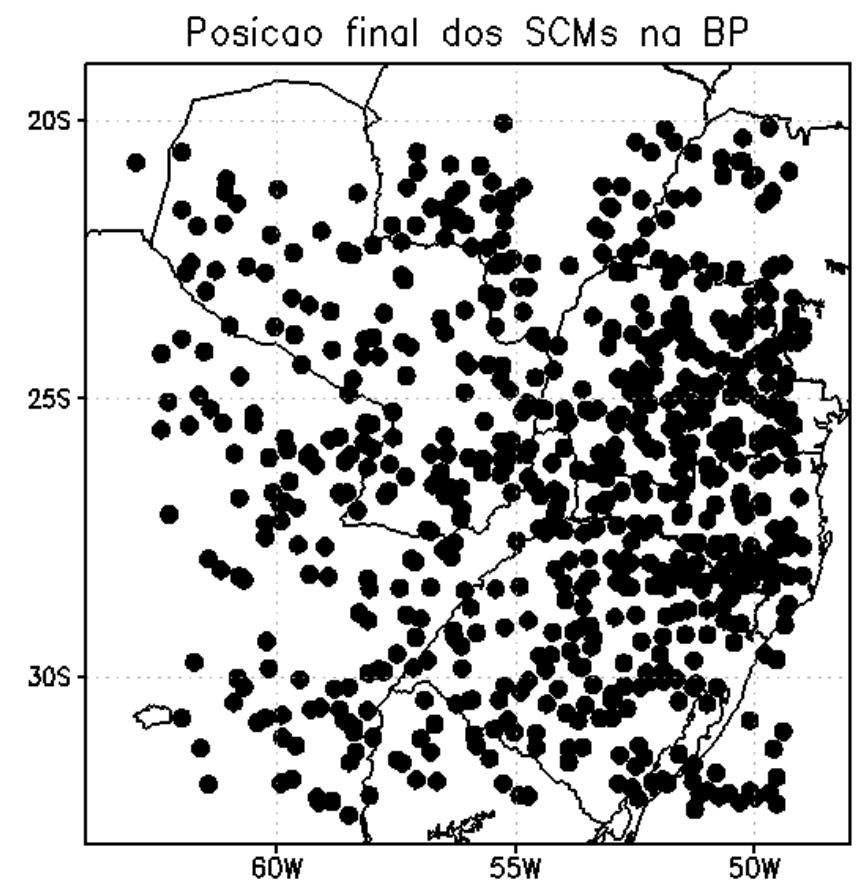

(b)

Figura 30: Posição inicial (30a) e final dos SCMs (30b) simulados pelo RegCM4 na AMZ de outubro a maio de 1997 a $20 \overline{03 .}$ 


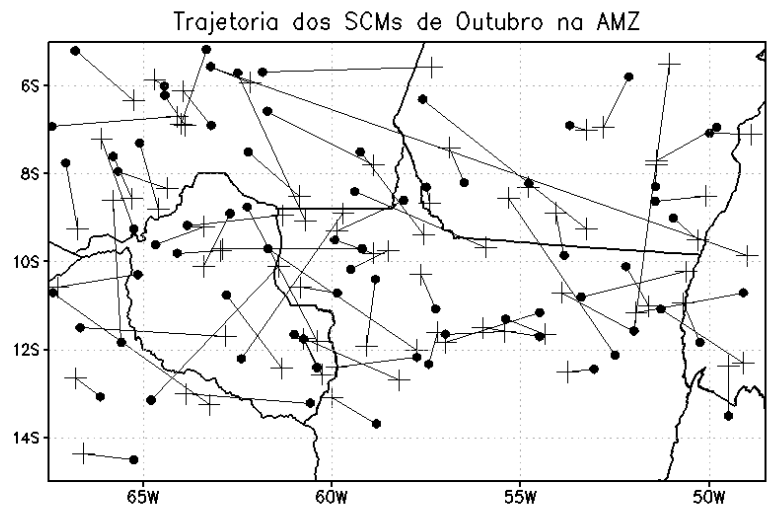

(a)

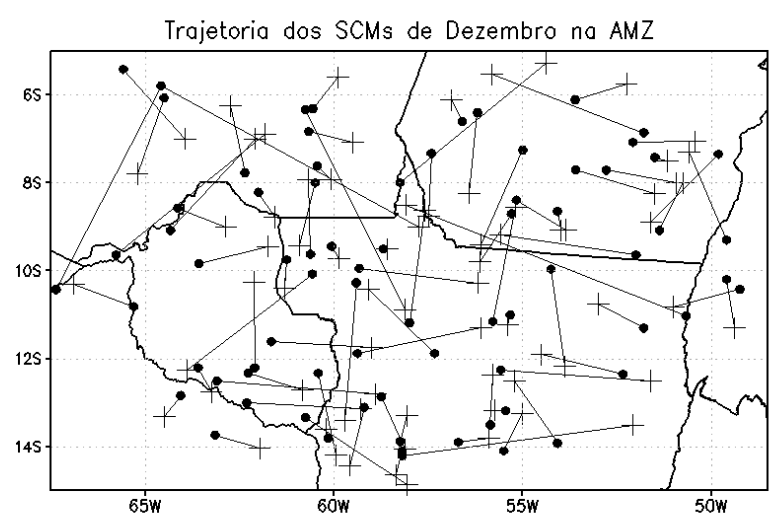

(c)

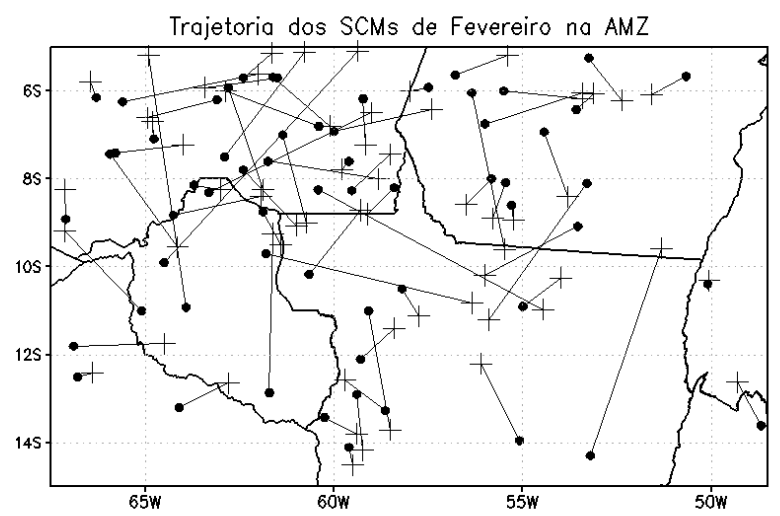

(e)

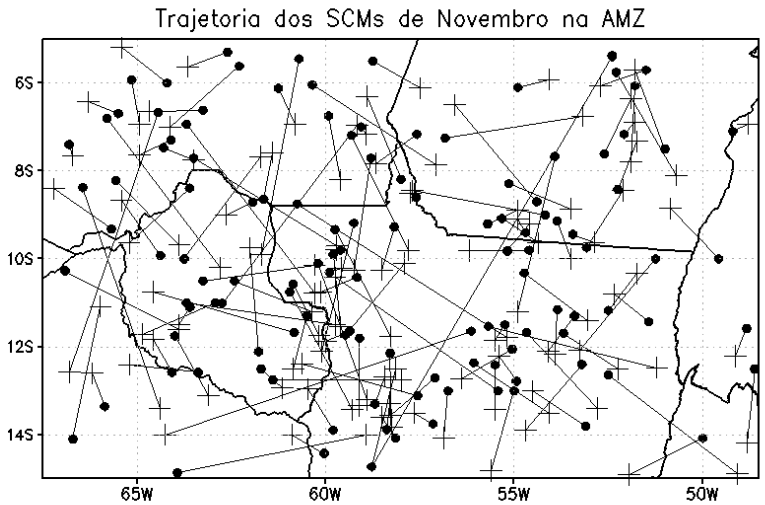

(b)

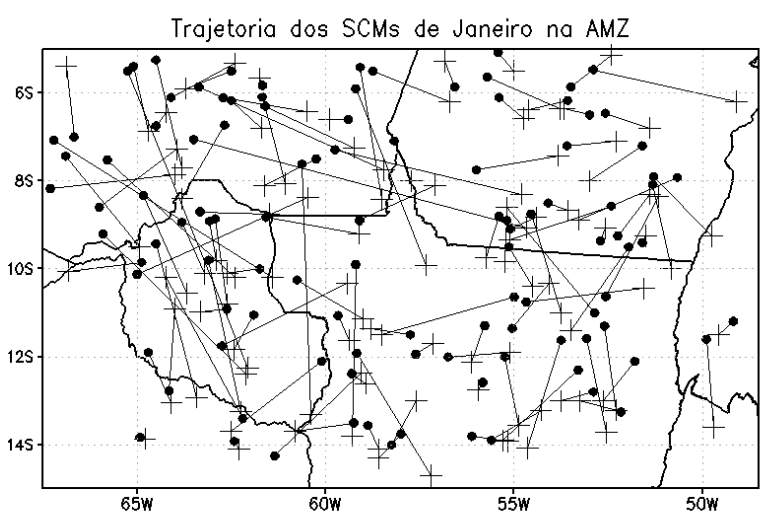

(d)

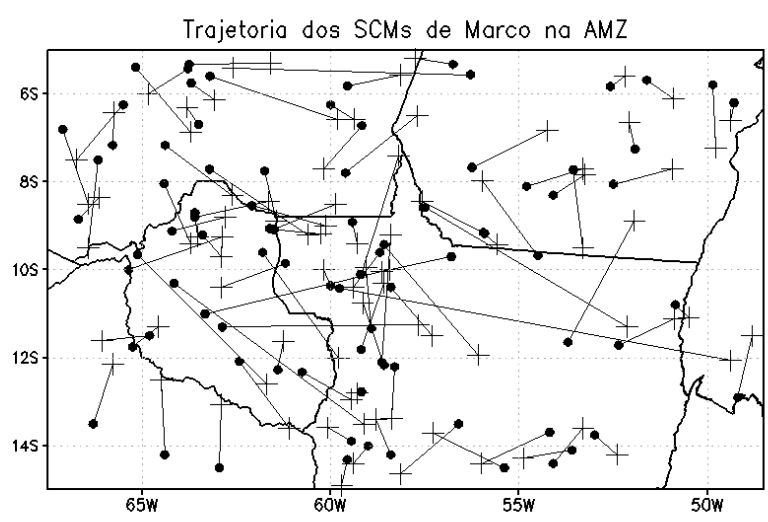

(f)

Figura 31: Trajetória em linha reta dos SCMs rastreados na AMZ que ocorreram em outubro (31a), novembro (31b), dezembro (31c), janeiro (31d), fevereiro (31e), março (31f), abril (31g) e maio (31h) de 1997 a 2003 . O sinal "+" representa a posição central do início do SCM e o ponto é a posição central final do sistema. 


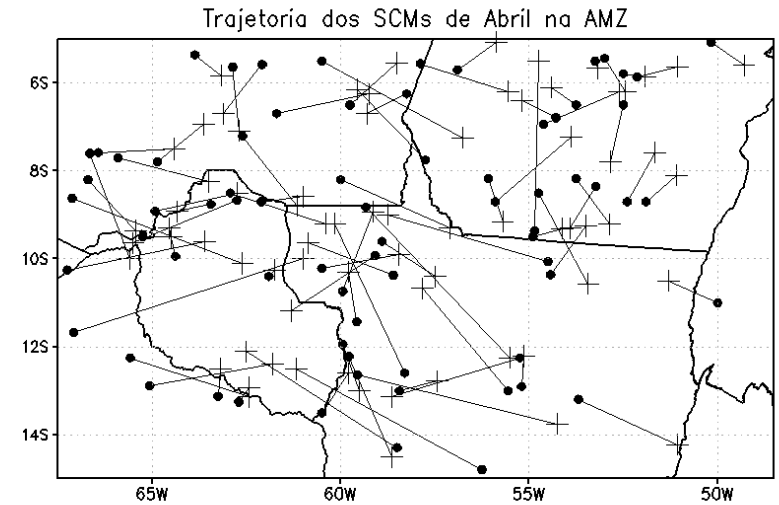

$(\mathrm{g})$

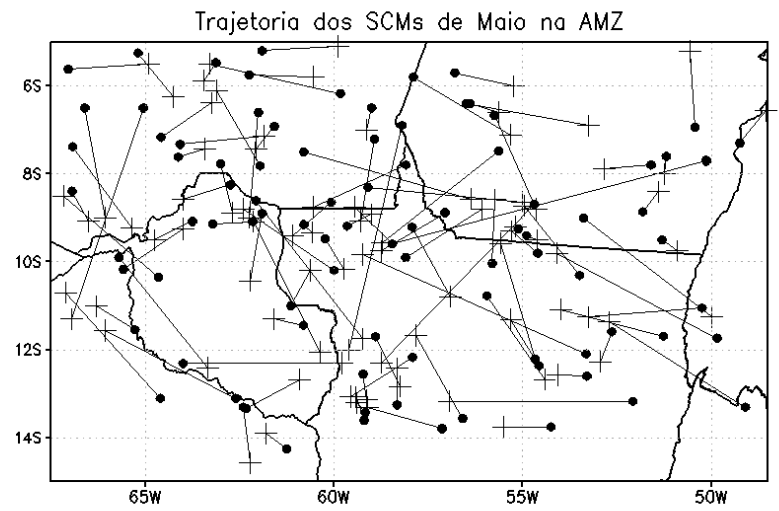

(h)

Figura 31: Continuação.

\subsection{Características gerais dos SCMs em toda a AS}

Nesta seção serão descritas de forma sucinta as características cinemáticas e morfológicas dos SCMs rastreados em toda a AS (figura 4a), englobando SCMs tropicais, subtropicais, continentais e oceânicos buscando entender características gerais desses sistemas simulados pelo RegCM4 independente do local de gênese.

O ForTraCC rastreou um total de 22701 SCMs em toda a AS de outubro a maio de 1997 a 2003. A figura 33a mostra a soma de todos os SCMs em cada mês. O maior número de SCMs ocorreu no mês de janeiro, seguido de dezembro e novembro. O RegCM4 simulou queda abrupta na ocorrência de SCMs de janeiro para fevereiro. A menor ocorrência de SCMs é no mês de maio, devido a redução da convecção à medida que avança mais no outono.

A figura 33b apresenta os horários de início, máxima extensão e dissipação dos SCMs. Os SCMs formam-se preferencialmente durante a noite e madrugada, atingem o tamanho máximo no início da manhã e dissipam no fim da manhã e início da tarde. Os horários preferenciais para início, máxima extensão e dissipação dos SCMs na AS são às 04, 07 e 13 UTC, respectivamente. Esse padrão se assemelha mais aos SCMs tropicais (figura 18a) que aos subtropicais (figura 18b) o que seria atribuído à maior presença de SCMs tropicais na AS (figura 39 ).

A grande maioria dos SCMs rastreados na AS possuem tempo de vida (figura 34) de até 25 horas (90,2\%), sendo que 51,7\% dos SCMs duram até 10 horas, com média de 13,36 horas e desvio padrão de 12,13 horas. Vale ressaltar que neste estudo foram 


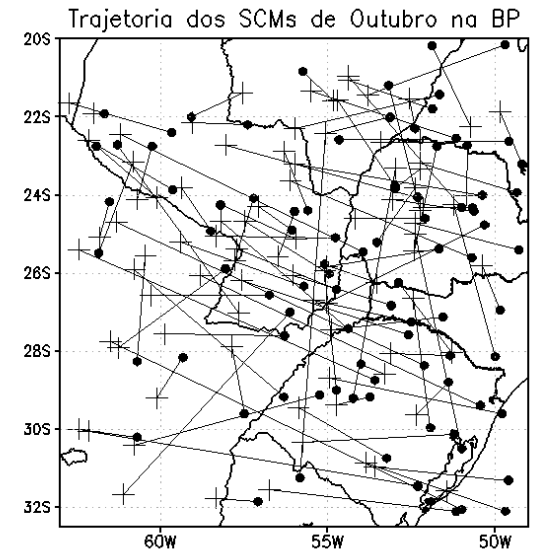

(a)

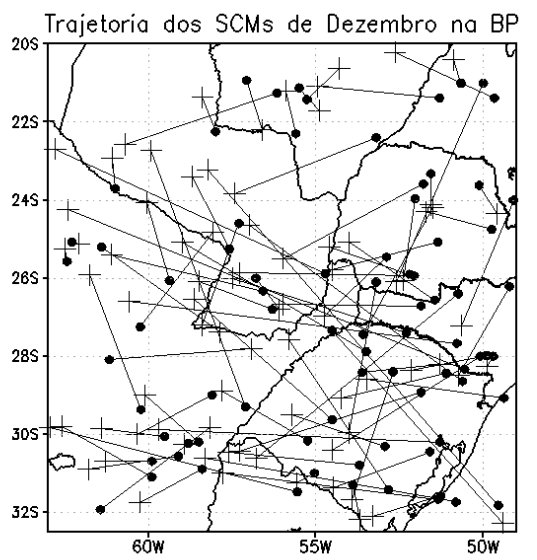

(c)

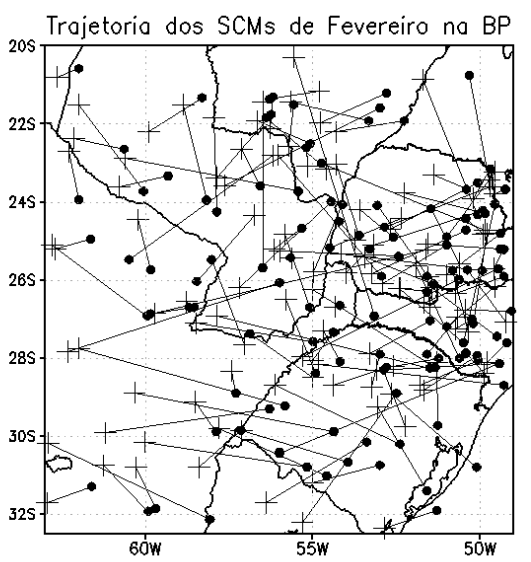

(e)

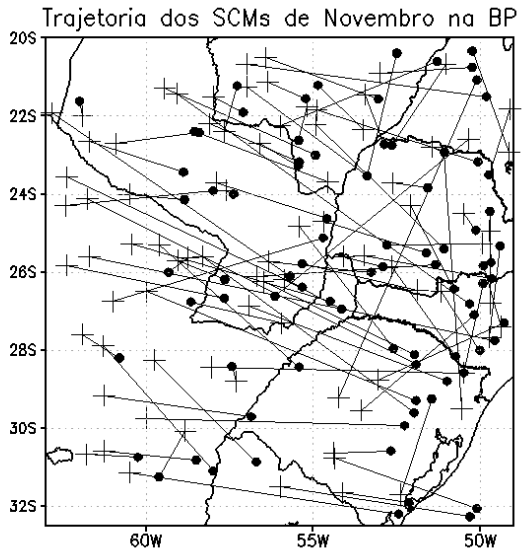

(b)

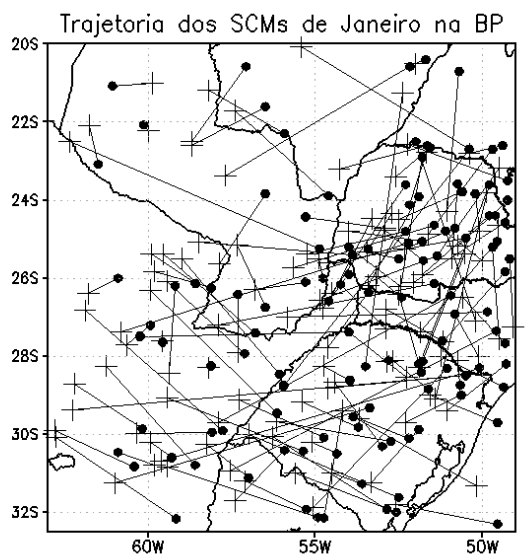

(d)

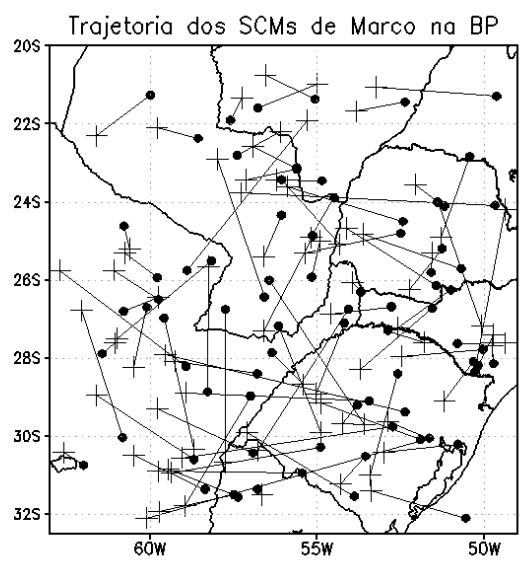

(f)

Figura 32: Trajetória em linha reta dos SCMs rastreados na BP que ocorreram em outubro (32a), novembro (32b), dezembro (32c), janeiro (32d), fevereiro (32e), março (32f), abril (32g) e maio (32h) de $199 \overline{7 \text { a }} 2003$. O sinal "+ "representa a posição centra do início do SCM e o ponto é a posição central final do sistema. 


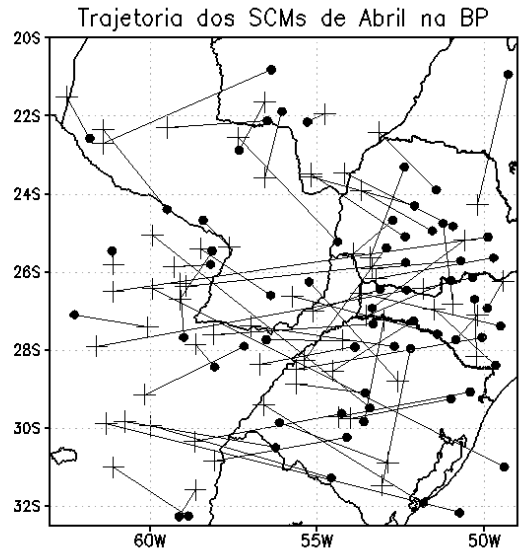

$(\mathrm{g})$

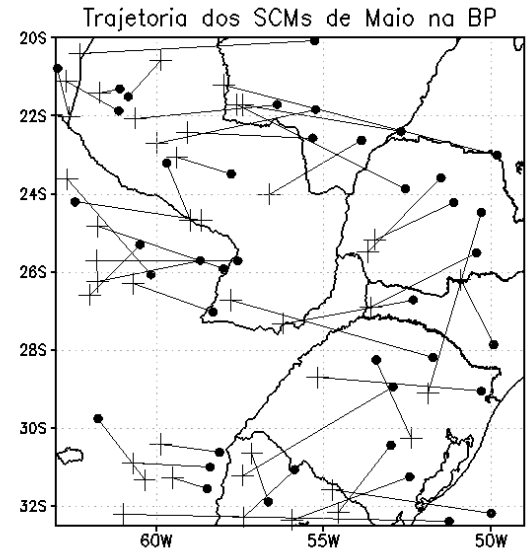

(h)

Figura 32: Continuação.

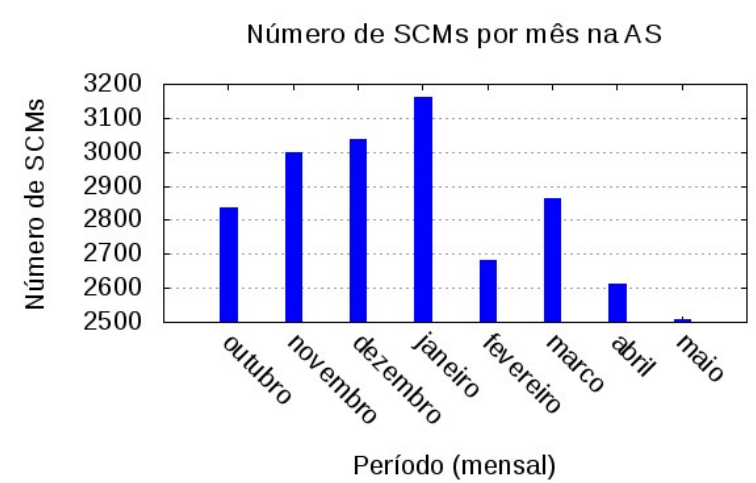

(a)

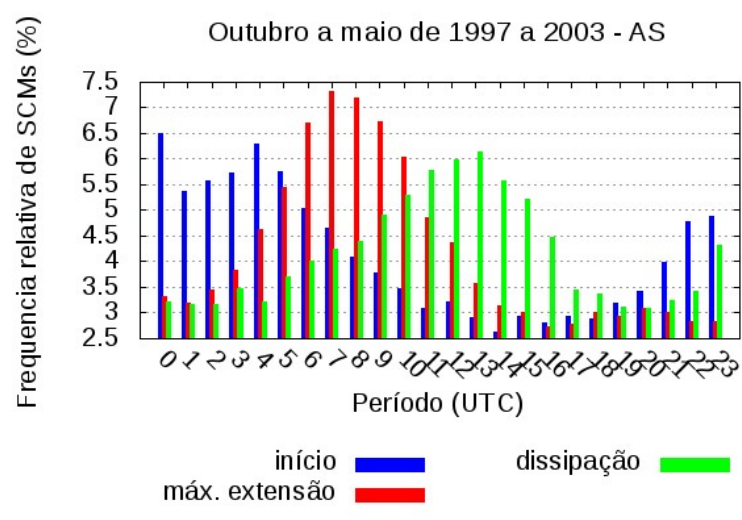

(b)

Figura 33: Número de SCMs por mês (33a),dos horários de início (azul), máxima extensão (vermelho) e dissipação (verde) dos SCMs (33b) na AS de outubro a maio de 1997 a 2003.

considerados apenas SCMs com tempo de vida de 6 horas ou mais. A distribuição de frequência do tempo de vida SCMs mostra decréscimo aproximadamente logarítmico. Os SCMs com mais de 40 horas de tempo de vida representam uma porcentagem pequena do total encontrado na $\mathrm{AS}(4,2 \%)$, sendo que sistemas mais duradouros, com 100 horas de duração, representam uma porcentagem pequena do total (0,09\%).

A distribuição de frequência de tamanhos dos SCMs também apresenta decréscimo aproximadamente logarítmico (figura 35), ou seja, SCMs menores são mais frequentes do que os muito grandes, resultado similar ao de Morel e Senesi (2002). A maioria dos SCMs atinge tamanho máximo menor que 50 pixels $\left(125.000 \mathrm{~km}^{2}\right)$, com média de 67,8 pixels $\left(169.500 \mathrm{~km}^{2}\right)$ semelhante ao encontrado por Sakamoto (2009), de $161.000 \mathrm{~km}^{2}$ para os SCMs continentais, mas maior que os SCMs oceânicos $\left(97.600 \mathrm{~km}^{2}\right)$. Contudo, alguns 


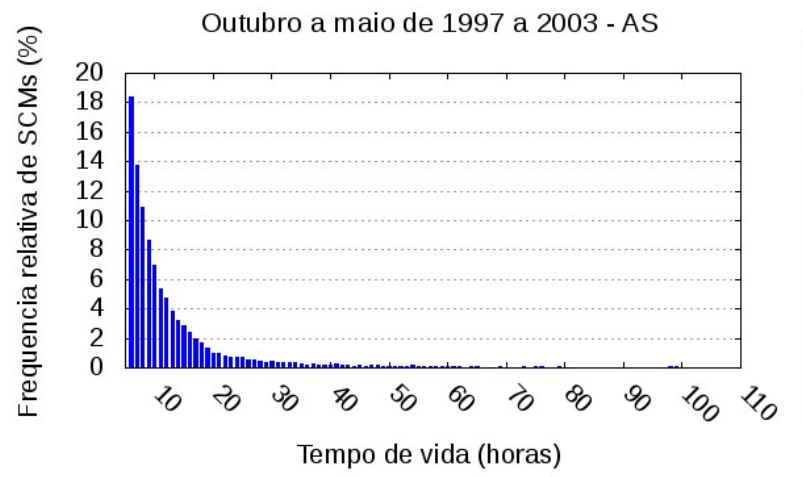

(a)

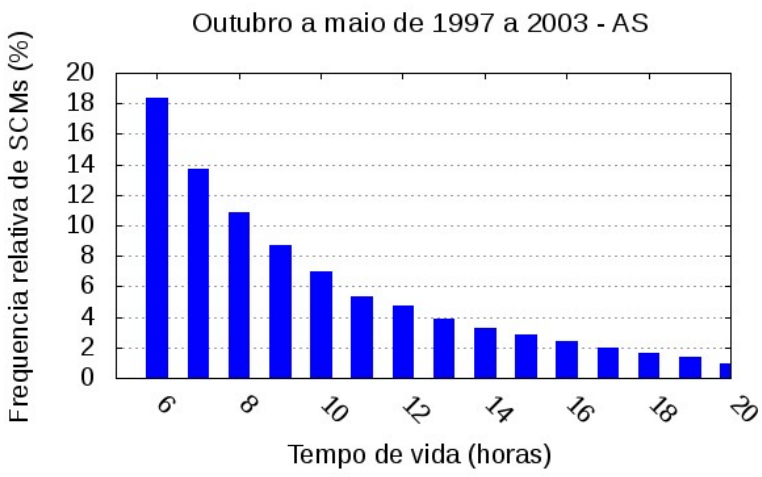

(b)

Figura 34: Distribuição de frequência de tempo de vida dos SCMs simulados pelo RegCM4 na AS (34a) e uma ampliação para SCMs com até 20 horas (34b) de outubro a maio de 1997 a 2003.

SCMs simulados podem atingir tamanhos até 1000 pixels $\left(2.500 .000 \mathrm{~km}^{2}\right)$.

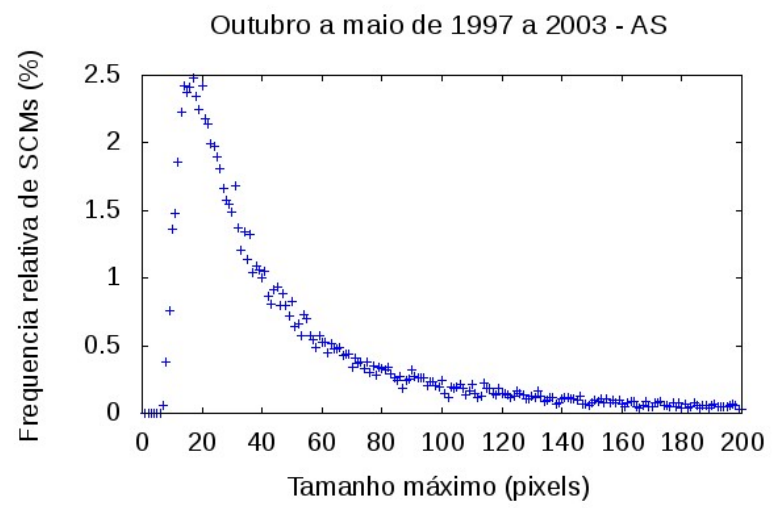

(a)

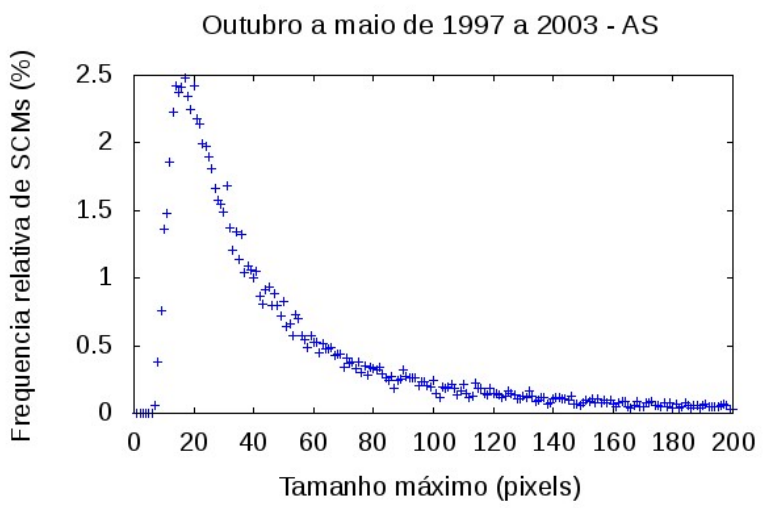

(b)

Figura 35: Tamanho máximo dos SCMs simulados pelo RegCM4 na AS (5a) e uma ampliação até 200 pixels (35b) de outubro a maio de 1997 a 2003.

No momento de máxima extensão dos SCMs a excentricidade mais frequente é de 0,4 (figura 36a). Os SCMs com formato mais circular, como os CCMs (excentricidade maior ou igual a 0,7 no momento de máxima extensão), representam menos de $25 \%$ do total, contudo esta não é a única característica que diferencia os CCMs dos demais tipos de SCMs. Uma porcentagem muito pequena de SCMs realmente é circular (excentricidade igual a 1) no momento de máxima extensão.

Aproximadamente 50\% dos SCMs apresentam temperatura mínima entre 227 e 225 $\mathrm{K}$, com maior frequência em $226 \mathrm{~K}$ (figura $\underline{36 \mathrm{~b}}$ ), e em apenas um terço dos SCMs os topos são mais frios que $226 \mathrm{~K}$. Essas temperaturas indicam topos mais quentes que os 
encontrados na literatura (MACHADO et al., 1998; SALIO et al., 2007; SAKAMOTO, 2009; EICHHOLZ, 2011). A hipótese para esta grande diferença entre o RegCM4 e os valores reportados na literatura estaria associada ao esquema convectivo utilizado no RegCM4, que resulta em "nuvens" com topos mais baixos e, portanto, mais quentes do que se esperaria para a convecção profunda. Para todo o período analisado, a menor temperatura mínima de topo de nuvem foi de $220 \mathrm{~K}$ e ocorreu em um único SCM.

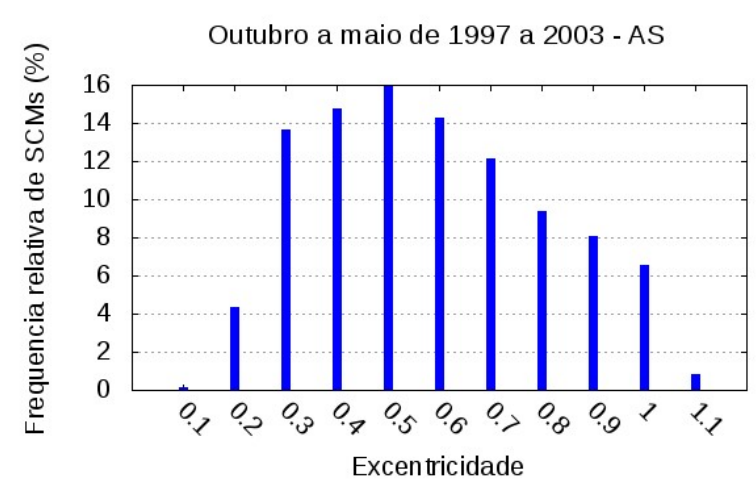

(a)

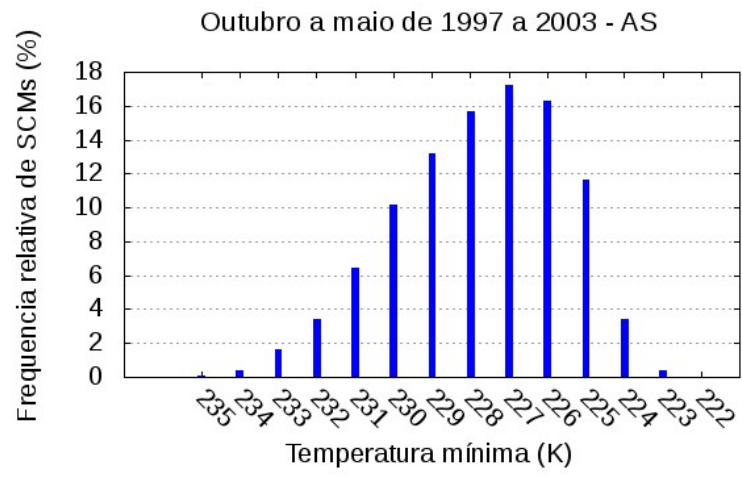

(b)

Figura 36: Excentricidade (36a) e temperatura mínima (36b) dos SCMs simulados pelo RegCM4 na AS, no momento de máxima extensão, de outubro a maio de 1997 a 2003.

A figura 37 a mostra que a temperatura mínima decresce com o aumento do tempo de vida dos SCMs, conforme obtido também para SCMs tropicais e subtropicais (figura 24). Foram rastreados somente $4 \mathrm{SCMs}$ com topo de $221 \mathrm{~K}$ com curta duração, exceto um SCM com temperatura mínima de $220 \mathrm{~K}$ que durou 25 horas. A relação da temperatura

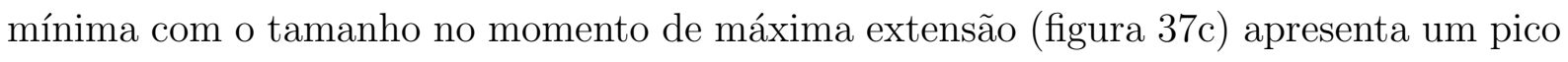
entre $223 \mathrm{~K}$ e $225 \mathrm{~K}$. A figura 37b apresenta maior densidade de SCMs entre 04 e 200 pixels e 6 e 30 horas, indicando que quanto menores o tamanho máximo e o tempo de vida maior a quantidade de SCMs rastreados.

A excentricidade dos SCMs não mostra relação clara com a temperatura mínima do

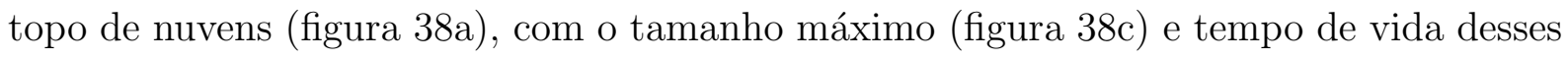
sistemas (figura 38b). Isso indica que no RegCM4 a forma que os SCMs irão adquirir é independente das demais variáveis, assim como na análise regional (AMZ e BP).

Para todos os SCMs rastreados na AS, a figura 39 mostra a posição do centro dos SCMs no momento de início (figura 39a) e dissipação (figura 39b). As regiões com máximos de iniciação de SCMs são continentais: ao longo dos Andes, no Peru e na Bolívia, devido ao efeito orográfico; no Equador também associados a efeitos orográficos e brisas marítimas; no Suriname, Guiana Francesa e os Estados do Amapá e Pará devido a atuação da ZCIT; 


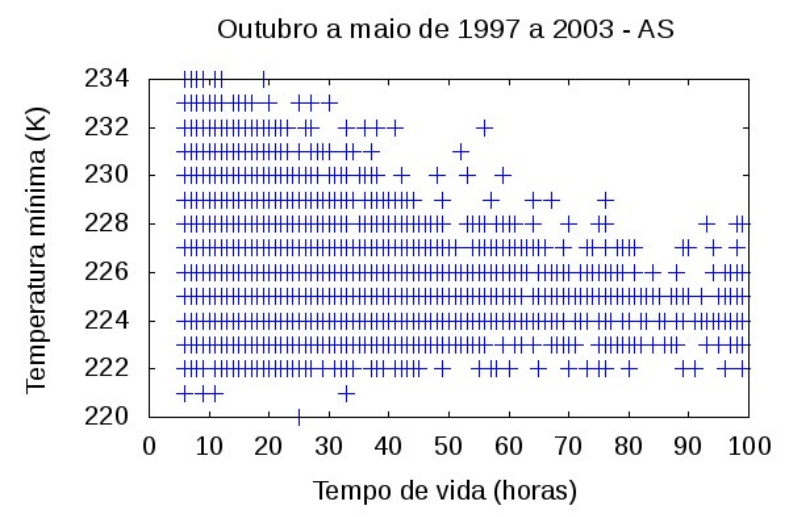

(a)

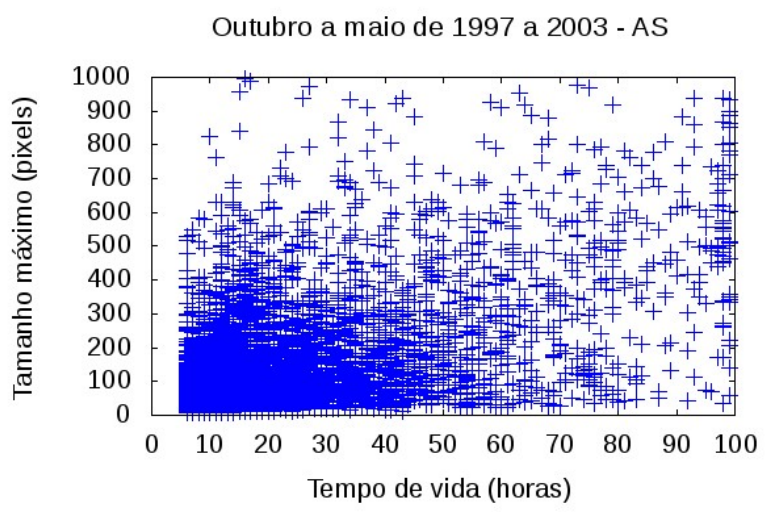

(b)

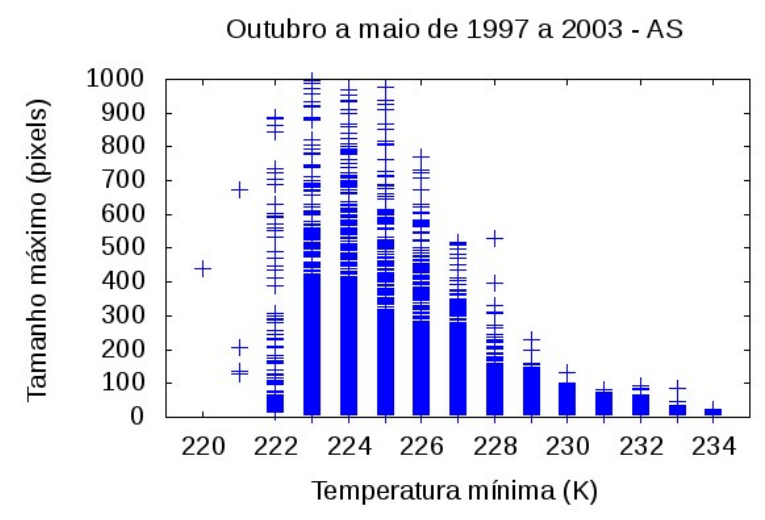

(c)

Figura 37: Relações entre tempo de vida e temperatura mínima (37a) e tamanho máximo (37b), e temperatura mínima e tamanho máximo (37c) dos SCMs simulados pelo RegCM4 na $\overline{\mathrm{AS}}$ de outubro a maio de 1997 a 2003.

nos Estados da Paraíba e Pernambuco associados as Ondas de Leste e brisas marítimas; e no nordeste do Rio Grande do Sul, em Santa Catarina, Paraná, São Paulo, Minas Gerais e Rio de Janeiro devido atuação de sistemas frontais, efeito orográfico, brisas marítimas, entre outros. No sul da $\mathrm{AS}$, na borda próximo à $45^{\circ} \mathrm{S}$, e próximo a $90^{\circ} \mathrm{W}$, entre 30 e $40^{\circ} \mathrm{S}$, o máximo de início dos SCMs está associado à passagem de sistemas transientes como os ciclones e sistemas frontais. Esse resultado mostra que os SCMs estão associados aos máximos de precipitação na AS na simulações do RegCM4. No momento de dissipação as regiões preferenciais dos SCMs são similares à do momento de gênese (posição inicial), mostrando que não há deslocamento muito grande desses sistemas.

\subsection{Complexos Convectivos de Mesoescala}

O ForTraCC rastreou 232 CCMs nas simulações do RegCM4 de outubro a maio, de 1997 a 2003, na região da Bacia do Prata (figura 4b). A figura 40a mostra o total de 


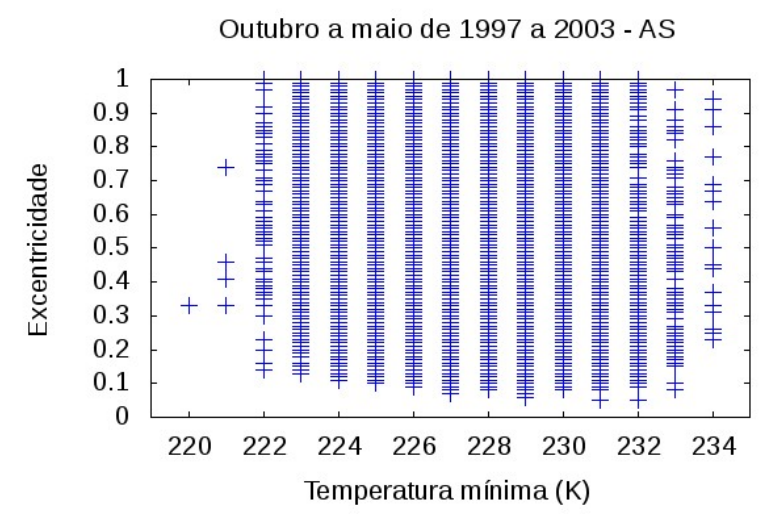

(a)

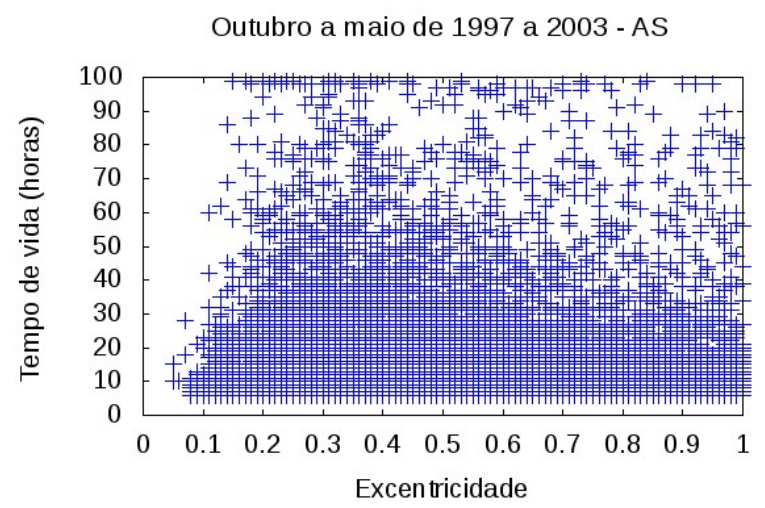

(b)

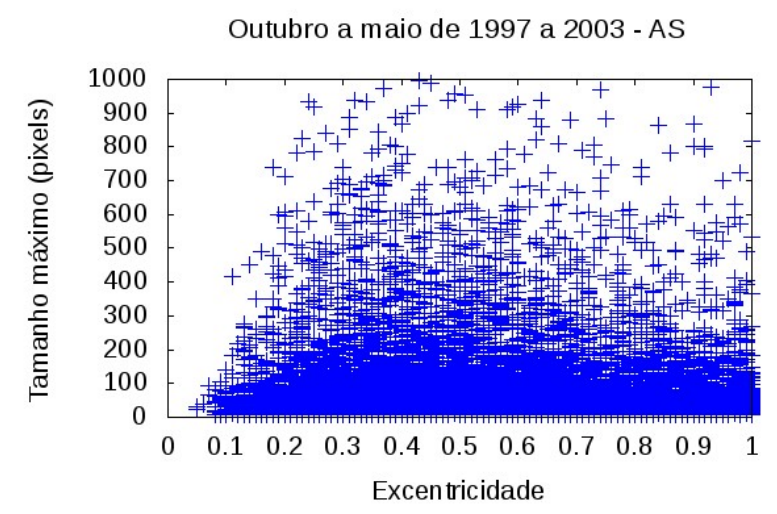

(c)

Figura 38: Relações entre a excentricidade e temperatura mínima (38a), tempo de vida (38b)

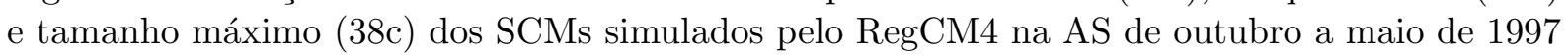
a 2003.

CCMs encontrados em cada mês. O maior número de CCMs ocorreu no mês de janeiro, semelhante a climatologia de Durkee e Mote (2010), onde o pico ocontece durante os meses de dezembro e janeiro. Nas simulações, após janeiro a frequência de CCMs diminui, apresentando número reduzido em abril e maio, também concordando com a climatologia de Durkee e Mote (2010). Segundo estes autores isso ocorre porque há forte conexão da frequência mensal dos CCMs com o ciclo de radiação sazonal, em concordância com o estudo de Laing e Fritsch (1997). Estes autores notaram evidências de que os CCMs em todo o globo possuem uma tendência a seguir o Sol, pois apresentam uma mudança de atividade de $35^{\circ} \mathrm{S}$ em janeiro, para $50^{\circ} \mathrm{N}$ no auge do verão boreal, e de volta para $35^{\circ} \mathrm{S}$ próximo a dezembro. Vale salientar que essa progressão latitudinal da atividade dos CCMs estaria relacionada com padrões de circulação de grande escala, e a migração pode variar substancialmente de uma região a outra. Por exemplo, na AS a localização dos CCMs muda menos que na América do Norte tanto devido ao arranjo fisiográfico específico 


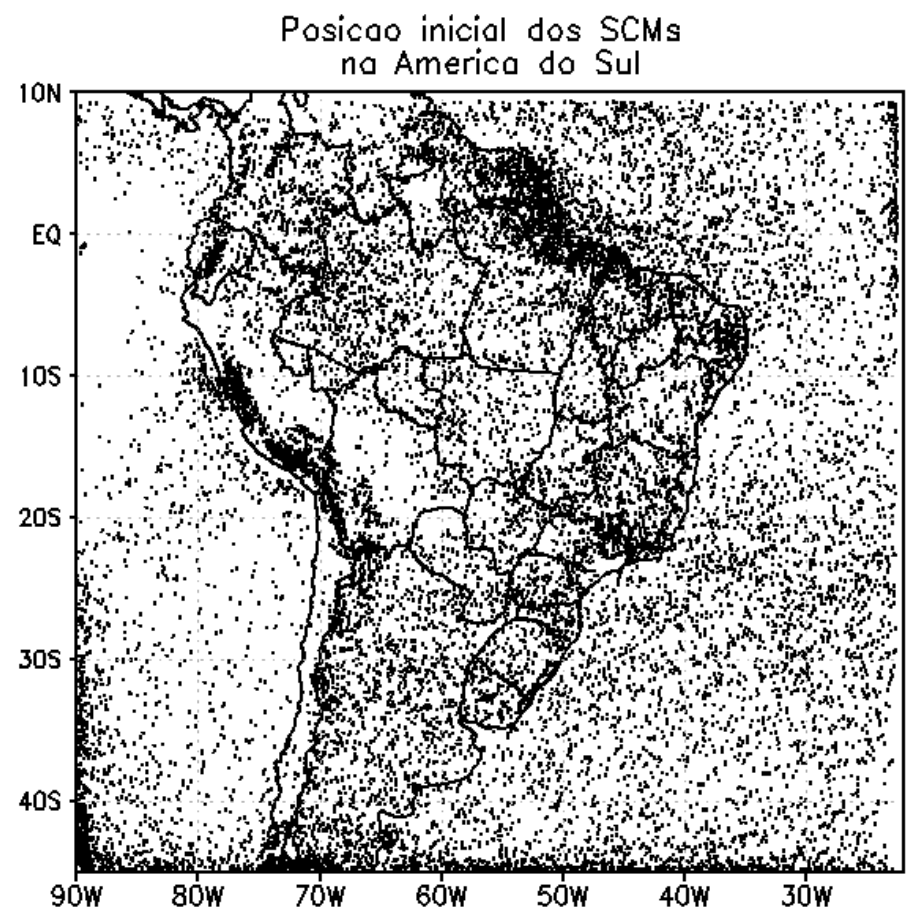

(a)

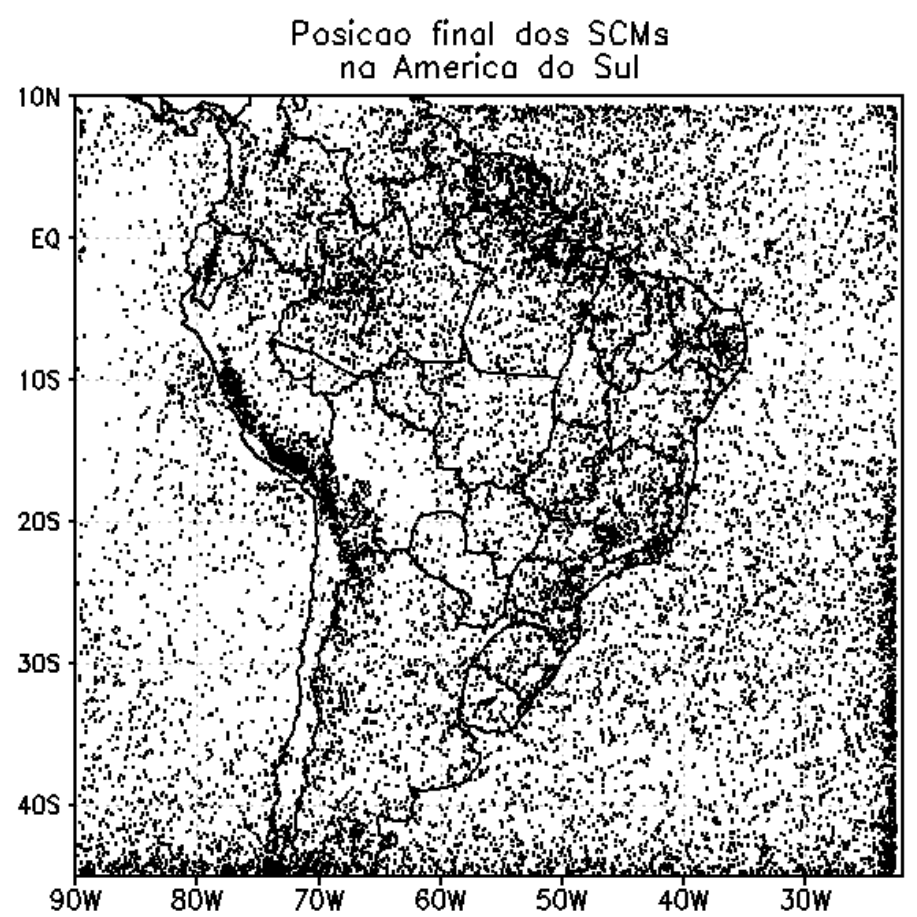

(b)

Figura 39: Posição inicial (39a) e final dos SCMs simulados pelo RegCM4 na AS (39b) de outubro a maio de 1997 a 2003.

como devido à sua interação com a corrente de jato subtropical quase-estacionária na AS (VELASCO; FRITSCH, 1987). 
O total anual de CCMs apresentou máxima frequência em 9899 e mínima no período seguinte, em 9900 (Fig. 40b). A variabilidade dos CCMs por período anual difere da climatologia de Durkee e Mote (2010) (comparando somente os períodos que são comuns). Isso indica que o RegCM4 representa melhor as variações mensais do que a variabilidade interanual dos CCMs.

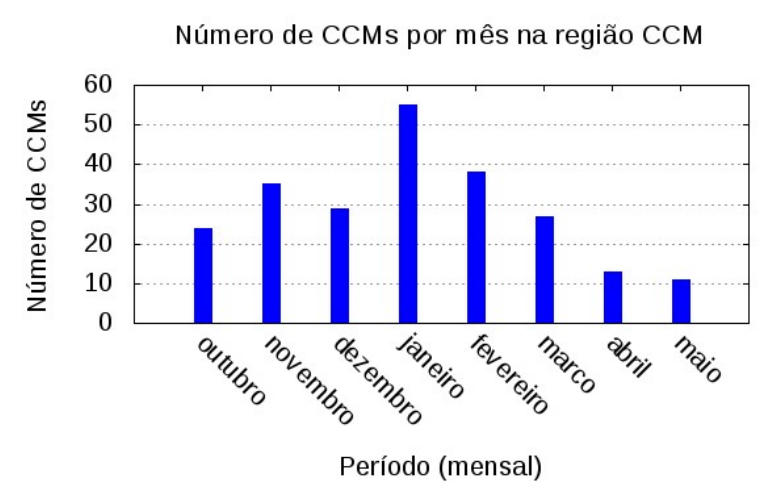

(a)

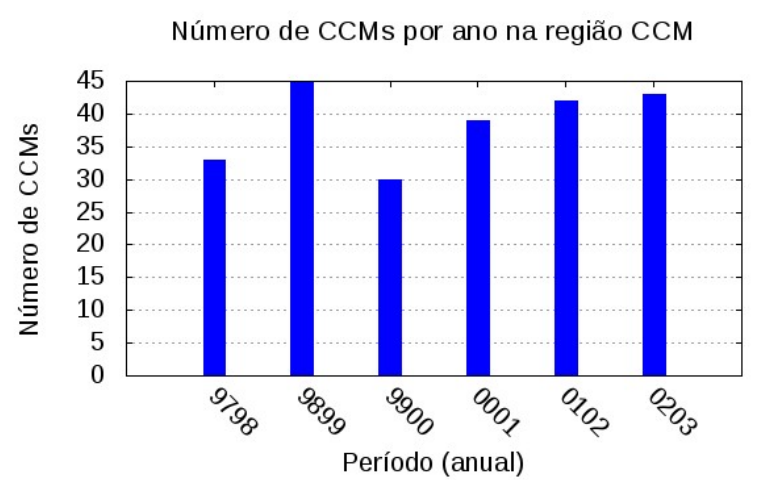

(b)

Figura 40: Número de CCMs rastreados pelo FroTraCC por mês (40a), e por período anual (40b), de outubro a maio de 1997 a 2003.

A maioria dos CCMs tem sua gênese durante a madrugada, com maior frequência de formação às 04 UTC (figura 41). A formação de CCMs durante a noite na AS ocorre como resultado da convergência noturna no vale do rio Paraná fortalecida pelo escoamento catabático dos Andes, enquanto que os CCMs cuja gênese acontece durante a tarde estão associados com o aquecimento diurno (VELASCO; FRITSCH, 1987). Segundo Cavalcanti et al. (2009), durante a noite, quando a atmosfera em baixos níveis se encontra mais estável, o fluxo de calor e umidade proveniente da região amazônica fornece condições necessárias para o crescimento desses sistemas.

O estágio de máxima extensão dos CCMs é atingido durante a manhã, com pico às 12 UTC (figura 41). Esse estágio de maturação coincide com o fim do período de máxima intensidade do JBN, entre as 06 e 12 UTC (MARENGO et al., 2004). Neste estágio os elementos convectivos intensos continuam se formando na região onde o escoamento em baixos níveis fornece combustível, muito instável, para o sistema (MADDOX, 1980).

A dissipação dos CCMs apresenta dois picos, um durante o dia e outro de noite, com máximos às 15 e 23 UTC, respectivamente. A dissipação ocorre por vários motivos, como o deslocamento do CCM para ambiente de grande escala onde o escoamento relativo muda e a convergência em baixos níveis diminui significativamente ou quando o fluxo de calor e umidade diminuem devido ao aumento dos processos turbulentos que desaceleram o 
escoamento de norte canalizado pelos Andes, interrompendo ou modificando o combustível para o sistema, entre outros fatores (MADDOX, 1980; CAVALCANTI et al., 2009).

Vários autores descrevem os CCMs com ciclo de vida preferencialmente noturno (MADDOX et al., 1982, VELASCO; FRITSCH, 1987, LAING; FRITSCH, 1997, LAING; FRITSCH, 1993a, LAING; FRITSCH, 1993b, FIGUEIREDO; SCOLAR, 1996, ASHLEY et al., 2003, DURKEE; MOTE, 2010, BLAMEY; REASON, 2012) e a versão 3 do RegCM também simulou essa característica noturna dos CCMs (GOMES, 2007). Os picos horários de início, máxima extensão e dissipação desses autores apresentam diferenças em algumas horas devido as diferentes regiões estudadas e/ou às diferenças nos intervalos de tempo entre imagens de satélite, como por exemplo, na climatologia de Durkee e Mote (2010), onde esse intervalo é de 3 horas, enquanto nas simulações do RegCM4 é de apenas 1 hora. Embora existam algumas diferenças horárias, o RegCM4 também simulou o padrão característico do ciclo de vida noturno dos CCMs.

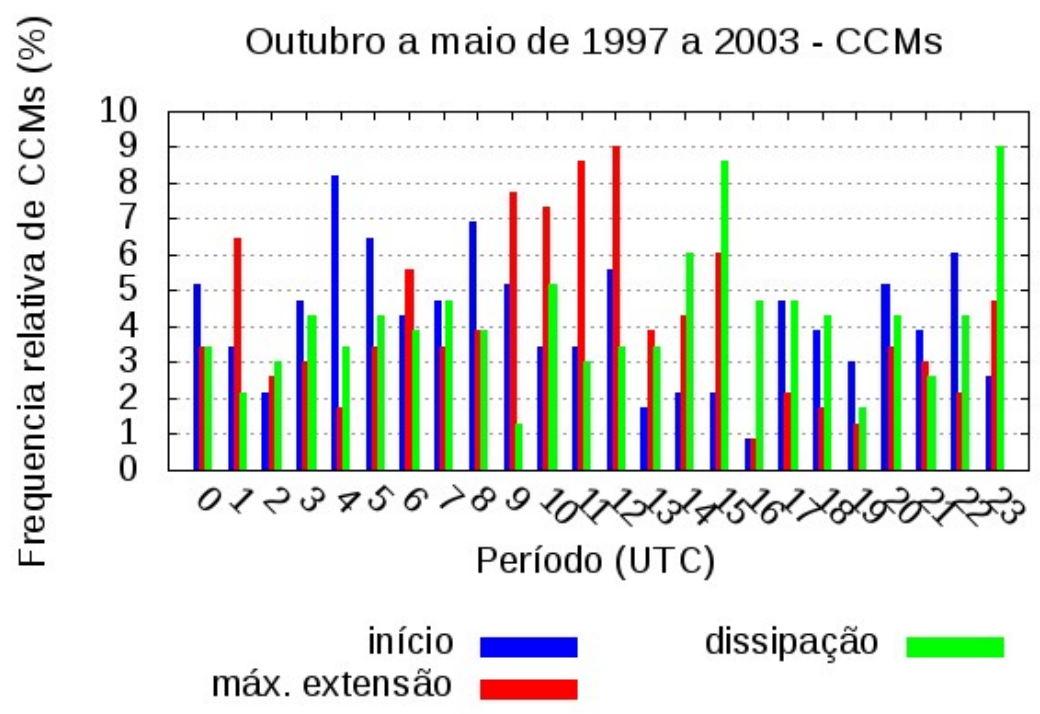

(a)

Figura 41: Distribuição de frequência dos horários de início (azul), máxima extensão (vermelho) e dissipação (verde) dos CCMs, de outubro a maio, de 1997 a 2003.

\subsubsection{Características morfológicas dos CCMs}

Nesta seção serão analisadas a distribuição de frequência das características morfológicas (tempo de vida, tamanho máximo, excentricidade no momento de máxima extensão e temperatura mínima) dos CCMs simulados pelo RegCM4 e rastreados pelo ForTraCC, entre outubro e maio de 1997 a 2003.

A figura $\underline{42}$ apresenta o tempo de vida dos CCMs, com média de 16,5 horas e desvio 
padrão também de 16,5 horas, o que mostra grande variabilidade de tempo de vida dos CCMs simulados, além de possuírem maior longevidade do que os da climatologia de Durkee e Mote (2010) e o estudo de Velasco e Fritsch (1987), cujas médias são de 14 e 11,5 horas, respectivamente. Esse tempo de vida médio maior dos CCMs simulados pode estar associado ao fato de que estes autores usaram o critério da região mais fria do CCM com $-52^{\circ} \mathrm{C}$ e $-64^{\circ} \mathrm{C}$, respectivamente, ou seja, os sistemas possuem topos mais frios e então menor duração do que sistemas com topo mais quente rastreados nesse trabalho (limiar de $\left.-32^{\circ} \mathrm{C}\right)$.

Os CCMs simulados apresentam um decréscimo aproximadamente logarítmico do tempo de vida, assim como os SCMs tropicais e subtropicais (figura 19), mas possuem tempo de vida médio maior que os SCMs. Grande parte dos CCMs tem tempo de vida

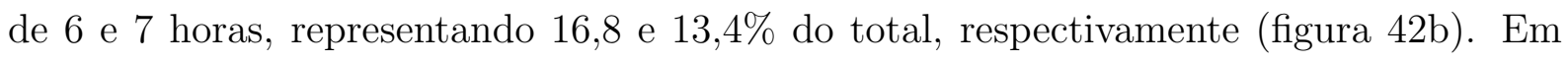
torno de 55\% dos CCMs têm tempo de vida menor ou igual a 11 horas, aproximadamente 95\% duram até 49 horas e uma minoria chega a atingir 99 horas de tempo de vida (1,3\%). Isso mostra que quanto maior o tempo de vida do CCM, menor o número de sistemas encontrados, padrão semelhante ao observado por Velasco e Fritsch (1987) e Laing e Fritsch (1997), onde os CCMs apresentam curva aproximadamente log normal com a frequência inversamente proporcional ao tempo de vida. Segundo Velasco e Fritsch (1987) CCMs com até 6 horas de duração seriam reflexo de um forte ciclo de aquecimento diurno de radiação, enquanto que sistemas mais longos ocorrem devido a um ambiente em grande escala favorável.

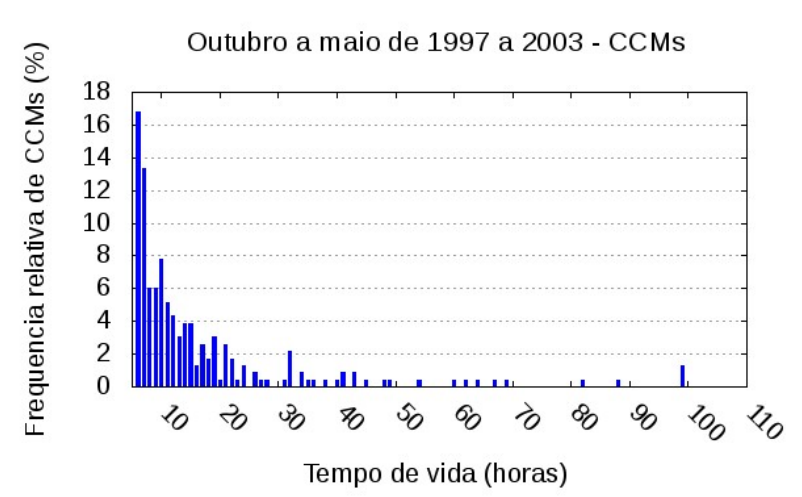

(a)

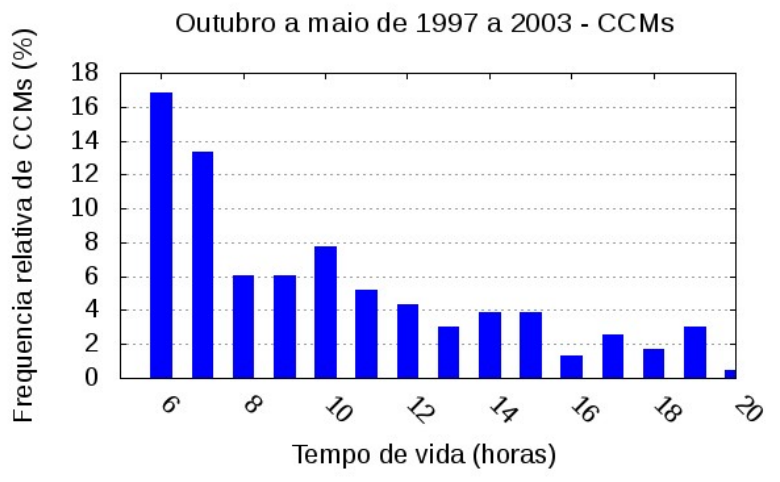

(b)

Figura 42: Distribuição de frequência do tempo de vida dos CCMs (42a), e uma ampliação do intervalo entre 6 e 20 horas de duração $(\underline{42 \mathrm{~b}})$, simulados pelo RegCM $\overline{4}$ entre outubro e maio de 1997 a 2003.

Com relação ao tamanho no momento de máxima extensão, a maioria dos CCMs 
simulados pelo RegCM4 possui tamanhos menores (figura 43a), onde 57,3\% dos CCMs têm até 200 pixels de tamanho máximo (figura 43b). A frequência dos CCMs, com agrupamento a cada 25 pixels, mostra de forma mais evidente uma curva log normal (figura 43b) sendo a frequência inversamente proporcional ao tamanho do CCM como em Velasco e Fritsch (1987) e Laing e Fritsch (1997). Há raros CCMs simulados (0,4\%) que atingiram tamanhos de até 950 pixels $\left(2.375 .000 \mathrm{~km}^{2}\right)$, embora esse tamanho seja extremamente grande, há relatos de CCMs observados com área de até 3.491 .000 km² (FIGUEIREDO; SCOLAR, 1996).

Os CCMs simulados apresentaram tamanho médio e tamanho médio no momento de máxima extensão de 141,76 $\left(354.400 \mathrm{~km}^{2}\right)$ e 245,85 $\left(614.625 \mathrm{~km}^{2}\right)$ pixels, com desvio padrão de 101,97 e 194,98 pixels, respectivamente. Nos estudos de Velasco e Fritsch (1987) e Durkee e Mote (2010) os valores de tamanho médio no momento de máxima extensão foram de $500.000 \mathrm{~km}^{2}$ e $256.500 \mathrm{~km}^{2}$, utilizando os limiares de temperatura de brilho de $-40^{\circ} \mathrm{C}$ e $-52^{\circ} \mathrm{C}$, respectivamente, indicando que diferenças nos limiares de temperatura influenciam diretamente os resultados obtidos, de modo que quanto menor a temperatura mínima utilizada, menor será o tamanho médio no momento de máxima extensão dos sistemas. Os resultados da simulação do RegCM4 mostraram média maior em virtude de utilizar o limiar de temperatura de topo de nuvem mais quente $\left(-32^{\circ} \mathrm{C}\right)$.

Segundo Laing e Fritsch (1997) os CCMs em todo o globo possuem tamanhos entre 200.000 e $400.000 \mathrm{~km}^{2}$, com média global de $354.000 \mathrm{~km}^{2}$, o que também mostra uma variação de tamanho em função da região de estudo. Os CCMs no AS, por exemplo, podem ser até $60 \%$ maiores que os dos Estados Unidos da América, para um mesmo limiar de temperatura, isso porque na AS subtropical a tropopausa é extremamente alta, em torno de $100 \mathrm{hPa}$, durante os meses de verão (VELASCO; NECCO, 1981 apud VELASCO; FRITSCH, 1987).

Embora os CCMs tenham sido filtrados com limiar de temperatura mínima de topo de nuvem de 226 K, o máximo de frequência de CCMs (praticamente um terço deles - 29,74\%) apresenta temperatura mínima de $224 \mathrm{~K}$ (figura $\underline{44 \mathrm{~b}}$ ). Para valores mais frios notase um decréscimo grande no número de CCMs, onde uma porcentagem muito pequena apresenta temperatura mínima de $222 \mathrm{~K}$ (0,86\% - apenas 2 CCMs). Esse limiar mínimo de temperatura que os CCMs simulados atingem é mais quente do que o limiar de 221 K utilizado para classificar o núcleo dos CCMs por Maddox (1980). Como mencionado para os SCMs, o RegCM4 não simula topos de nuvens muito frios devido ao esquema de convecção de cumulus adotado. 


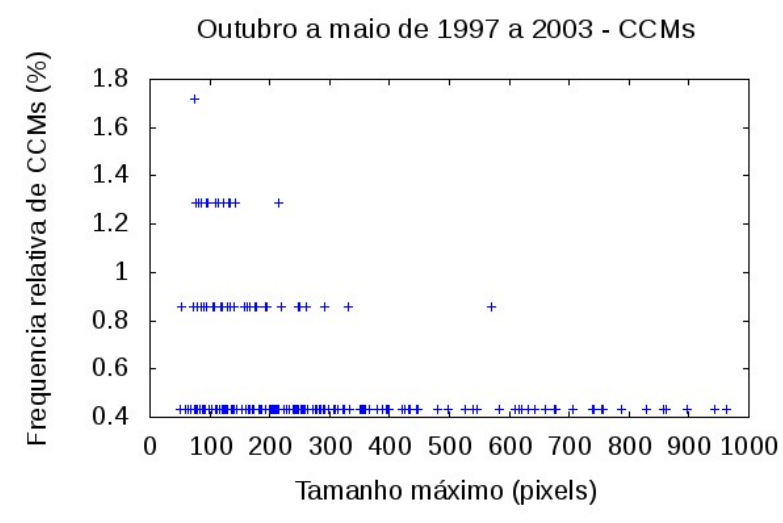

(a)

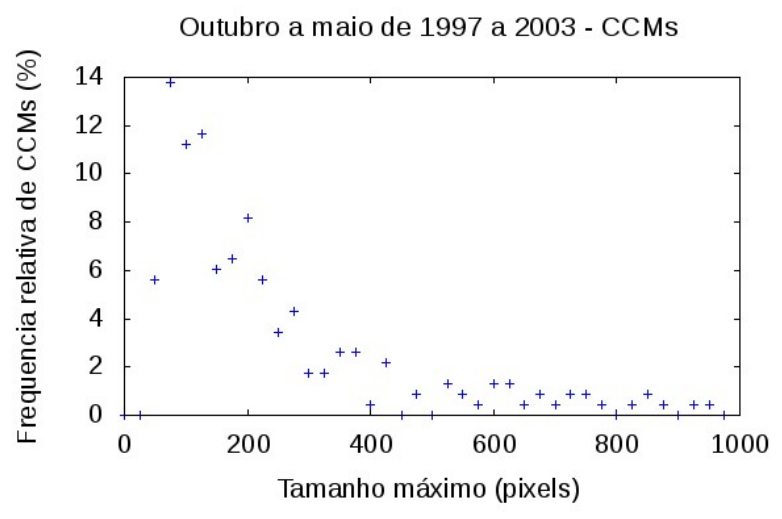

(b)

Figura 43: Distribuição de frequência do tamanho máximo dos CCMs (43a) e um agrupamento a cada 25 pixels (43b), simulados pelo RegCM4 de outubro a maio de $\overline{1997}$ a 2003.

Diferente da temperatura mínima, o limiar de excentricidade utilizado como um dos critério pra classificar CCMs (0,7 no momento de máxima extensão), é o limiar com maior frequência de CCMs, ou seja, com 41,8\% dos sistemas. A frequência de CCMs diminui com o aumento da excentricidade, onde, assim como para a temperatura mínima, somente dois sistemas apresentaram excentricidade de 1,0 no momento de máxima extensão, ou seja, CCMs circulares são mais raros de se formarem do que os quase-circulares. O que pode ser devido às condições necessárias para o sistema ter formato circular serem mais difícil de se obter na atmosfera e, consequentemente, de serem simuladas pelo modelo, como circulações de mesoescala geradas convectivamente (MADDOX, 1980), fluxo vertical de massa dominante sobre a deformação e o cisalhamento horizontal de grande escala (advecção de vorticidade é frequentemente fraca e a advecção térmica em baixos níveis é forte - VELASCO; FRITSCH, 1987) e a existência de regiões de vorticidade ciclônica em baixos níveis e anticiclônica em altos níveis (DA ROCHA, 1992).

A relação do tempo de vida dos CCMs com tamanho máximo (figura 45a) mantém os mesmos padrões dos SCMs tropicais e subtropicais (figura 23). Há uma tendência de que quanto mais duradouro o CCM maior será o seu tamanho no momento de máxima extensão, e isto está de acordo com o comportamento dos CCMs na climatologia de Durkee e Mote (2010) na AS e também com os observados por Laing e Fritsch (1997) em todo o globo. A relação do tempo de vida dos CCMs com sua temperatura mínima (figura $\underline{45 b}$ ) também é similar ao padrão encontrado nos SCMs tropicais e subtropicais (figura 24 ), mostrando que com a redução da temperatura mínima os CCMs tendem a ter tempo de vida mais longo.

A relação entre tamanho máximo e temperatura mínima de topo de nuvem dos CCMs 


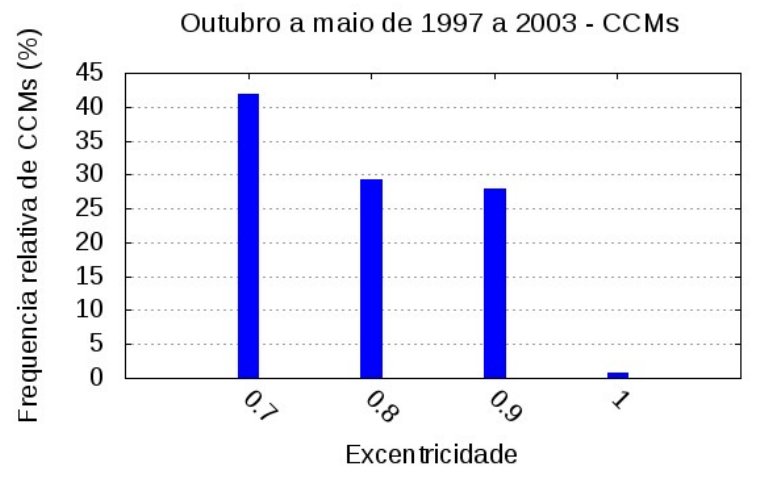

(a)

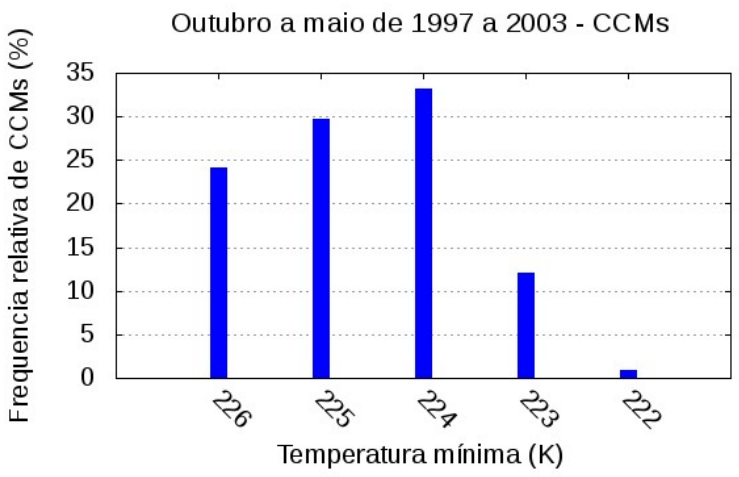

(b)

Figura 44: Distribuição de frequência de excentricidade no momento de máxima extensão(44a) e de temperatura mínima (44b) dos CCMs simulados pelo RegCM4, de outubro a maio de $\overline{1997}$ a 2003 .

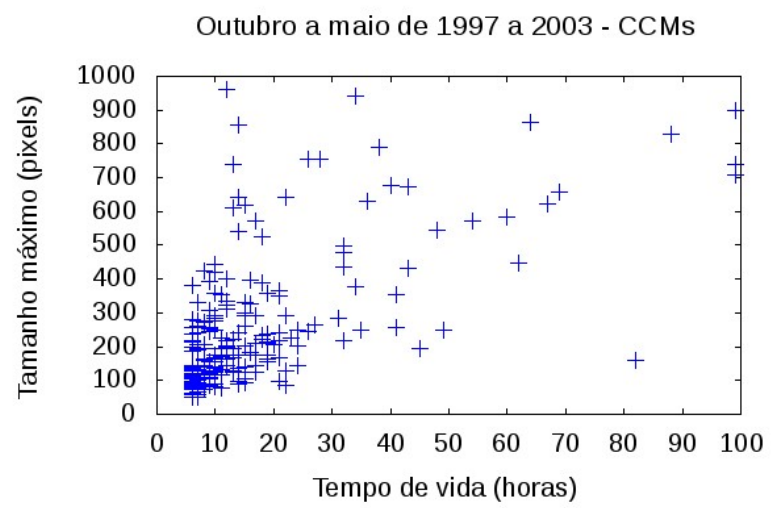

(a)

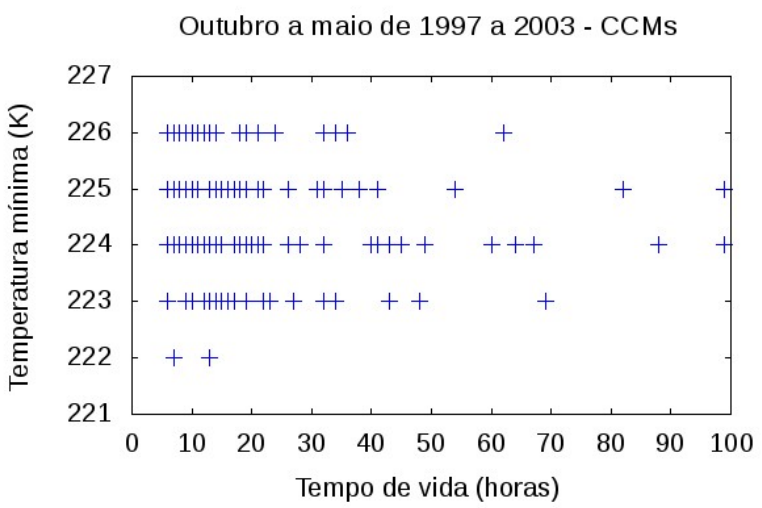

(b)

Figura 45: Relações do tempo de vida dos CCMs simulados pelo RegCM4 com seu tamanho máximo (45a) e sua temperatura mínima (45b), de outubro a maio, de 1997 a 2003.

(figura 46a) apresenta leve decréscimo na temperatura mínima com o aumento do tamanho máximo, mas que é menos evidente do que nos SCMs (figura 25). Isto sugere que o modelo conceitual de Machado e Rossow (1993) de que durante a etapa de formação, o sistema primeiro se resfria para em seguida se expandir até a etapa de máxima extensão, também se aplica aos CCMs simulados pelo RegCM4, mas de forma menos evidente do que nos SCMs. Isso pode indicar também que assim como para os SCMs de forma geral o máximo de precipitação ocorre após o mínimo de temperatura devido à forte corrente ascendente, e em seguida o CCMs atinge sua máxima extensão (GOYENS et al., 2011).

A excentricidade dos CCMs no momento de máxima extensão não apresenta nenhuma correlação com o seu tamanho máximo (figura 46b), temperatura mínima (figura 47a) e tempo de vida (figura 47b), assim como para os SCMs (figuras 28, 27 e 26, respectiva- 
mente). Isto enfatiza que no RegCM4 a forma do sistema não influencia claramente no tamanho máximo, na temperatura mínima ou no tempo de vida. Essas variáveis também não interferem diretamente na forma dos CCMs, pois o formato quase-circular desses sistemas ocorre devido às circulações de mesoescala geradas convectivamente (MADDOX, 1980), fluxo vertical de massa dominante sobre a deformação e o cisalhamento horizontal de grande escala (VELASCO; FRITSCH, 1987) e a existência de regiões de vorticidade ciclônica em baixos níveis e anticiclônica em altos níveis (DA ROCHA, 1992).

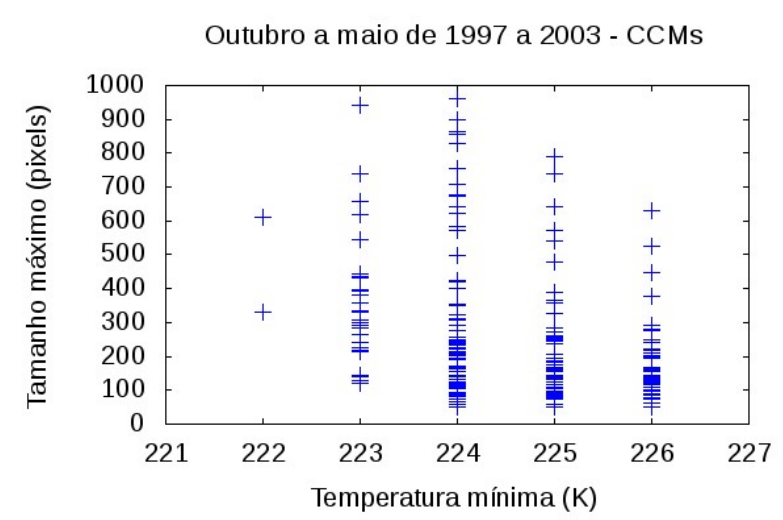

(a)

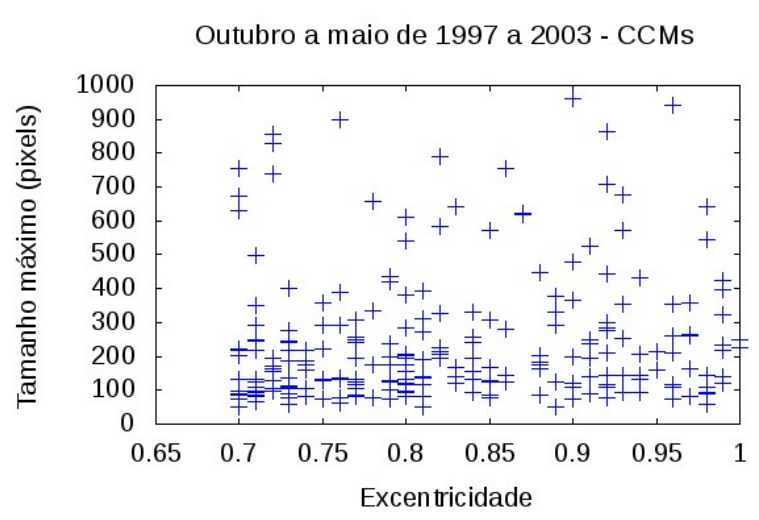

(b)

Figura 46: Relações do tamanho máximo dos CCMs com sua temperatura mínima (46a) e sua excentricidade (46b), simulados pelo RegCM4 de outubro a maio de 1997 a 2003.

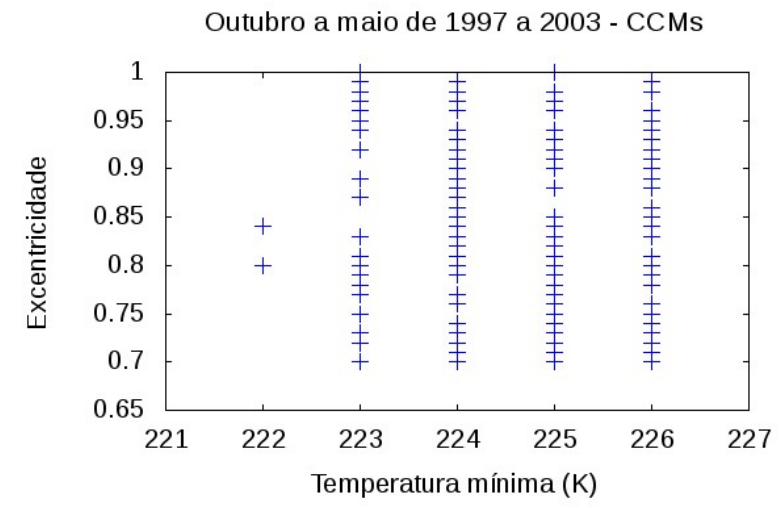

(a)

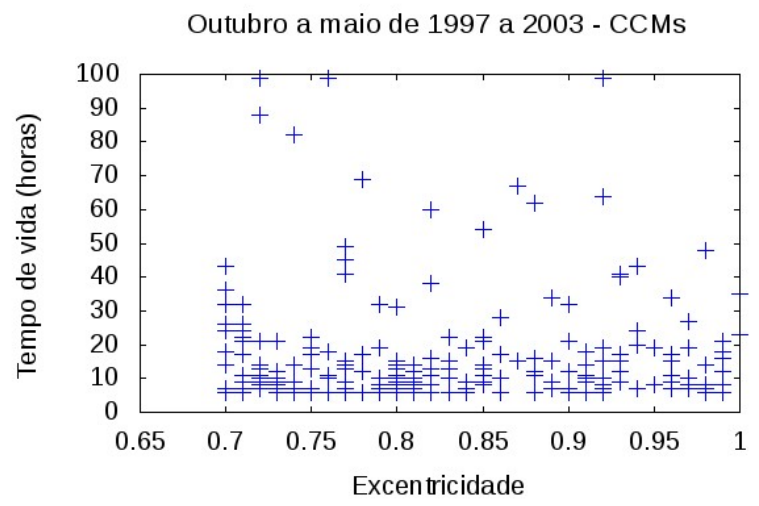

(b)

Figura 47: Relações entre a excentricidade no momento de máxima extensão dos CCMs e sua temperatura mínima (47a) e seu tempo de vida (47b) , simulados pelo RegCM4 de outubro a maio de 1997 a 2003.

\subsubsection{Características cinemáticas dos CCMs}

Esta seção apresenta as características cinemáticas dos CCMs rastreados pelo ForTraCC nas simulações do RegCM4, de outubro a maio de 1997 a 2003. Características 
cinemáticas são posição inicial, de máxima extensão e dissipação dos CCMs, bem como suas trajetórias de deslocamento (em linha reta) desde a posição inicial até a dissipação.

O RegCM4 simula uma das características principais dos CCMs, a de que eles são um fenômeno preferencialmente continental (LAING; FRITSCH, 1997). Esta característica é apresentada na figura $\underline{48}$, onde a maioria dos CCMs situa-se sobre o continente, independente da fase de seu ciclo de vida. Os CCMs com gênese no oceano ocorrem próximo à costa. Os locais com maior densidade de CCMs são a parte centro norte da Argentina, sul e sudeste do Brasil e sul do Peru. No RegCM4 a posição inicial dos CCMs ocorre mais a leste do que o encontrado por Velasco e Fritsch (1987), Figueiredo e Scolar (1996) e Durkee e Mote (2010).

Embora os CCMs simulados no Peru não apareçam na climatologia de Durkee e Mote (2010), eles são vistos em Velasco e Fritsch (1987), porém em menor quantidade, o que estaria associado às diferenças no período e limiares de temperatura mínima utilizados. O sul do Peru é uma região com convecção intensa, como mostra a chuva presente na climatologia do TRMM (figura $\underline{8 c}$ ), e essa convecção é simulada adequadamente pelo RegCM4 (figura 8a). A máxima extensão dos CCMs (figura $\underline{48 b}$ ) e a dissipação (figura 48c) ocorrem nas mesmas regiões de gênese, indicando que a maioria dos CCMs apresenta curtos deslocamentos efetivos. Isto pode ser observado nas trajetórias que, em sua maioria, são de distâncias curtas (figuras $\underline{49}$ e $\underline{50}$ ). Isso ocorre devido à maior parte dos CCMs possuírem tempo de vida pequeno (figura $\underline{42 \mathrm{a}}$.

Os CCMs apresentam trajetórias com forte componente zonal, de oeste para leste (figuras 49 e 50), como encontrado em $70 \%$ dos CCMs estudados por Figueiredo e Scolar (1996). Blamey e Reason (2012) encontraram uma tendência dos sistemas moverem-se para leste em direção às altas temperaturas potenciais equivalentes do ar associadas às águas mais quentes. Os CCMs com maiores deslocamentos (trajetória maior) são os que se formam na Argentina, principalmente no mês de dezembro (figura 49c) e maio (figura 50d). No mês de janeiro (figura 49d), onde há maior formação de CCMs (figura 40a), os sistemas apresentam trajetórias mais curtas que nos demais meses.

Os CCMs do setor nordeste da região estudada movem-se mais lentamente (trajetórias mais curtas - figuras $\underline{49}$ e 50) do que os do sul. Segundo Blamey e Reason (2012) isso seria devido a ausência do escoamento de oeste em médios níveis nas latitudes mais baixas. Os CCMs simulados também concentram-se mais ao sul no outono do que no verão, como os CCMs observados por Durkee e Mote (2010), devido ao ciclo sazonal de radiação (LAING; FRITSCH, 1997). 


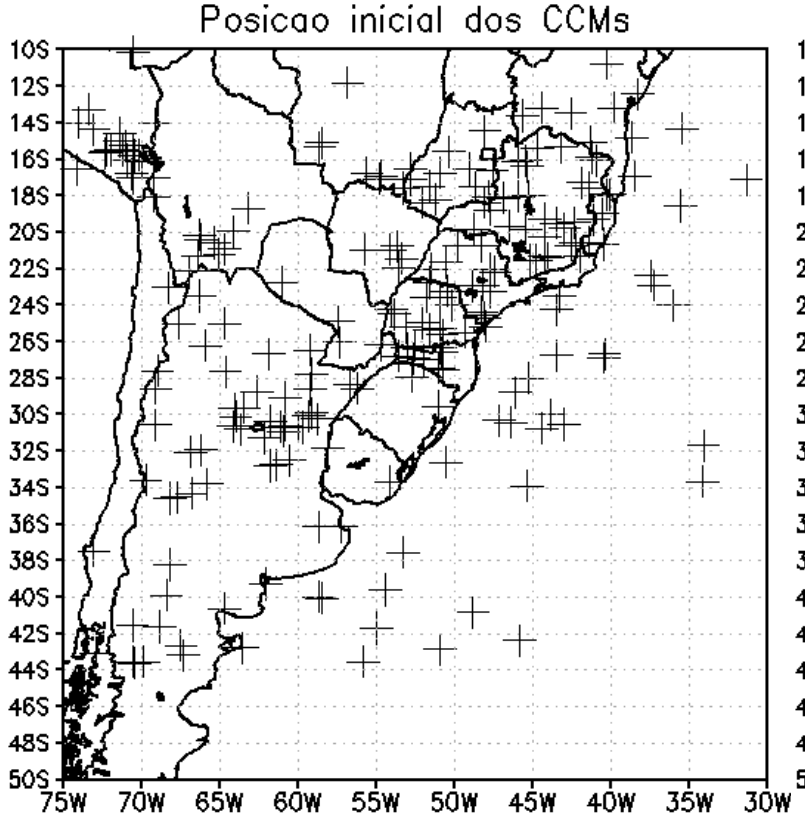

(a)
Posicao de maxima extensao dos CCMs

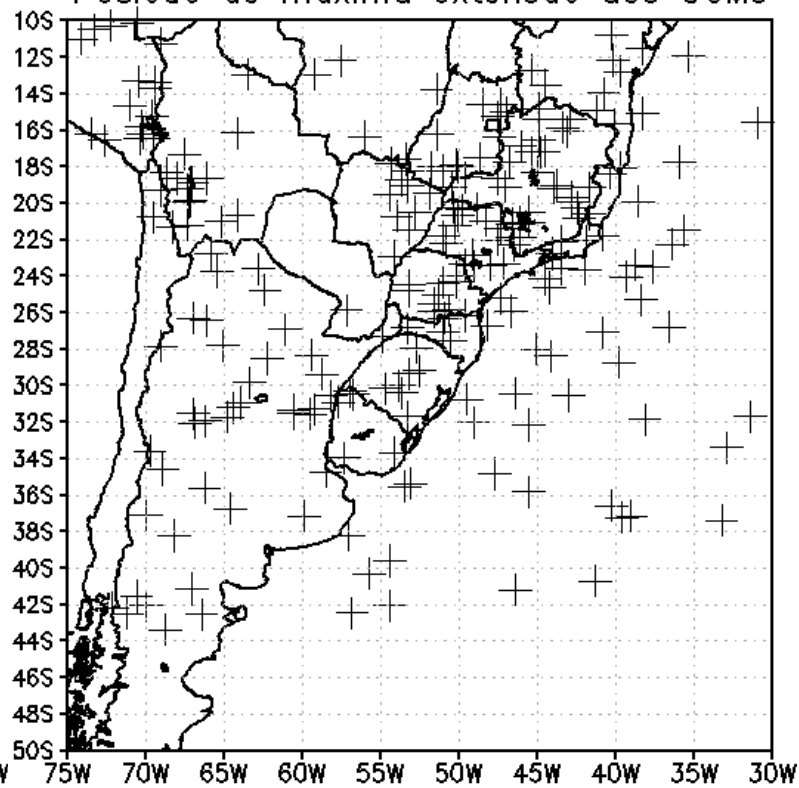

(b)

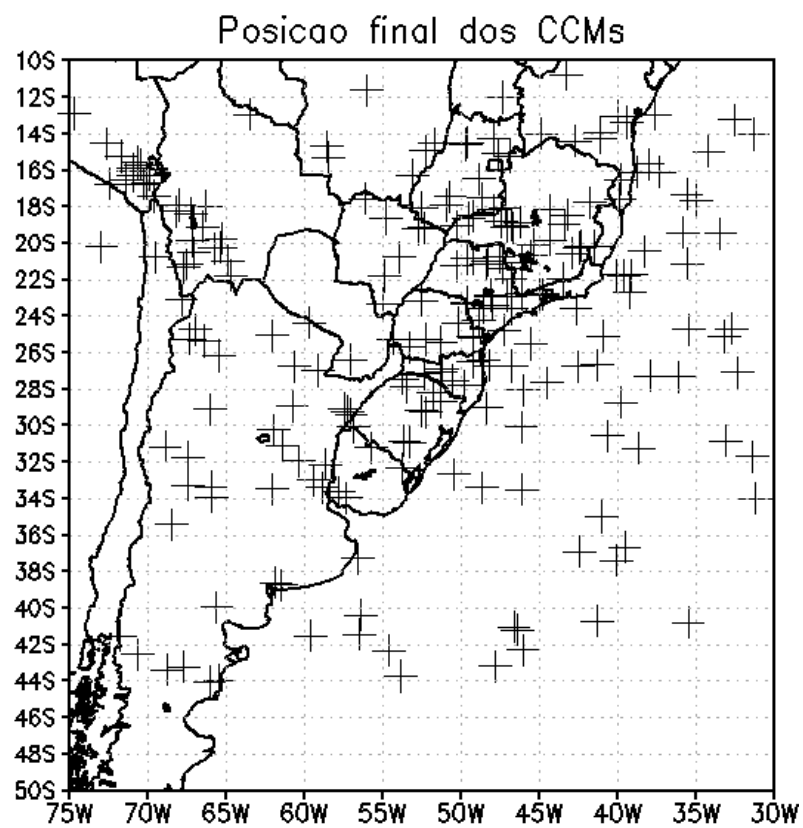

(c)

Figura 48: Posição do centro geométrico dos CCMs simulados pelo RegCM4 no momento de início (48a), máxima extensão (48b) e dissipação (48c) do sistema. 


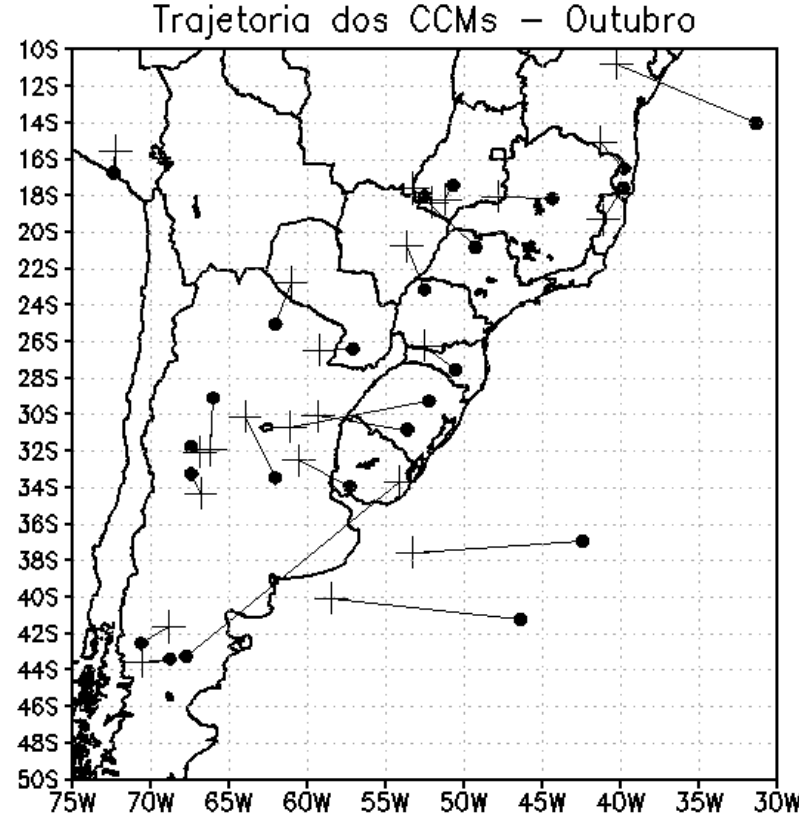

(a)

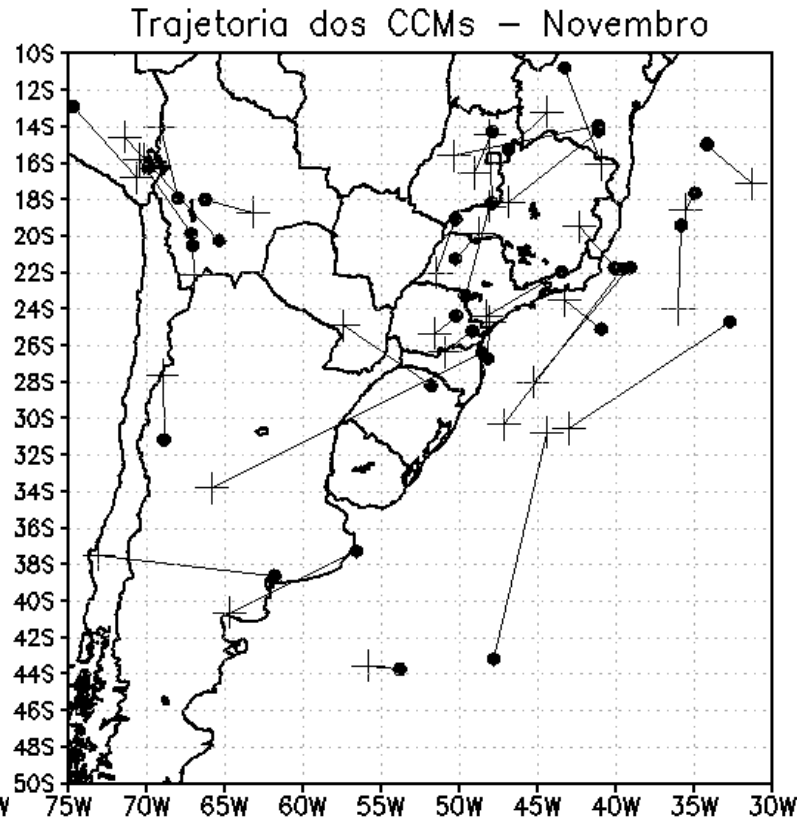

(b)

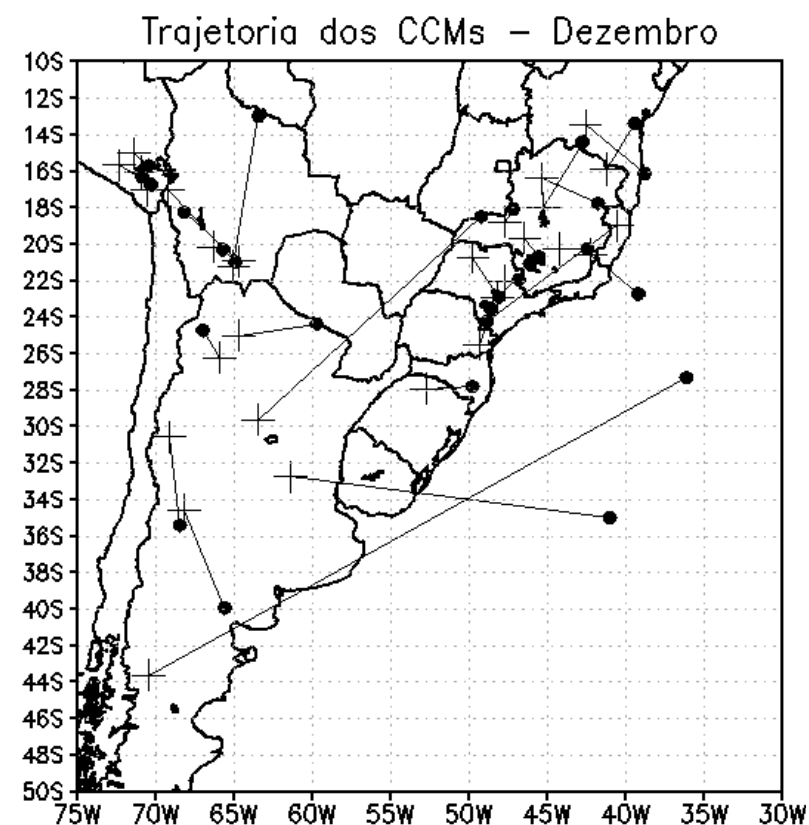

(c)

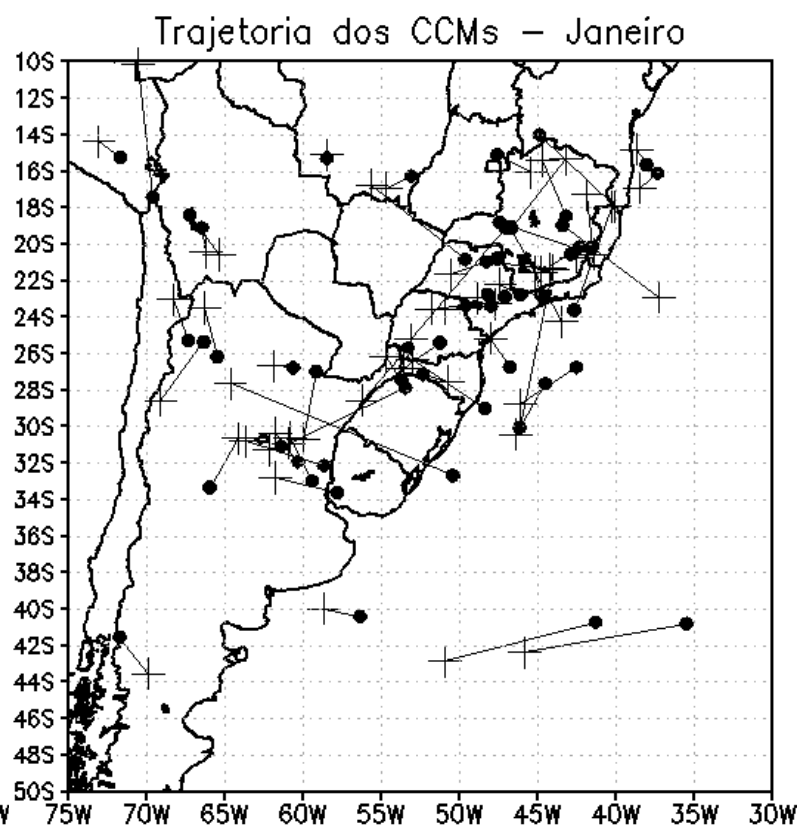

(d)

Figura 49: Trajetória (em linha reta) dos CCMs simulados pelo RegCM4 em outubro (49a), novembro (49b), dezembro (49c) e janeiro (49d) de 1997 a 2003. O sinal " +"representa a posição inicial e o ponto a posição final do CCM. 


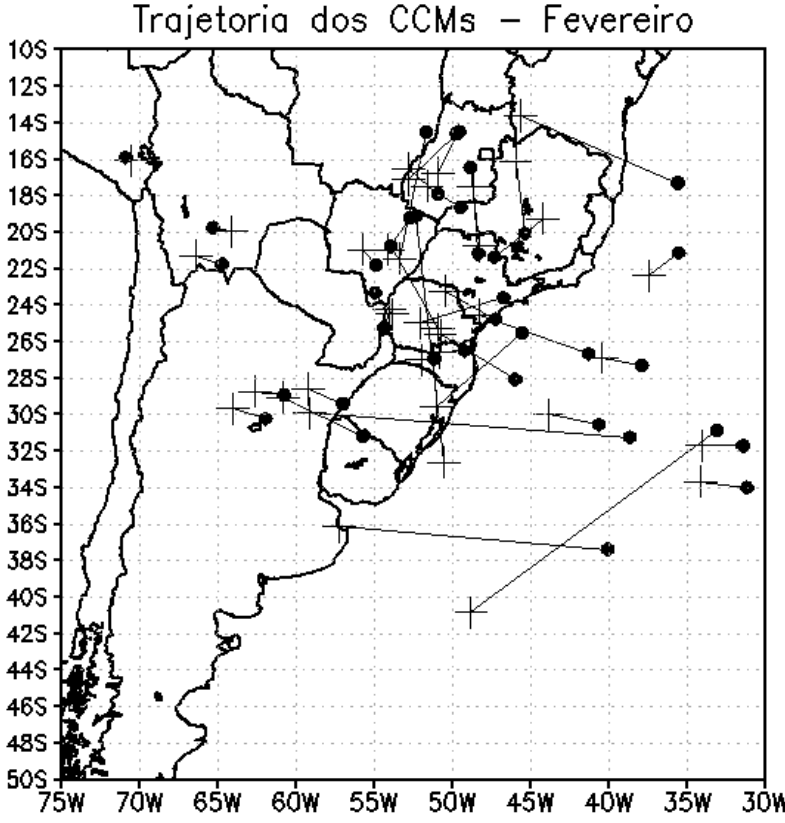

(a)

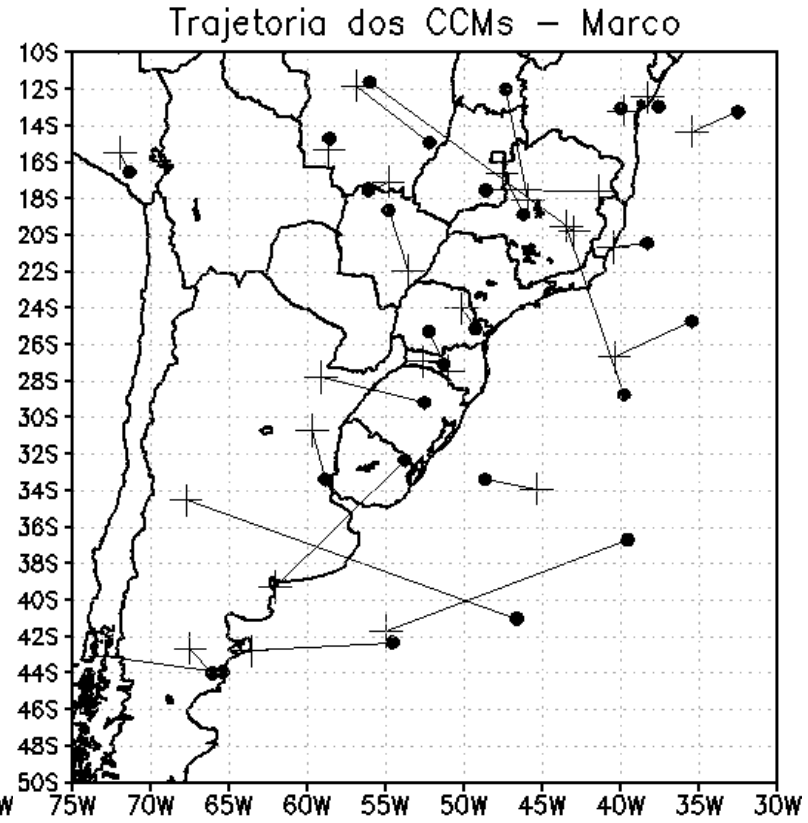

(b)

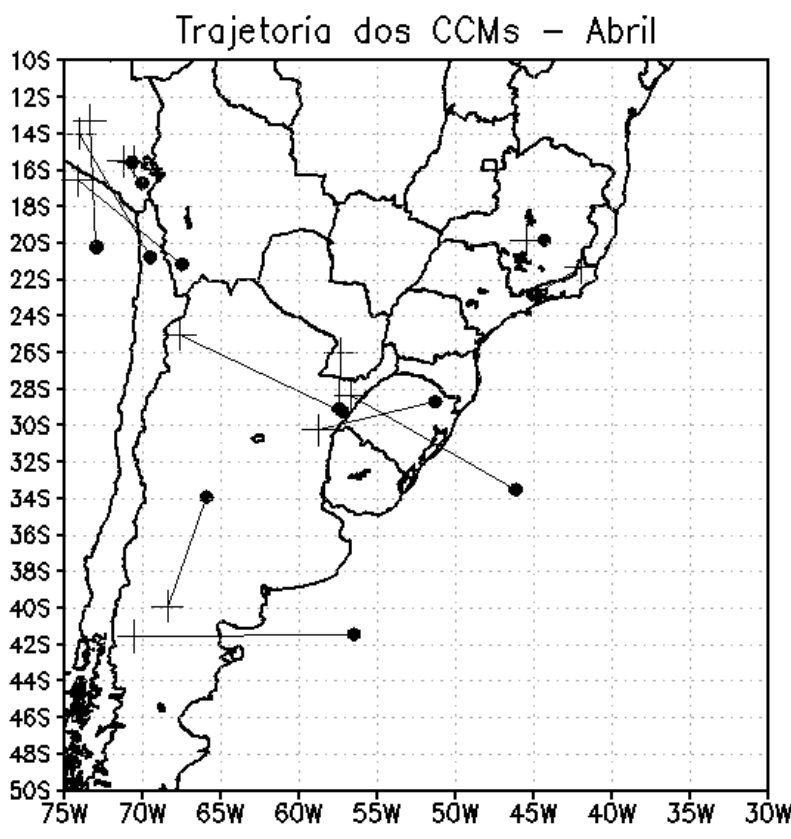

(c)

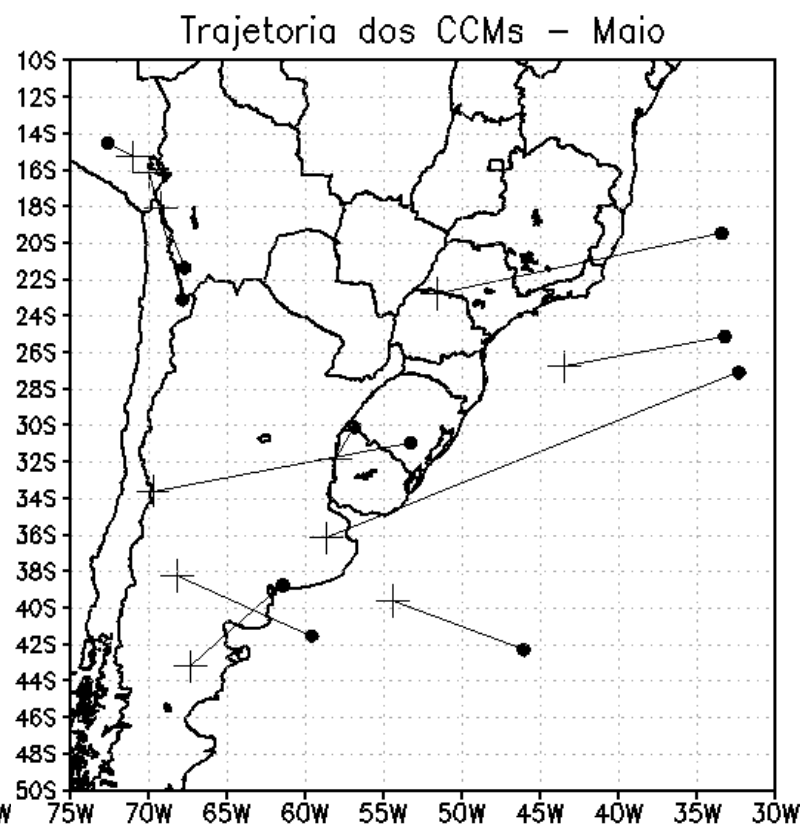

(d)

Figura 50: O mesmo que na figura 49, mas para os meses de fevereiro (50a), março (50b), abril (50c) e maio (50d). 


\section{SUMÁRIO E CONCLUSÕES}

Neste trabalho o ForTraCC foi adaptado para rastrear SCMs nas simulações do RegCM4. A validação desta adaptação indicou que o ForTraCC rastrea corretamente os SCMs. Entre os dois exemplos utilizados para validar o ForTraCC, o SCM com fusão e divisão durante o seu ciclo de vida, apresentou tempo de vida e consequente trajetória maiores, tamanhos máximo e médio maiores e menor temperatura mínima, já que a fusão atuou intensificando o sistema.

Entre outubro-maio de 1997 a 2003, a precipitação média diária simulada pelo RegCM4 apresenta máximos na costa leste da AS, desde o sul até o nordeste do Brasil, que não estão presentes nas análises do CMAP e TRMM. Adicionalmente, o padrão de chuva característico de ZCAS não está devidamente definido na simulação. O máximo de precipitação na Amazônia está deslocado para leste, com chuvas mais intensas na costa norte do Brasil, devido à combinação dos esquemas Grell e Emanuel. Isto resulta principalmente do esquema de Emanuel utilizado sobre o oceano que em geral superestima a chuva (PAL et al., 2007). No entanto, na região subtropical a chuva simulada se assemelha às observações do CMAP, exceto pela maior taxa de precipitação no Paraná e Santa Catarina, que é mais próxima ao TRMM. Esta maior taxa de chuva pode estar relacionada aos SCMs e ao efeito orográfico da Serra do Mar.

A ROLE simulada pelo RegCM4 na região tropical é mais alta do que no NCEP, devido à combinação dos esquemas de convecção de cumulus Grell e Emanuel que induzem "nuvens" com topo não muito altos e, portanto, a ROLE é mais alta do que se esperaria para a convecção profunda. Todavia na região subtropical a ROLE é próxima dos valores do NCEP. O RegCM4 simula a distribuição da umidade específica na região subtropical similar à ERA-Interim, mas nos trópicos apresenta problemas semelhantes aos da precipitação.

Em 200 hPa a AB simulada pelo RegCM4 tem posição semelhante à da ERA-Interim enquanto que o cavado do nordeste tem orientação mais meridional e o JAN está deslocado 
para sudeste, mas apresenta mesma intensidade da ERA-Interim. Em 850 hPa o RegCM4 simula os anticiclones subtropicais do Atlântico e Pacífico com maior intensidade que na ERA-Interim, mas representa corretamente a circulação nos subtrópicos da AS. Tanto o escoamento como a temperatura em $850 \mathrm{hPa}$ apresentam padrões semelhantes à ERAInterim, embora os alísios de sudeste no Atlântico e norte/nordeste do Brasil sejam mais intensos no RegCM4. De modo geral o RegCM4 representa as principais características de circulação e termodinâmica da região subtropical da AS no período de estudo.

O ForTraCC rastreou SCMs e CCMs nas simulações de ROLE do RegCM4, de outubro a maio de 1997 a 2003, e encontrou 686, 687 e 22701 SCMs na AMZ, BP e em toda AS respectivamente, e 232 CCMs em região similar aonde Durkee e Mote (2010) apresentaram uma climatologia de CCMs. Embora o RegCM4 tenha simulado praticamente a mesma quantidade de SCMs na AMZ e BP, as características desses sistemas são diferentes.

O mês com maior frequência de SCMs na AMZ, BP e AS é novembro, janeiro-fevereiro, e janeiro, respectivamente, e para os CCMs também é janeiro, semelhante à climatologia de Durkee e Mote (2010). O ciclo sazonal de SCMs na BP acompanha a precipitação mensal (mm/dia) observada na Bacia do Prata por Pinto et al. (2009), indicando a influência desses sistemas na precipitação da região. Os valores máximos mensais de ocorrência de SCMs na BP podem ser favorecidos pela atividade convectiva na ZCAS, que em janeiro e fevereiro muitas vezes apresenta posicionamento mais ao sul da posição climatológica (ANDRADE, 2011), e também pela maior ocorrência de JBN. Para os SCMs da AMZ não há uma clara relação com a ZCAS, porém o máximo em novembro pode estar associado à menor ocorrência de JBN a leste dos Andes, pois os SCMs tropicais são mais frequentes durante dias sem este JBN (SALIO et al., 2007).

Os SCMs na AMZ iniciam preferencialmente às 03 UTC, máxima extensão às 06 UTC (três horas após seu início) e dissipam nas 6 horas seguintes (12 UTC). Esse intervalo de 6 horas entre máxima extensão e dissipação também foi encontrado por Salio et al. (2007). Contudo, o ciclo diurno simulado apresenta picos horários muito defasados da literatura. A diferença entre horários preferenciais de gênese e dissipação entre os sistemas simulados e observados pode estar associada a metodologia aplicada, uma vez que os SCMs simulados são rastreados a partir de um limiar de tamanho maior que os observados em imagens de satélite devido à resolução espacial do modelo ser menor. Os SCMs em toda a AS apresentam padrão semelhante ao da AMZ, pois há mais SCMs tropicais que subtropicais na $\mathrm{AS}$. Na BP o ciclo de vida dos SCMs é mais irregular que na AMZ, mas nota-se maior frequência de SCMs às 09 UTC, que coincide com o horário de maior frequência 
e intensidade do JBN (MARENGO et al., 2004), indicando o JBN como forçante mais importante do que o ciclo diurno de aquecimento.

Para os CCMs simulados a gênese ocorre durante a madrugada (pico às 04 UTC). O ciclo de vida preferencialmente noturno é uma característica dos CCMs observados descritos na literatura, que resultam da convergência noturna no vale do rio Paraná fortalecida pelo escoamento catabático dos Andes (VELASCO; FRITSCH, 1987). Os CCMs apresentaram máximo anual em 1998-1999 que difere da climatologia de Durkee e Mote (2010), indicando que o RegCM4 simula melhor a variabilidade sazonal dos CCMs do que a interanual. Os CCMs atingem máxima extensão durante a manhã (12 UTC) coincidindo com a máxima intensidade do JBN a leste dos Andes. A dissipação dos CCMs apresenta dois picos, um durante o dia e outro de noite (15 e 23 UTC) o que seria atribuido aos diferentes mecanismos, descritos por Maddox (1980), atuando na dissipação desses sistemas

O tempo de vida médio dos SCMs simulados na AMZ, BP e AS, e dos CCMs é de 8, 9.7, 13.36 e 16.5 horas. Isso indica que os CCMs tendem a durar mais que os SCMs, e os sistemas na região subtropical duram mais que nos trópicos. O tempo de vida mais longo dos CCMs ocorre devido a um ambiente em grande escala favorável (VELASCO; FRITSCH, 1987). A maioria dos SCMs possuem tamanho máximo entre 4 (critério de início) e 50 pixels, enquanto o dos CCMs variam entre 40 (critério de início) e 200 pixels, ou seja, consideravelmente maiores.

Os SCMs simulados na BP atingem tamanhos máximos extremos que podem ser até duas vezes maior que os eventos extremos tropicais, e também apresentam extremos com maior longevidade e são mais frios que na AMZ. Isso estaria associado à presença do JBN e de sistemas sinóticos, que fornecem suporte dinâmico e termodinâmico para a manutenção prolongada dos SCMs subtropicais. Os SCMs e CCMs simulados têm temperatura mínima mais quente que os observados na literatura devido ao esquema de convecção utilizado. Contudo, seguem o padrão observado de diminuir em frequência com o aumento do tempo de vida e com o aumento da área de máxima extensão.

Regionalmente SCMs não apresentam local preferencial de gênese. No entanto, em toda a AS as regiões com máximos de iniciação de SCMs são continentais e semelhantes aos máximos de precipitação nas simulações do RegCM4. As regiões preferenciais de dissipação são similares às de gênese, mostrando que não há um deslocamento muito grande desses sistemas. Na BP os SCMs apresentam trajetórias com componente para leste e consequentemente dissipam na parte leste da BP, em concordância com as observações (ROMATSCHKE; HOUZE JR, 2010). Na AMZ não há trajetória preferencial nem região 
de dissipação.

Os CCMs também são um fenômeno preferencialmente continental, com maior densidade no centro-norte da Argentina, sul e sudeste do Brasil e sul do Peru, mais a leste do que na climatologia de Durkee e Mote (2010). As regiões de máxima extensão e dissipação dos CCMs são também regiões similares às de gênese, indicando que a maioria dos CCMs simulados apresenta curtos deslocamentos efetivos, assim como os SCMs. Isto provavelmente seria explicado pelo pequeno tempo de vida da maioria desses sistemas. Os CCMs apresentam trajetórias preferencialmente zonais, de oeste para leste. Os CCMs com trajetórias maiores se formam na Argentina, enquanto os do setor nordeste da região estudada movem-se mais lentamente (trajetórias mais curtas) do que os do sul, devido a ausência do escoamento de oeste em médios níveis nas latitudes mais baixas (BLAMEY; REASON; 2012). Os CCMs simulados também concentram-se mais ao sul no outono do que no verão, como os observados por Durkee e Mote (2010), devido ao ciclo sazonal de radiação (LAING; FRITSCH, 1997).

Semelhante ao reportado na literatura os SCMs simulados são em geral pequenos e com tempo de vida curto. SCMs e CCMs duradouros e/ou grandes são menos frequentes, embora os CCMs sejam maiores e com tempo de vida mais longo que os SCMs em geral. Outras características dos SCMs e CCMs simulados similares à literatura são a correlação positiva entre tempo de vida e tamanho máximo, e negativa da temperatura mínima com o tempo de vida e com o tamanho máximo. Não foi encontrada relação evidente entre a excentricidade dos SCMs e CCMs e o seu tempo de vida, tamanho máximo e temperatura mínima, também não há estudos observacionais relacionando essas variáveis. Isso indica que a forma dos sistemas depende das circulações de mesoescala geradas convectivamente.

Muitas das diferenças entre os horários de início, máxima extensão e dissipação dos SCMs e CCMs com relação à literatura, podem resultar da metodologia utilizada. Diferentes critérios de classificação desses sistemas são utilizados por cada autor, assim como a utilização de imagens de satélite em diferentes canais e de diferentes tipos de satélite (ver tabela 1 de GOYENS et al.,2011). Assim como diferentes intervalos de tempo entre as imagens impactam nas estatísticas sobre os sistemas, como o tempo de vida, por exemplo.

Em virtude dos critérios utilizados para classificar os sistemas surge a necessidade de, em trabalhos futuros realizar simulações com resolução mais alta e esquema convectivo que simule ROLE mais baixa para poder utilizar limiares mais frios de temperatura no rastreamento de sistemas convectivos pelo ForTraCC e também efetuar testes com limiares de tamanho e temperatura diferentes. Próximos estudos podem utilizar uma simulação 
mais longa para uma climatologia mais completa e comparar com simulações para o clima futuro e também fazer composições dos sistemas rastreados com as diversas variáveis disponíveis nas simulações a fim de avaliar padrão sinótico e de mesoescala presentes nesses sistemas. 


\section{REFERÊNCIAS BIBLIOGRÁFICAS}

ALVES, L. M. Simulação da variabilidade do clima presente sobre a América do Sul utilizando um modelo climático regional. Dissertação (Mestrado) Instituto Nacional de Pesquisas Especiais, São José dos Campos, 2007.

ANABOR, V.; STENSRUD, D.; MORAES, O. de. Simulation of a serial upstreampropagating mesoscale convective system event over southeastern South America using composite initial conditions. Monthly Weather Review, v. 137, n. 7, p. 2144-2163, 2009.

ANDRADE, F. M. de. Influências remotas na previsibilidade, estrutura e ciclo de vida da Zona de Convergência do Atlântico Sul. Dissertação (Mestrado) Instituto Nacional de Pesquisas Espaciais, São José dos Campos, fevereiro 2011.

ANTHES, R. A cumulus parameterization scheme utilizing a one-dimensional cloud model. Monthly Weather Review, v. 105, p. 270-286, 1977.

ANTHES, R.; HSU, E. Y.; KUO, Y. H. Description of the penn state/ncar mesoscale model version 4 (mm4). NCAR Tech. Note, NCAR/TN-282+STR, p. 66pp, 1987.

ASHLEY, W. S.; MOTE, T. L.; DIXON, P. G.; TROTTER, S. L.; POWELL, E. J.; DURKEE, J. D.; GRUNDSTEIN, A. J. Distribuition of mesoscale convective complex rainfall in the united states. Monthly Weather Review, v. 131, p. 3003-3017, Dezembro 2003.

BERBERY, E.; BARROS, V. The hydrologic cycle of the La Plata basin in South America. Journal of Hydrometeorology, v. 3, n. 6, p. 630-645, 2002.

BLAMEY, R. C.; REASON, C. J. C. Mesoscale Convective Complexes over Southern Africa. Journal of Climate, v. 25, p. 753-766, Janeiro 2012.

CARVALHO, L.; JONES, C. A satellite method to identify structural properties of mesoscale convective systems based on the maximum spatial correlation tracking technique (mascotte). Journal of Applied Meteorology, v. 40, n. 10, p. 1683-1701, 2001.

CAVAlCANTI, I. F. de A.; FERREIRA, N. J.; SILVA, M. G. A. J. da; DIAS, M. A. F. da S. Tempo e Clima no Brasil. [S.l.]: Oficina de Textos, 2009.

COTTON, W. Storm and cloud dynamics. [S.l.]: Academic press, 2010.

DA ROCHA, R. Simulação numérica de Sistema Convectivo de Mesoescala sobre a América do Sul. Dissertação (Mestrado) - Universidade de São Paulo, 1992.

DA ROCHA, R.; MORALES, C.; CUADRA, S.; AMBRIZZI, T. Precipitation diurnal cycle and summer climatology assessment over south america: An evaluation of regional 
climate model version 3 simulations. Journal of Geophysical Research, American Geophysical Union, v. 114, n. D10, p. D10108, 2009.

DA ROCHA, R. P.; REBOITA, M. S.; CUADRA, S. V. Characterization of wet and dry spells simulated by RegCM4 over the South America. In: EGU General Assembly Conference Abstracts. [S.l.: s.n.], 2012. v. 14, p. 10962.

DEMARIA, E. M. C.; RODRIGUEZ, D. A.; EBERT, E. E.; SAliO, P.; SU, F.; VALDES, J. B. Evaluation of mesoscale convective systems in South America using multiple satellite products an an object-based approach. Journal of Geophysical Research, v. 116, 2011.

DICKINSON, R. E.; HENDERSON-SELLERS, A.; KENNEDY, P. J. Biosphereatmosphere-transfer scheme (BATS) version 1E as coupled to NCAR Community Climate Model. NCAR Tech. Note, Natl. Cent. For Atmos. Res., Boulder, Colorado., 1993.

DUQUIA, C.; SILVA DIAS, M. A. F. Complexo convectivo de mesoescala: um estudo de caso para o oeste do Rio Grande do Sul. In: Congresso Brasileiro de Meteorologia. [S.l.: s.n.], 1994. v. 8, p. 610-612.

DURKEE, J.; MOTE, T.; SHEPHERD, J. The contribution of mesoscale convective complexes to rainfall across subtropical South America. Journal of Climate, v. 22, n. 17, p. 4590-4605, 2009.

DURKEE, J. D.; MOTE, T. L. A climatology of warm-season mesoscale convective complexes in subtropical south america. Internatonal Journal of Climatology, v. 30, p. 418-431, 2010.

EICHHOLZ, C. W. Características físcias dos Sistemas Convectivos de Mesoescala que afetaram o Rio Grande do Sul no período de 2004 a 2008. Dissertação (Mestrado) — Universidade Federal de Pelotas, 2011.

EMANUEL, K. A. A scheme for representing cumulus convection in large-scale models. Journal Atmospheric Sciences, v. 48, p. 2313-2335, 1991.

FEDOROVA, N.; LEVIT, V.; CARVALHO, M. H. de. Eventos de precipitação na cidade de Pelotas - RS associados a processos e sistemas sinóticos. Revista Brasileira de Meteorologia, v. 22, n. 2, p. 134-159, 2007.

FERNANDES, D. S. Caracterização das Tempestades a partir dos canais Infravermelho e Vapor d'água do Satélite Goes 10 e 12. 144 p. Dissertação de Mestrado do Programa de Pós-Graduação em Meteorologia - Universidade de São Paulo, São Paulo, 2010.

FERREIRA, R. N.; RICKENBACH, T. M.; HERDIES, D. L.; CARVALHO, L. M. V. Variability of South American Convective Cloud Systems and Tropospheric Circulation during January-March 1998 and 1999. American Meteorological Society, v. 131, p. 961-973, May 2003.

FIGUEIREDO, J. C.; SCOLAR, J. O tempo de vida média dos sistemas convectivos de mesoescala na América do Sul. IX Congresso Brasileiro de Meteorologia, SBMET, Anais, v. 2, p. 563-566, 1996. 
FIGUEROA, S. N. Estudo dos sistemas de circulação de verão sobre a América do Sul e suas simulações com modelos numéricos. 181 p. Tese de Doutorado do Programa de Pós-Graduação em Meteorologia - Instituto Nacional de Pesquisas Especiais, São José dos Campos, 1997.

GIORGI, F.; COPPOLA, E.; SOLMON, F.; MARIOTTI, L.; SYLLA, M.; BI, X.; ELGUINDI, N.; DIRO, G.; NAIR, V.; GIULIANI, G. et al. RegCM4: Model description and preliminary tests over multiple CORDEX domains. Clim. Res, v. 52, p. 7-29, 2012.

GIORGI, F.; MARINUCCI, M.; BATES, G. Development of a second-generation regional climate model (RegCM2). Part I: Boundary-layer and radiative transfer processes.

Monthly Weather Review;(United States), v. 121, n. 10, $1993 \mathrm{a}$.

GIORGI, F.; MARINUCCI, M.; BATES, G.; De Canio, G. Development of a second-generation regional climate model (RegCM2). II: Convective processes and assimilation of lateral boundary conditions. Monthly Weather Review, American Meteorological Society, v. 121, n. 10, p. 2814-2832, 1993b.

GOMES, H. B. Modelagem climática regional dos CCMs que atinge o sul-sudeste brasileiro. Dissertação (Mestrado) — Universidade de São Paulo, 2007.

GOYEnS, C.; LAUWAET, D.; SCHRODER, M.; DEMUZERE, M.; AND, N. P. M. V. L. Tracking mesoscale convective systems in the Sahel: relation between cloud parameters and precipitation. Internatonal Journal of Climatology, 2011.

GRAY, W.; JACOBSON, R. Diurnal variation of deep cumulus convection. Monthly Weather Review, v. 105, n. 9, p. 1171-1188, 1977.

GRELL, G. A. Prognostic evaluation of assumptions useds by cumulus parameterization. Monthly Weather Review, v. 121, p. 764-787, 1993.

GRIMM, A.; FERRAZ, S.; GOMES, J. Precipitation anomalies in southern Brazil associated with El Niño and La Niña events. Journal of Climate, v. 11, n. 11, p. 2863-2880, 1998a.

GRIMM, A.; ZARATINI, P.; MARENGO, J. Sinais de El Niño na precipitação da Amazônia. In: Anais do X Congresso Brasileiro de Meteorologia. Sociedade Brasileira de Meteorologia. [S.l.: s.n.], 1998b.

GUEDES, R. L. Condições de grande escala associadas a sistemas convectivos de mesoescala sobre a região central da América do Sul. Dissertação (Mestrado) — Universidade de São Paulo, 1985.

HOLTSLAG, A.; BRUIJN, D.; PAN, H. A high resolution air mass transformation model for short-range weather forecasting. Monthly Weather Review, v. 118, n. 8, p. 1561-1575, 1990.

HOUZE, R. Cloud dynamics. [S.l.]: Academic Pr, 1994.

JUNK, W.; MELLO, J. Impactos ecológicos das represas hidrelétricas na bacia amazônica brasileira. Estudos avançados, Scielo Brasil, v. 4, n. 8, p. 126-143, 1990. 
KALNAY, E.; KANAMITSU, M.; KISTLER, R.; COLLINS, W.; DEAVEN, D.; GANDIN, L.; IREDELL, M.; SANA, S.; WHITE, G.; WOOLLEN, J. et al. The NCEP/NCAR 40-Year Reanalysis Project. 1996.

KIEHL, J. T.; HACK, J. J.; BONAN, G. B.; BOVILLE, B. A.; BRIEGLEB, B. P.; WILLIAMSON, D. L.; RASCH, P. J. Description of the NCAR Community Climate Model (CCM3). NCAR Technical Note, NCAR/TN-420+STR, n. 156 pp., 1996.

KOUSKY, V. E. Pentad outgoing longwave radiation climatology for the South American sector. Revista Brasileira de Meteorologia, v. 3, p. 217-231, 1988.

KUMMEROW, C.; SIMPSON, J.; THIELE, O.; BARNES, W.; CHANG, A.; STOCKER, E.; ADLER, R.; HOU, A.; KAKAR, R.; WENTZ, F. et al. The status of the Tropical Rainfall Measuring Mission (TRMM) after two years in orbit. Journal of Applied Meteorology, v. 39, n. 12, p. 1965-1982, 2000.

LAING, A. G.; FRITSCH, J. M. Mesoscale Convective Complexes in the Africa. Monthly Weather Review, v. 121, p. 2254-2263, Agosto 1993a.

LAING, A. G.; FRITSCH, J. M. Mesoscale Convective Complexes over the Indian Monsoon Region. Journal of Climate, v. 6, p. 911-919, Maio $1993 \mathrm{~b}$.

LAING, A. G.; FRITSCH, J. M. The global population of mesoescale convective complexes. Quart J Royal Meteorological Society, n. 123, p. 389-405, 1997.

LAURENT, H.; MACHADO, L. A. T. Comparação das características dos sistemas convectivos observados na Amazônia e na África. XII Congresso Brasileiro de Meteorologia, 2002.

LAURENT, H.; MACHADO, L. A. T.; MORALES, C. A.; DURIEUX, L. Characteristics of Amazonian mesoscale convective systems observed from satellite and radar during the WETAMC/LBA experiment. Journal of Geophysical Research, v. 107, n. 8054, 2002.

LENTERS, J. D.; COOK, K. H. On the Origin of the Bolivian High and Related Circulation Features of the South American Climate. Journal of Atmospheric Sciences, v. 54, p. 656-678, 1997.

LI, J.; WANG, B.; WANG, D.-H. The caracteristics of Mesoscale Convective Systems (MCSs) over East Asia in Warm Seasons. Atmospheric and Oceanic Science Letters, v. 5, n. 2, p. 102-107, 2012.

LLOPART, M.; DA ROCHA, R. P. CLM Coupled in the RegCM4. 1 Model: Sensitivity to the Cumulus Convective Schemes over the Amazon Rainforest. In: EGU General Assembly Conference Abstracts. [S.l.: s.n.], 2012. v. 14, p. 6386.

MACEDO, S. R.; MACHADO, L.; VILA, D. ForTraCC - Previsão a curto prazo e evolução dos sistemas convectivos. ForTraCC V1.1 - Guia do Usuário, p. 20pp, 2004.

MACHADO, L. A. T.; LAURENT, H. The convective system area expansion over Amazonia and its relationships with convective system life duration and hight-level wind divergence. Monthly Weather Review, v. 132, p. 714-725, 2004. 
MACHADO, L. A. T.; ROSSOW, W. B. Structural characteristics and radiative properties od tropical cloud clusters. Monthly Weather Review, v. 121, p. 3234-3260, Dezembro 1993.

MACHADO, L. A. T.; ROSSOW, W. B.; GUEDES, R. L.; WALKER, A. W. Life cycle variations of mesoscale convective systems over the americas. Monthly Weather Review, v. 126, p. 1630-1654, 1998.

MADDOX, R. Large-scale meteorological conditions associated with midlatitude, mesoscale convective complexes. Monthly Weather Review, American Meteorological Society, v. 111, n. 7, p. 1475-1493, 1983.

MADDOX, R. A. Mesoscale Convective Complexes. Bulletin American Meteorological Society, v. 61, n. 11, p. 1374-1378, November 1980.

MADDOX, R. A.; RODGERS, D. M.; HOWARD, K. W. Mesoscale convective complexes over the united states during 1981 - annual summary. Monthly Weather Review, v. 110, p. 1501-1514, 1982.

MARENGO, J.; SOARES, W.; SAUlO, C.; NICOLINI, M. Climatology of the lowlevel jet east of the andes as derived from the ncep-ncar reanalyses: Characteristics and temporal variability. Journal of Climate, v. 17, n. 12, p. 2261-2280, Junho 2004.

MARENGO, J. A.; LIEBMANN, B.; KOUSKY, V. E.; FILIZOLA, N. P.; WAINER, I. C. Onset and end of the rainy season in the brazilian Amazon Basin. Journal Climate, v. 14, p. 833-852, 2001.

MATHON, V.; LAURENT, H. Life cycle of Sahelian mesoscale convective cloud systems. Quart J Royal Meteorological Society, v. 127, p. 377-406, 2001a.

MATHON, V.; LAURENT, H. Life cycle of the Sahelian mesoscale systems over Europe using satellite infrared imagery. I: Methodology. Quart J Royal Meteorological Society, v. 127, p. 377-406, 2001b.

MCPHADEN, M. Genesis and evolution of the 1997-98 El Niño. Science, American Association for the Advancement of Science, v. 283, n. 5404, p. 950, 1999.

MISRA, V.; DIRMEYER, P.; KIRTMAN, B.; JUANG, H.; KANAMITSU, M. Regional simulation of interannual variability over South America. J. Geophys. Res, v. 107, n. 10.1029, 2002.

MOREL, C.; SENESI, S. A climatology of mesoscale convective systems over Europe using satellite infrared imagery. I: Methodology. Quart J Royal Meteorological Society, v. 128, p. 1953-1971, 2002.

ORLANSKI, I. A rational subdivision of scales for atmospheric processes. Bull. Amer. Meteor. Soc, v. 56, n. 5, p. 527-530, 1975.

OYAMA, M. Erros sistemáticos no clima da região tropical da América do Sul simulado pelo modelo regional MM5 em baixa resolução horizontal. Revista Brasileira de Meteorologia, v. 21, n. 1, p. 118-133, 2006. 
PAL, J. S.; GIORGI, F.; BI, X.; ELGUINDI, N.; SOLMON, F.; GAO, X.; RAUCHER, S. A.; FRANCISCO, R. A.; ZAKEY, A.; WINTER, J.; AHFAQ, M.; SYED, F. S.; BELL, J. L.; DIFFENBAUGH, N. S.; ARMACHARYA, J. K.; KONARÉ, A.; MARTINEZ, D.; ROCHA, R. P. da; SLOAN, L. C.; STEINER, A. L. Regional Climate Modeling for the Developing World: The ICTP RegCM3 and RegCNET. American Meteorological Society, v. 88, p. 1397-1409, January 2007.

PALMEIRA, F. L. B. Amálise de características dos sistemas convectivos através de imagens do satélite GOES-12. Dissertação (Mestrado) - Universidade Federal do Rio de Janeiro, 2005.

PINTO, L. I. C.; COSTA, M. H.; LIMA, F. Z.; DINIZ, L. M. F.; SEDIYAMA, G. C.; PRUSKI, F. F. Comparação de produtos de precipitação para a América do Sul. Revista Brasileira de Meteorologia, v. 24, n. 4, p. 461-472, 2009.

PUNKKA, A.-J.; BISTER, M. Occurrence of Summertime Convective Precipitation and Mesoscale Convective Systems in Finland during 2000-01. Monthly Weather Review, v. 133, p. 362-373, Julio 2005.

RAMANATHAN, V.; DOWNEY, P. A nonisothermal emissivity and absorptivity formulation for water vapor. Journal of Geophysical Research, American Geophysical Union, v. 91, n. D8, p. 8649-8666, 1986.

REBOITA, M.; GAN, M.; DA ROCHA, R.; AMBRIZZI, T. et al. Regimes de precipitação na América do Sul: uma revisão bibliográfica. Revista Brasileira de Meteorologia, Sociedade Brasileira de Meteorologia, v. 25, n. 2, p. 185-204, 2010.

REBOITA, M. S.; DA ROCHA, R. P.; AMBRIZZI, T. Avaliação da precipitação e da temperatura do ar simuladas pelo regcm3 sobre o Atlântico Sul. XIV Congresso Brasileiro de Meteorologia, 2006.

ROMATSCHKE, U.; HOUZE JR, R. Extreme summer convection in South America. Journal of Climate, v. 23, n. 14, p. 3761-3791, 2010.

ROMATSCHKE, U.; MEDINA, S.; JR, R. A. H.; RASMUSSEN, K. Topographic and diurnal effects on tropical and subtropical convection in South America. 0th International Conference on Alpine Meteorology (ICAM), Maio 2009.

SAKAMOTO, M. S. Sistemas Convectivos de Mesoescala observados na Região Subtropical da América do Sul durante o SALLJEX. Tese (Doutorado) Universidade de São Paulo, 2009.

SAKAMOTO, M. S.; AMBRIZZI, T.; POVEDA, G. Moisture Sources and Life Cycle of Convective Systems over Western Colombia. Advances in Meteorology, v. 2011, p. 11, 2011.

SALIO, P.; NICOLINI, M.; ZIPSER, E. J. Mesoscale Convective Systems over Southeastern South America and Their Realtionship with the South American Low-Level Jet. Monthly Weather Review, v. 135, p. 1290-1309, 2007.

SEGALIN, B.; DA ROCHA, R. P.; MORALES, C. A. R.; MICADEI, K. Adaptação do ForTraCC para rastrear sistemas convectivos de mesoescala no RegCM3: Metodologia e Validação. IV Simpósio Internacional de Climatologia, João Pessoa - PB, 2011. 
SILVA DIAS, M. A. F. Sistemas de mesoescala e previsão de tempo a curto prazo. Revista Brasileira de Meteorologia, v. 2, p. 133-150, 1987.

SIMMONS, A.; UPPALA, S.; DEE, D.; KOBAYASHI, S. ERA-Interim: New ECMWF reanalysis products from 1989 onwards. ECMWF Newsletter, v. 11, p. 25-35, 2007.

SIQUEIRA, J. R.; MARQUES, V. da S. Ocorrence frequencies and trajectories of mesoscale convective sistems over southeast Brazil related to cold frontal and non-frontal incursions. Australian Meteorological Magazine, v. 57, p. 345-357, 2008.

SODEN, B. J. The diurnal cycle of convection, clouds, and water vapor in the tropical upper troposphere. Geophysycal Research Letters, v. 27, n. 15, p. 2173-2176, Agosto 2000.

SOUZA, C. A. de; CAVALCANTI, I. F. de A. Características sinóticas associadas ao jato em baixos níveis e a influência na atividade convectiva sobre a bacia do prata. In: Congresso Brasileiro de Meteorologia. [S.l.: s.n.], 2004. v. 8, p. 473-477.

SUGAHARA, S.; DA ROCHA, R.; RODRIGUES, M. L. Condições atmosféricas de grande escala associadas a jato de baixos níveis na América do Sul. In: VIII CONGRESSO BRASILEIRO DE METEOROLOGIA. [S.l.: s.n.], 1994. v. 2, p. $573-577$.

SUGAHARA, S.; DA ROCHA, R.; RODRIGUES, M. L. Condições atmosféricas de grande escala associadas a jato de baixos níveis. In: SOCIEDADE BRASILEIRA DE METEOROLOGIA, 1996, Belo Horizonte-MG, Brasil. Belo Horizonte-MG, Brasil: Anais do VIII Congresso Brasileiro de Meteorologia, 1996.

SUI, C.-H.; LAU, K.-M.; TAKAYABU, Y. N.; SHORT, D. A. Diurnal Variations in Tropical Oceanic Cumulus Convection during TOGA COARE. Journal of the Atmospheric Sciences, v. 54, p. 639-655, Março 1997.

VELASCO, I.; FRITSCH, J. M. Mesoscale Convective Complexes in the Americas. Journal of Geophysical Research, v. 92, n. D8, p. 9591-9613, Agosto 1987.

VELASCO, I.; NECCO, G. V. Caracteristicas del campo termico de la atmosfera libre de la Replubica Argentina. Meteorologica, v. 12, p. 7-22, 1981.

VIANA, D.; AQUINO, F.; BURGOBRAGA, R.; FERREIRA, N. Mesoscale convective complexes in Rio Grande do Sul between October and December of 2003 and associated precipitation. Revista Brasileira de Meteorologia, SciELO Brasil, v. 24, n. 3, p. 276-291, 2009.

VILA, D. A.; MACHADO, L. A. T.; LAURENT, H.; VELASCO, I. Forecast and Tracking the evolution of cloud clusters (ForTraCC) using satellite infrared imagery: Methodology and Validation. American Meteorological Society, v. 23, p. 233-245, 2008.

VILA, D. A.; MACHADO, L. A. T.; VELASCO, I. Some relationships between mesoscale convective systems life cycle and observed rainfall over del Plata Basin. 2nd Workshop of the International Precipitation Working Group, p. 8, 2004. 
VILA, D. A.; MACHADO, L. A. T.; VELASCO, I. Los sistemas convectivos de mesoescala sobre la cuenca del Plata: la técnica ForTraCC. Congresso Brasileiro de Meteorologia, p. 14, 2006.

WANDISHIN, M.; STENSRUD, D.; MULLEN, S.; WICKER, L. On the predictability of mesoscale convective systems: three-dimensional simulations. Monthly Weather Review, v. 138, n. 3, p. 863-885, 2010.

WILLIAMS, M.; HOUZE, R. A. Satellite-observed characteristics of winter monsoon cloud clusters. Monthly Weather Review, v. 115, p. 505-519, 1987.

XIE, P.; ARKIN, P. Global precipitation: A 17-year monthly analysis based on gauge observations, satellite estimates, and numerical model outputs. Bulletin of the American Meteorological Society, [Lancaster, Pa., etc., American Meteorological Society], v. 78, n. 11, p. 2539-2558, 1997.

ZHOU, J.; LAU, K. Principal modes of interannual and decadal variability of summer rainfall over South America. International Journal of Climatology, Wiley Online Library, v. 21, n. 13, p. 1623-1644, 2001.

ZIPSER, E.; CECIL, D.; LIU, C.; NESBITT, S.; YORTY, D. Where are the most intense thunderstorms on Earth? Bulletin of the American Meteorological Society, [Lancaster, Pa., etc., American Meteorological Society], v. 87, n. 8, p. 1057-1072, 2006. 